Illinois State University

ISU ReD: Research and eData

Theses and Dissertations

$5-22-2017$

\title{
Canvases of Representation: Addressing the Cultural Politics of Black Male Superhero Identity in Graphic Narratives
}

Danielle L. Cochran

Illinois State University, dlcochran81@gmail.com

Follow this and additional works at: https://ir.library.illinoisstate.edu/etd

Part of the African American Studies Commons, and the English Language and Literature Commons

\section{Recommended Citation}

Cochran, Danielle L., "Canvases of Representation: Addressing the Cultural Politics of Black Male Superhero Identity in Graphic Narratives" (2017). Theses and Dissertations. 731.

https://ir.library.illinoisstate.edu/etd/731

This Dissertation is brought to you for free and open access by ISU ReD: Research and eData. It has been accepted for inclusion in Theses and Dissertations by an authorized administrator of ISU ReD: Research and eData. For more information, please contact ISUReD@ilstu.edu. 


\title{
CANVASES OF REPRESENTATION: ADDRESSING THE CULTURAL POLITICS OF BLACK MALE SUPERHERO IDENTITY IN GRAPHIC NARRATIVES
}

\author{
Danielle L. Cochran
}

201 Pages

Canvases of Representation: Addressing the Cultural Politics of Black Male Superheroes Identity in Graphic Narratives is an analytical literary mixtape dedicated to Black male superheroes Black Panther, Luke Cage, and Black Lightning. Cochran draws out how superheroes play a role in the socio-political, identity, and cultural representations Black identity. The work argues that what is not just the symbolic/cultural destruction of the Black image in popular culture but how such representations provide a template for how the Black body is actively managed, controlled, surveilled, and contained in the material world. Examining these figures through the blended genres of Afrofuturism, film, and hip-hip as well, this research explores how Black creators have begun to dis-articulate fictional representations and develop a collective catharsis more "authentic" to the complex Black experience.

KEYWORDS: Graphic narratives; Cultural studies; African-American studies; Black Panther; Luke Cage; Black Lightning; African-American pedagogy; African-American literature 
CANVASES OF REPRESENTATION: ADDRESSING THE CULTURAL POLITICS OF

BLACK MALE SUPERHERO IDENTITY IN GRAPHIC NARRATIVES

DANIELLE L. COCHRAN

A Dissertation Submitted in Partial

Fulfillment of the Requirements

for the Degree of

DOCTOR OF PHILOSOPHY

Department of English

ILLINOIS STATE UNIVERSITY 
Copyright 2017 Danielle L. Cochran 
CANVASES OF REPRESENTATION: ADDRESSING THE CULTURAL POLITICS OF BLACK MALE SUPERHERO IDENTITY IN GRAPHIC NARRATIVES

DANIELLE L. COCHRAN

COMMITTEE MEMBERS:

Ricardo Cortez Cruz, Chair

Christopher Breu

Paul Ugor 


\section{ACKNOWLEDGMENTS}

Thank you to God. Just thank you and all the ancestors who have sacrificed and paved the way for me to be in this situation and contribute to the large body of Black aesthetic work.

Thank you to the Brass and Cochran family for your love and support! It is because of your prayers, wise council, and service in love I was able to finish this process!

Thank you to the multiple faculty and staff (inside and outside) of the English department at Illinois State University for your kindness and support!

Thank you to Dr. Christopher Breu and Dr. Paul Ugor. Thank you for always having time for me, pushing my ideas, and supporting my content!

Thank you to Dr. Pamela Hoff for providing a space to process my Blackness in this fraught environment and reminding me of the mighty stock from which we come!

Thank you to Dr. Nancy D. Tolson who took an easily-distracted lost Black poet as an undergraduate and made him focus on the beauty of our culture and being Black and intelligent in a space that often renders us invisible. Thank you for seeing me...

Thank you to Professor Ricardo Cortez Cruz for mentoring me through several stages of my academic career. It has been a wild ride. It is because of your belief in my gifts and ideas that they have come to manifest. You made hip-hop an academic possibility with your course work and you taught me responsibility and follow through. Thank you for continuing to encourage me...

Thank you to my beautiful wife, Elise Marissa Cochran, for being a supportive and inspiring presence throughout this whole doctoral process and since you've came into my life. I could not have done this without your love and motivation. You are my orange moon and I shine because you shine. 143 !

Last, but not least, this scholarship is for my daughter Emma Corryn as an example that with faith, dedication, and hard work you can follow and achieve anything that you believe in!

D. L. C. 


\section{CONTENTS}

\section{Page}

ACKNOWLEDGMENTS

CONTENTS

CHAPTER I: (CULTURAL) POLITICS AS USUAL 1

$\begin{array}{ll}\text { Scholastic Sankofa } & 1\end{array}$

$\begin{array}{ll}\text { The Set-Up } & 3\end{array}$

Comics, Power, Respect is the Key to Life $\quad 9$

$\begin{array}{ll}\text { Words Paint Pictures } & 11\end{array}$

Made -Not- In Our Image $\quad 15$

$\begin{array}{ll}\text { So What's The Fuss? } & 23\end{array}$

Black Is, Black Aint... 29

$\begin{array}{ll}\text { The Blueprint } & 31\end{array}$

CHAPTER II: CAPES AND CURRICULUM: BLACK PEDAGOGICAL SUPERHEROISM 36

One in a Million Questions (The Introduction) 36

$\begin{array}{ll}\text { The Structure (Course Content) } & 44\end{array}$

Dig, If You Will, The Picture (Demographic and Logistics of the Internship) 50

Scenario 1: Hustling for Classroom Quotas 53

Scenario 2: Black (Angry) Lit 56

Scenario 3: The Checkout (Engaging in non-White literature with White students) 62

Scenario 4: Reverse Racism 66

$\begin{array}{ll}\text { As We Proceed (Further Investigations) } & 68\end{array}$

\#TheAcademicClapBack (Conclusion) $\quad 70$ 
$\begin{array}{ll}\text { BLACK PANTHER } & 74\end{array}$

Commodified Colonized Intellect from the Jump 79

Same Ol' Song: Marvel Premiere featuring Black Panther 85

Opening Doors to Difficult Conversations in Graphic Narratives 94

$\begin{array}{ll}\text { Conduits for Commodification } & 98\end{array}$

Power to the People: The Conflict of the Black Panther Character and Symbolism 103

Conclusion: With Great Power... 107

CHAPTER IV: “SWEET SIGNYFYIN(G) CHRISTMAS”: UNCHAINING LUKE CAGE 110

“It’s About to Get Ugly!" The Problematic Luke Cage 113

$\begin{array}{ll}\text { Out of Satire - A Fool is Born! } & 117\end{array}$

The Death of a Damn Fool 130

A Hero Not For Hire, But To Inspire 135

Hoodie and Hopes $\quad 140$

$\begin{array}{ll}\text { The Outro } & 144\end{array}$

CHAPTER V: JUST “US” LEAGUE: RACIALIZED EXCLUSION IN THE RECRUITMENT

OF BLACK LIGHTNING INTO THE JUSTICE LEAGUE OF AMERICA 149

Here We Are Now, Entertain Us... 154

More Than Meets the Eye 163

$\begin{array}{ll}\text { (Not) All in the Same Gang } & 170\end{array}$

CHAPTER VI: I, TOO, AM AMERICA (Conclusion) 174

$\begin{array}{ll}\text { Where Do We Go } & 183\end{array}$

$\begin{array}{ll}\text { REFERENCES } & 189\end{array}$ 


\section{FIGURES}

Figure

Page

1.1. John Stewart's first appearance in DC Comics' Green Lantern/Arrow \#87 17

1.2. Will Eisner's character, Ebony White. $\quad 24$

3.1. Black Panther arrives on the scene in Fantastic Four \#52. 79

3.2. Black Panther is seen looming over the Fantastic Four in Fantastic Four \#52. 80

3.3. Cover art for Marvel Premiere \#51.

3.4. Black Panther battles Windeagle in Marvel Premiere \#51. 86

3.5. Cover art for Marvel Premiere \#52. 87

3.6. Cover art for Marvel Premiere \#53.

3.7. Black Panther defeats Soul Strangler in Marvel Premiere \#53. 92

3.8. The covers of the Jungle Action featuring Black Panther \#19, 20, 22 \& 24.

3.9. Green Lantern/ Green Arrow \#76, Green Lantern is challenged on race. 95

3.10. The Soul Strangler from the Marvel Premiere series. 105

4.1. The cover for Luke Cage, Hero for Hire \#1 (Marvel, 1972). 113

4.2. Luke Cage (left), Tyroc (center), and Buck Wild (right). 121

4.3. Buck Wild’s “groovy rant” from Icon \#13(DC Comics, 1994). 125

4.4. Mike Colter as Luke Cage (Den of Geeks, 2016). 136

4.5: Luke Cage breaks out the experimental chamber. $\quad 140$

4.6. Luke Cage pays homage to his original costume. 141

4.7. Luke Cage sees his reflection in the car and insults himself. 141

4.8. Picture of Trayvon Martin in a hoodie that would become symbolic of racial protest. 142

4.9. Luke Cage's hoodie as costume/symbol (iMDB, 2016). 144 
5.1. Cover art for Black Lightning's guest appearance in Justice League of America \#173.

5.2. The JLA surveying Black Lightning stopping crime in $J L A \# 173$.

5.3. The Flash and Green Lantern have a conflict over Black Lightning in JLA \#173.

5.4. Superman PSA on discrimination from 1949.

5.5. Black Lightning rejects the JLA invitation the first time $\mathrm{n}$ in $J L A \# 173$.

5.6. Black Lightning rejects the JLA invitation again in JLA \#174.

6.1. Black protesters march in the Memphis Sanitation Strike of 1968.

6.2. Black Kirby and Tan Lee's Kid Code: Channel Zero (2014).

6.3. Cover art for Black \#1 by Kwanza Osajyefo (2016). 


\section{CHAPTER I: (CULTURAL) POLITICS AS USUAL}

[T]hink of how these cultures have used the body - as if it was, and it often was, the only cultural capital we had. We have worked on ourselves as the canvases of representation.

Stuart Hall, "What is this 'Black' in Black Popular Culture"

In general, mainstream groups hold the ability to define reality through the tools of education, mass media, and social institutions. When children are taught by parents, the mast media, and schools that LGBTs are sick or deviant, when people of color are portrayed as dangerous and unintelligent, and when women are stereotyped as the weaker sex and less capable in leadership positions, a system of hierarchy and access to privilege and power is established in our society.

Derald Wing Sue

The worst injury is feeling you don't belong so much

to you-

Claudine Rankine, Citizen: An American Lyric

\section{Scholastic Sankofa}

Before we begin this intellectual exodus, I want to quickly shout out the texts that were instrumental in providing the jump off point to lay my literary analytical flow. Thank you to Professor William H. Foster III, John Jennings, and Stacey Robinson for their conversations regarding Black graphic narratives. Props to Foster's texts Dreaming of a Face like Ours: Collected Essays, Articles and Scholarly Presentations on the Changing Image of Blacks in Comics (2010) and Looking for a Face like Mine: The History of African Americans in Comics (2005). These two texts provided an extensive list of Black graphic narratives I never knew existed and information for key texts that I used in this analysis. Shout out to Adilifu Nama whose text Super Black: American Pop Culture and Black Superheroes critically analyzes how Black-male superheroes and heroes are portrayed through not only graphic narratives, but also other forms of popular culture such as TV shows and movies. Although Nama's groundbreaking work provides the raison d'tere to further review these Black male bodies within graphic narrative culture, it often becomes a place of high contention and scathing criticism in general. 
On one hand, Nama is celebratory of these figures' presence in popular culture and their influence for opening the space for critical analysis. On the other hand, Nama does not approach the characters through the intersectionality of literary theory and the critique becomes a jeremiad of criticism with no resolution. Yet, even in this, I found important concepts and direction for my dissertation.

Blessings to Jonathan Gayles in his documentary White Scripts and Black Supermen: Black Masculinities in Comic Books (2012). Gayles uses the documentary to engage with the problematic nature of mainstream Black Male superheroes such as Black Panther, Luke Cage, Black Lightning, Tyroc, Falcon, and John Stewart through a myriad of interviews with Black scholars from the visual, history, and sociological studies to graphic narratives writers and artists. Among those involved are Black graphic narrative historian William Foster III, Mark Anthony Neal, Stanley Carpenter, John Jennings and Adilifu Nama. Although the critiques presented within this documentary are informative, they do not address the crucial issues central to my work and the literary intersections to which my study is guided. However, this documentary provided useful insights for the research.

Much love to Deborah Whaley and her book, Black Women in Sequence: Re-inking Comics, Graphic Novels, and Anime, which was highly informative. The work "illustrates the malleability of cultural production where writers, artists, and readers coproduce narratives that serve the restrictive and the transformative representational ends that constitute American pop culture," especially for Black women in graphic narratives and anime (27). The criticism and scholarship produced by scholars such as Jeffery A. Brown, Black Superheroes, Milestone Comics, and Their Fans (2001), Marc Singer, ““'Black Skins” and White Masks: Comic Books 
and the Secret of Race" (2002), and Michael Van Dyke, "What's Going On? Black Identity in the Marvel Age" (2006) are also important to this critical discourse

Additional texts that have been insightful in my understanding of Black bodies and graphic narratives are Black Comics: Politics of Race and Representation (2013) and The Blacker the Ink: Constructions of Black Identity in Comics and Sequential Art (2015). Both of these texts offer a multitude of topics, which range from the body politics of Black superhero outfits to consumerist culture influencing the content of Black superheroes. These topics were debated and analyzed by a diverse field of scholars from various cultural backgrounds. These texts also enabled me to engage critically with content by deciphering what had not been addressed within these works to cultivate a critical critique in this scholarly research.

\section{The Set-Up}

In an interview for Vox Magazine, Sanaa Amanat, director of content and character development at Marvel Comics, discusses incorporating more multicultural characters and narratives within the Marvel universe. Amanat, who is also the creator for the new Ms. Marvel (2014) title, sees her Pakistani-American background as inspiration for remixing this traditionally White character. The Amanat-inspired Ms. Marvel, Kamala Khan, is a PakistaniAmerican teenage girl trying to reconcile her American cultural beliefs with her Islamic culture. What makes Kamala Khan such a fascinating character is that she also struggles with the ideology of what it means to be a superhero by physically emulating Captain Marvel, a Whitewoman superhero, because she identifies this as the superhero. Throughout the first series of stories, Kamala struggles with notions of cultural assimilation and Whiteness as a Pakistani- 
Muslim American superhero. It is through Kamala's narrative that we experience Amanat's own struggle with acceptance in a post-911 world (Abad-Santos) ${ }^{1}$

In her interview with Abad-Santos, Amanat discloses the story about the relaunch of the Black Panther (1966) series for Marvel Comics. She notes one particular conversation concerning who should author the reboot. Amanat states, "I was one of the voices in the room saying if we're doing a Black Panther book, we have to push for an African American writer to write it...We have to make the effort to be inclusive" (Abad-Santos). It was this inclusive desire that prompted Amanat to pursue renowned Black journalist Ta-Nehisi Coates to write the new Black Panther series. Coates is famous for his previous articles in The Atlantic Journal centered on reparations for slavery and racism. He recently turned an essay from one of his articles into the book Between the World and Me (2015). This text is a self-reflective prose about the epidermal and internal experience with his Black body written in a letter format to his son right after the Michael Brown verdict is read. It is this work where Coates denotes a fatalism of the Black male body as always being aligned with its historical and contemporary image as a place of destruction or something to be destroyed through the White gaze. What is at stake here is not just the symbolic/cultural destruction of the Black image in popular culture, but also how such representations provide a template for how the Black body is actively managed, controlled, surveilled, and contained in the material world.

David Harvey in "The Body as An Accumulation Strategy" considers the body as a place of multiple interpretation where value and meanings are developed, distributed, and received (97-98). Harvey argues, "Capital continuously strives to shape bodies to its own requirements, while at the same time internalizing within its modus operandi effects of shifting and endlessly open bodily desires, wants, needs, and social relations (sometimes overtly expressed as collective

\footnotetext{
${ }^{1}$ Abad-Santos, "Meet Sana Amanat, The Shonda Rhimes of Marvel Comics".
} 
class, community, or identity -based struggles on the part of the laborer)" (115). Harvey grounds his inquisition through "Marxism to approach questions surrounding how "bodies get produced, how they become signifies and referents of meanings, and how internalized bodily practices might in turn modify the processes of their self-production under contemporary conditions of capitalistic globalization" (116). However, the most important point he makes is the human body as capital: "The human body is a battleground within which and around which conflicting socioecological forces of valuation and representation are perpetually at play" (116). Although Harvey's argument is presented through the human body, we can transfer these ideas to fictionalized Black bodies since the Black image bears the burden of capitalist interests driving the representation, repackaged, and recycled in Marvel and DC Comics graphic narratives.

With that in mind, it makes sense that Amanat would want someone familiar with the embodied experience of the Black ${ }^{2}$ male body to helm the first Black mainstream superhero of the Marvel universe, Black Panther. However, we must ask ourselves why is this important? Why the imperative of the lived-experienced Black writer to write about the lived experience in fictional plane? Can one who has not literally embodied a life write about other's experience in a deeply emotive and sensory-laden style? Amanat's prescient suggestion is a clear indication of familiarity with previous failed attempts to helm Black Panther by other writers who would contend to understand "Blackness." "More importantly, this authorial suggestion sanctions Black writers to retain agency and control of their own image in the literary genre of a graphic narrative. The matter at hand is about not only race, but also power and control over one's body and identity in reality and fictional spaces.

\footnotetext{
${ }^{2}$ I will be using Black as the main descriptive for any person apart of the African Diaspora (i.e. African American or African).

${ }^{3}$ It should be noted that Black writers Christopher Priest (1998-2003) and Reginald Hudlin (2005-2008) would eventually write the stories for Black Panther after 32 years of the character's existence (Black Panther was created in 1966).
} 
My research addresses issues of Black male identity politics within visual and literary culture. By surveying the importance of Black identity within graphic narratives and the genre of the superhero, the role of identity creation and control as propaganda of Black male imagery in a predominantly White discourse becomes clear. This critique wants to empower Black identity and challenge its presence or public configuration especially when presented through the lens of a dominant culture. This presentation is critical when "authentic" representations of Blackness are written, drawn, and presented by White writers as accurate depictions. While the mainstream graphic narrative industry has taken strides to increase diversity in its texts and the superhero genre, there is still an absence of critical analysis concerning the cultural politics surrounding creative production of Black superheroes. While the emergence and proliferation of the Black superhero in American popular culture is itself a sign of cultural integration and pluralism, what is still lacking is a thoughtful critique of the problematic ways in which the Black image appears in these representations. There needs to be more development of contemporary voices that speak to these fraught spaces with images and narratives that have been replicated by the mainstream publications of DC Comics and Marvel Comics. ${ }^{4}$

The research seeks to address the development of Black male superheroes by White authors who deploy (whether consciously or unconsciously) racial tropes of Black heroism through a White gaze. While I agree with the argument that writers should never be restricted in writing subject matter I suspect there is a certain danger in such thinking. It is not so much about the inability of writers to offer a genuine representation of experiences outside of their own or even the possibility of obscuring the nuances of other cultures. More or less it is about the higher chances of inadvertently replicating the negative representations that these characters are often

\footnotetext{
${ }^{4}$ DC Comics and Marvel are always considered the mainstream standard or often referred to as "The Big Two" by various artists and writers who work within and outside of these companies.
} 
victim to and contend. This precariousness regarding representation and the ways in that it expresses itself in Marvel and DC Comics is at stake in this critique. For as one power group (White-male creators) asserts its power through visual and literary narrative, a countervailing force (Black-Male creators), is resisting using counter-narration. I argue that as early mainstream Black male superheroes encounter conflict they are often laboring with the weight of Blackness, hegemony, commodification, and racial rejection that hinders their ability to be vehicles of fantasy for Black readers. Furthermore, Black superheroes, originally been read as Black after being written by White writers, have now been rewritten/reinvented as tools of agency reclamation and resistance by Black authors and artists. They accomplish this revisionism through the blended genres of Afrofuturism and hip-hop with the influence of social justice to develop a collective catharsis for not only Black consumers of graphic narratives, but multicultural audiences. Lastly, this scholastic endeavor also serves as a personal journey in the rediscovery and reframing of Black male [super]heroism, and indeed the Black body/image, in graphic narrative format and the broader spectrum of graphic narratives.

I use the term "graphic narrative" based on comic studies scholar Derek Royal's suggestion that we need to rename how we best describe comic books when wanting to use them through analytical processes. Royal posits:

Given all of these considerations, the term "graphic narrative" best captures the comics medium in most of its permutations. If we define narrative as the representation of an event/action or a series of events/actions, then most of what we see out there would certainly qualify: various forms of fiction, memoir, autobiography, and journalism. In this way, we consider the narrativity of a particular graphic text, its set of properties that characterize it as narrative and distinguish it from non-narrative forms of graphic 
representation...Graphic narrative is a varied medium. Scholars can expand their understanding of ethnic American writing, as well as the developing 'canon' of comics itself, to include a wide range of graphic narrative-from its most pedestrian expressions in the popular media, to its fanboy base in mainstream comics, to its most obscure manifestations in the niches of art culture. $(14,19)$

Renaming comic books as "graphic narratives" creates further engagement with the text by removing the negative connotation of the comic book terminology and now situates comic books within more complex fields of study as well as evaluations of ethnicity and culture. The importance of renaming/revisionism is not in the removal of the "negative connotations" associated with the genre, but the genre legitimacy created as a narrative worthy of critical questioning, especially as a narrative form implicated in signifying practices that have concrete material implications for everyday life. The emphasis here is not on the form in which the content/narrative reaches us, but that it is first and foremost a story, and stories have the power to destroy or make people and cultures.

Noted postcolonial thinker Edward Said, in the introduction to Orientalism, argues that politics is at the root of cultural production in academic work. Said claims, "No one has ever devised a method for detaching the scholar from the circumstances of life, from the fact of his involvement (conscious or unconscious) with a class, a set of beliefs, a social position, or from the mere activity of being a member of a society" (10). I assert that this detachment is applicable to the creators of graphic narratives. These narratives have a political weight that influences readers by their subliminal narrative. Said further argues, "Too often literature and culture are presumed to be politically, even historically innocent; it has regularly seemed otherwise to me, and certainly my study of Orientalism has convinced me (and I hope will convince my literary 
colleagues) that society and literary culture can only be understood and studies together" (27).

We must presume that since graphic narratives are considered literature in themselves there is a danger in ignoring the authorial intent of writers and artists-especially when it comes to the bodies of Black superheroes. These popular Black graphic texts contain implicit and explicit political knowledge that they perform on the reader.

\section{Comics, Power, Respect is the Key to Life}

To engage with the issue of Black-male superheroism in graphic narratives, we must first rationalize the imperative of working with graphic narratives and graphic novels as sites of power contestation. More often than not, graphic narratives are relegated to the field of visual studies due to the graphic design nature of comic books, but this monolithic practice ignores and displaces the intertextuality and intersectionality of graphic narratives between multiple genres (narration, art, and semiotic interpretation). Yet, this same intertextual and intersectional connectivity can be beneficial for reading the genre especially through a cultural studies approach. Situating the graphic narrative genre within the field of English Studies is particularly useful because it offers a multidimensional approach from which to mount a thoughtful critique of representations of Black male superheroes. This approach is accomplished by treating graphic narratives as narrative-driven texts reinforced by a variety of narrative tropes that transcend generic boundaries. Graphic narratives offer a nexus of genres to be studied, critiqued, and appreciated as narratives in their own right. But beyond graphic narrative's legitimacy as a genre that is intrinsically trans-generic, I am particularly invested in engaging the genre as popular art, recognizing popular culture as a site of cultural politics, power and resistance. English Studies is an umbrella that also includes narrative theory, visual rhetoric, and permits one to discuss these texts as creative writing to see the panels as white space filled with text, for example, as one 
might find in poetry. English Studies enables a stronger critical reading of these narratives and lets us evaluate Black graphic narrative in ways in which other approaches are perhaps lacking. In the essay "What Is This 'Black' in Black Popular Culture?," cultural theorist Stuart Hall argues that it is necessary to investigate "popular culture" as a site of cultural hegemony (24). Hall asserts, "[Popular culture] is the space of homogenization where stereotyping and the formulaic mercilessly process the material and experiences it draws into its web, where control over narratives and representations passes into the hands of the established cultural bureaucracies, sometimes without a murmur" (26). What Hall theorizes here is a legitimation of popular culture as a space worthy of academic investigation since it functions as a powerful cultural site where identity is created and distributed to a mass audience with overt and covert agendas.

Hall further theorizes the necessity and urgency of paying attention to popular culture in "Notes on Deconstructing 'the Popular"” Hall argues:

Cultures, conceived not as separate 'ways of life', but as 'ways of struggle', constantly intersect: the pertinent cultural struggles arise at the points of intersection...Popular culture is one of the sites where this struggle for and against a culture of the powerful is engaged: it is also the stake to be won or lost in that struggle. It is the arena of the consent and resistance. It is partly where hegemony arises, and where it is secured. It is not a sphere where socialism, a socialist culture - already fully formed - might be simply 'expressed'. But it is one of the places where socialism might be constituted. That is why 'popular culture' matters. (451 \& 453)

Hall contends that as superficial as popular culture can be it is not without the influence of hegemonic practices. Upon reflection, popular culture is still a place where Black 
performance/performers (whether artists, athletes or academics) are heralded, but are often left empty-handed at dominant establishment-based award programs seeking a universal acceptance because of their self-reclamation performances.

Considering Hall's notion of struggle, the contention manifests in how one sees him/herself in a position of power within popular culture. This leaves a question of agency. Can one still be autonomous in spaces meant to assimilate outsiders to "fit" the mold of the mainstream? For example, is one striving to resist the mainstream normative ideal by involving oneself in it or seeking to conform to the exact image that they see as themselves? In order to understand how this self is written we must assert the power in controlling the narrative as the Black mind attempts to renegotiate Black identity — an identity plagued by negative racial historical discourse.

\section{Words Paint Pictures}

According to artist Scott McCloud in the highly referenced Understanding Comics: The Invisible Art, comics are simply defined as "juxtaposed pictorial and other images in deliberate sequence, intended to convey information and/or to produce an aesthetic response in the viewer" (9). Given this definition, let us place emphasis on the fact that these pictures "convey information" by portraying a narrative in a visual manner. The readers imagine this narrative by their own semiotic understanding of the visual text through a subjective reading process. McCloud notes that these interpretations of images are abstract constructions that we subliminally create through the process of what he calls "closure." This closure, McCloud argues, "fosters an intimacy only by the written word" and relies on the imagination's inventive conventions to align itself with a text (69). Still, this type of closure is problematic since it does indicate that whatever the artwork/text conveys is a matter of subjective interpretation by the 
reader engaging with the content. "Closure" absolves creators from the weight of messages we are left to interpret. We will address this exoneration of the author later, but the most important point here is the reading of the text that conveys a specific response based on subjectivity.

If we perceive comics through the aforementioned sequential art argument stated above as the monolithic concept of defining comics, then we will miss the narrative context of graphic narratives. Will Eisner, author and illustrator of The Spirit (1940) graphic narrative series and the first graphic novel A Contract with God (1978), suggests that we cannot leave out the narrative portion in how graphic narratives function for fear of the graphic content pushing the story instead of working in conjunction with the writing leaving nothing "more than literary junk food" (Eisner xi). Eisner further posits:

Despite the high visibility and attention that artwork compels, I hold that the story is the most critical component in a comic. Not only is it the intellectual frame on which all artwork rests, but it, more than anything else, helps the work endure... Writing, as I use it in comics, is not confined to the employment of words... Writing in comics includes all the elements in a seamless mix and becomes part of the mechanics of the art form.

\section{(Eisner xii)}

Eisner insists that the text and image align to develop the narrative in graphic narratives and is part of the actual art itself. In short, the writing is art or art is always writing.

Complimenting Eisner's perspective, graphic narrative academics Berninger et al assert that this literary intersectionality in graphic narratives is often ignored due to the stigma associated with the genre. They contend, "[c]omics manifest at the intersection of text, image, and sequence. Because they are a hybrid form, it is deceptively easy to focus on their similarities to other media, and ignore their uniqueness" (Berninger, et al 1). As stated earlier, graphic 
narratives are often neglected sites of criticism because of the nature in which the genre works historically as being inchoate narratives and low art. However, if we attempt to challenge this prescribed notion by adding in the cultural political aspect, we can assess the narrative function of the work. They continue, "Comics are thus a potential nexus of the public and the private, the social and the personal, and they may be uniquely suited to describe the multiple fragments of human experience" (Berninger, et al. 3). We ascertain that this nexus warrants intersectional criticism through various theoretical tools such as those offered by critical race studies, cultural studies, and postcolonial theory.

Adopting the idea of the centrality of 'narrative' in graphic novels, incorporating the intricacies of graphic narratives demonstrates how they function as sites of intersectionality in the notion of crossover. This concept of "crossover" derives from graphic narrative Jake Jakaitis and Frank Wurtz who state that:

[t]he idea of 'crossover' is essential to understanding this genre: graphic narrative functions most effectively precisely through many of its points of intersection. At its most basic level, the connections and disjunctions between image and word drive the text, guiding the reader's eye from panel to panel to comprehend the story. Graphic narrative, however, frequently engages in multiple acts of crossing over, between different genres, different forms, different linguistic registers, different types of art, and different storylines and character 'universes.'” (2)

Graphic narratives serve as a nexus of not only culture, but also interweaving narratives that navigate between worlds and interact with each in what I denote as metanarrative universalization. Metanarrative universalization claims that narrative stories have their own stories that are interconnected at multiple levels through character interaction/or lack of 
interaction. Marvel Comics and DC Comics (albeit two different companies with two separate literary universes) and other graphic narratives use shared universes to boosts guest appearances of superheroes or villains interacting with others outside of their specified monthly titles. This act only solidifies the concept of metanarrative universalization since these characters can occupy the same city, state, nation or universe as others. One can equate this type of literary act to the metafictional spaces created by William Faulkner through his fictional Yoknapatawpha county or even Octavia Butler through her Parable saga. The difference here is Faulkner's limited counties to Butler's global-spanning narrative while the mainstream graphic narrative universes span into fabricated galaxies. However, even this space is not without its flaws.

Not only do graphic narratives operate as a nexus of cultures at the metanarrative universalization level, production level (story development, art creation, etc.), and analytical level (academic engagements) they also operate through a multi-billion dollar globalized business empire that delivers these narratives and images worldwide. As we perceive here, mass distribution is the problem. Who is in charge of these distributed images, and what do these sequential images and narratives imply when it comes to portraying Black charactersspecifically Black male superheroes? More specifically, what and how do these images portray Black male superheroes as? Are they replicates of Jim Crow-esque depictions or simply White characters with Black masks? Given the commercial and mass production of these texts, they definitely operate as a space for cultural politics. Consequently, the images and how these images of Black identity are globally circulated become an issue. If popular culture is a signifying practice with huge ideological force, as Hall previously argues, what are the cultural codes circulated by these narratives and what do these codes achieve in terms of how the Black body is understood within the global cultural imagination? These codes create something 
dangerous about these narratives beyond the stereotypes of Blackness they purvey. You can place metanarrative universalization outside of the realm of the fictional and universe and apply it to how images are then mass produced and distributed creating (often) monolithic and static images of cultures that often signify a negative reception of that image from those within the portrayed culture. In a fictional story, one can create the perception of reality that operates as a cyclical confluence of identity perception, acceptance, rejection or reflection for the Black body.

\section{Made -Not- In Our Image}

Black graphic narratives superheroes are a literary conundrum. Let's consider that the first wave of largely popular Black graphic narrative superheroes were cultural products of the Black power movements of the 1960's and 70's. White authors created these characters as a response to the lack of diversity within the superhero genre. Famous graphic narrative artists Neal Adams recalls the story of having to fight in order to make John Stewart, DC Comics' first Black superhero, a Black Green Lantern character when the company was considering making their third reiteration of this character another blue-eyed, blond-hair White guy. ${ }^{5}$ This criticism was in itself considered counternarrative to the White-male dominated world of the superhero. The issue within this resistance is that John Stewart is often criticized for his hypermasculine and brash actions, which occur in origin, story (Green Lantern \#87, DC Comics 1971) and further in this continuity (see fig. 1.1). He, like other Black superhero characters, still reinforced cultural hegemony by their all-too-familiar presentation within the superhero genre. With Luke Cage (Marvel 1972), the first African-American superhero, altruism comes at the cost of monetary payment for services rendered and can never afford to pay his bills. Black Panther (Marvel 1966), the first African king and mainstream Black superhero, is always at the service of his

\footnotetext{
${ }^{5}$ Adams, Neal, perf. Superheroes: A Never-Ending Battle. Episode 2: "Great Power, Great Responsibility.” Dir. Danny Fingeroth and Mark Waid. Ghost Light Films, 2013.
} 
White allies (Avengers) displaced from his fictionalized African homeland of Wakanda. These are problematic cultural representations of Black superheroes. Although some argue that there may have been empowerment with the appearance of these characters, they have also contributed to the reinforcement of stereotypes such as Black hypermasculinity (John Stewart and Luke Cage) and totemic tropes (Black Panther invoking the spirit of a panther god for superpowers). The problem is not just the creation of these tropes, but how they are received by various audience and, again, contribute to the overall historical representation of the Black body. I contend that the "something better than nothing attitude" often leads to neglecting the larger cultural political role these images connote. A few noted scholars have suggested that engaging in research that automatically aligns Black male superheroes imagery as products of racial discourse is being reductive (Nama 34; Foster 2007). Even though I comprehend their position, it seems shortsighted to believe that further investigation is not warranted. In fact, we need more scholarship to address the racialized and fetishized body of the Black male superhero that has led to the replication and distribution of racialized images. If graphic narratives serve as an element of propaganda reinforcing Eurocentric fantasies and values, why should they be exempt from examination and criticism as their role in imposing and replicating stereotypical Black images in graphic narratives? In doing this we have to consider these stereotypical images as iconic cultural products worthy of critical investigation. In addition, not only as racialized figures, but also as sites where power of identity is constructed within a fictionalized cultural war zone of power and resistance through encoding and distribution of said identity. 


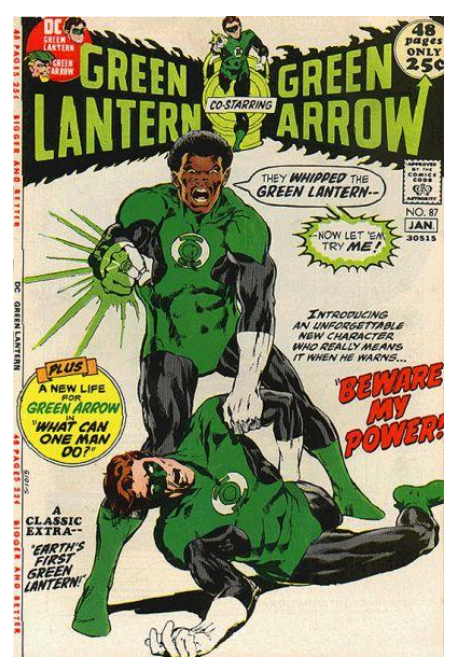

Fig. 1.1. John Stewart's first appearance in DC Comics' Green Lantern/Arrow \#87

In the essay "The Crisis of 'Race' and Raciology," cultural critic Paul Gilroy is critical of race and how it complicates textual analysis when one creates a crisis for raciology, which is defined as "the lore that brings the virtual realities of 'race' to dismal and destructive life" (517). Gilroy insists this raciology has become oversaturated in discourses and refined as empty rhetorical devices of idealization (517). He suggests that moving past race is best suited for proper analysis and the premise for getting to a solution of the race issue overall. By remixing tools of hate into weapons of empowerment, Gilroy concludes this causes a culture to become frozen and disable them to move outside a racial category once constructed to hinder or dehumanize them (518-20). He also mentions that relinquishing this type of remixed empowerment is difficult to do, but necessary if we are to start finding solutions to the problem of race. In fact, Gilroy's main argument is that "the crisis of 'race' and representation, of politics and ethics, offers a welcome cue to free ourselves from the bonds of all raciology in a novel and ambitious abolitionist project" (520). In the section "Genes and Bodies in Consumer Culture," Gilroy alludes to the desecration of Henrietta Lacks cells as a moment of racializing bodies. He states, "This has unexpected consequences where the ideal of physical prowess, to which [B]lacks were given a special title in exchange for their disassociation from the mind, assumes an 
enhanced significance" (525) and "[t]his crisis has ensured that racialized bodies represented as objects — objects among other objects—are never going to be enough to guarantee that racial differences remain what they were when everyone on both sides of the line between white and colored knew what 'race' was supposed to be" (526). Gilroy concludes that there is too much analyzing of bodies in culture when they are commodified and corporatized causing them to lose true analysis due to relying solely on a racial lens. This process is often due to graphic narrative artists who subsume bodies of different cultures to comment on these cultures only to escape these fictional identities without warrant of concern for their cultural impact due to their temporary fictional engagement in an Avatar-like action.

Although Gilroy and others attempt to make a progressive stance on race, they also bring forth such questions as: If we relinquish race, then what does these now absolved cultures free of racial categorization get subsumed by? Does this relinquishment of raciology also negate classism that it is structured or derived from? I hope that this research/project serves as a reminder of the danger of relinquishing raciology without having a replacement strategy for analyzing texts that affect us so much. In fact, I would charge that we still have to consider race in terms of cultural products. Even if we (Black people) abandon the cultural restrictions of race, what other systems of culture will relinquish power surrounding their cultural identity from which they benefit? As ambitious as Gilroy proposition is, he must not forget it is because of the normalized notion of race that these institutions exist and have pervaded multiple spaces. By dismissing race we give merit to the often-discursive practices of institutionalized racist beliefs.

Cultural studies theorist and critic Herman Gray in Cultural Moves: African Americans and the Politics of Representation argues that these intentional images within mainstream graphic narrative creators are purposely created and distributed. Gray states, 
The cause for much of our collective anxiety is blamed on the image and a sense of the disproportionate influence that the image exercises over us. Implicit in this moral anxiety is some notion of a normative ideal. But normative ideals are made, not given; they are the products of historical struggle and discursive productions. (116-17)

Gray concludes that this normalization is intentional in reifying the idea of normative through the circulation of privileged images. These images play a role in what he considers cultural politics:

$[R]$ epresentation itself should be critically scrutinized, especially when it is coupled with the critiques of cultural politics (as appeals to state and corporate power, correct and accurate representation, and some appropriate number of representations, and the nation) as a racially pluralistic, bounded, stable, geo-political entity whose legitimacy is secured through representations of the nation as family, land, and tradition. (188)

Combining representation in cultural politics generates a lens to address images that cause an internal dissidence of a past self made new through a dominant gaze. As Hall and Gray assert, we must investigate these spaces of representation in cultural politics and why they trouble our perception/reception of these images.

Continuing the dialogue on images as cultural products, theorist Michelle Stephens, in Skin Acts: Race, Psychoanalysis, and the Black Male Performer, contends, "The 'subject of representation' is simultaneously a spectacle and a look, an object and a subject, and neither is in the place of the gaze as the social agency with imprinting and interpolating power. The [B]lack subject racialized on the grid as a sign in not so much silent as articulating himself as he is seen, making himself seen as he is spoken (about), flesh conveying word" (23). Stephens reifies the notion that although Black bodies are just seen they perform beyond the epidermalization of their 
mere presence. By this mere appearance of Black male superheroes, we expect a respected and respectful narration, but we are only left with a cutaneous caricature. Stephen says, "At the very limits of an epidermalized symbolic order, the incorporeal aspect of the black male performer acts as a body without an image, a sensory, bodily impression, the shadowy brush-stroke of the dancing self projected on a wall, a self that has no audience" (151). If we consider what Gray and Stephens are proposing with the cultural politics of subjugation through imagery, it is obvious why we have to critique the multi-billion mainstream distribution of the Black body in graphic narratives. Since graphic narratives operate as a nexus between multiple avenues of economy and media, there is politics established by the distribution of the recycled racialized image. It is within this very political climate that Frantz Fanon implores that graphic narratives contribute to the lack of identity or confrontation with the fraught self reflected through these texts.

In Black Skins, White Masks (1952) Fanon postulates the idea of a collective catharsis ${ }^{6}$. Fanon alleges, "[I]n every society, in every community, there exists, must exists, a channel, an outlet whereby the energy accumulated in the form of aggressiveness can be released. The purpose of games in children's institutions, of psychodramas in group therapy, and more generally speaking, of the weekly comics for the young - every society naturally requiring its own specific form of catharsis" (124). Fanon highlights that of all the roles media plays in the depiction of the self (or corporeal schema-seeing-one's self being seen), graphic narratives (comic books) contribute to this cultural zeitgeist of expression and fantasy as the catalyst in the nexus of operations that "a host of information and series of propositions slowly and stealthily work their way into an individual through books, newspapers, school texts, advertisements,

\footnotetext{
${ }^{6}$ Although other scholars (Nama and Whaley) have used Fanon's Black Skins, White Mask as a focal point in their research regarding the Black body as seen and being seen, they have often neglected the notion of his collective catharsis concept, which is the reason why this research effort exists.
} 
movies, and radio and shape his communities vision of the world" (Fanon 131). For Fanon, image and distribution work together to reinforce the notion of displacement normalization in cultural politics — especially when this combination is situated in graphic narratives. Yet, this representation is contingent upon a foreign gaze, which often displaces us from experiencing a self since this self is manufactured for someone else to enjoy. If we were to engage with Fanon's collective catharsis for a moment, we have to inquire whom this collective catharsis actually represents. Given the context of Fanon's Antillean appeal, we know that he is speaking about the Black experience through the Francophonic gaze. However, we can adapt this same reading to how Black readers encounter themselves through the culturally produced gaze of the predominately-[W]hite texts.

Black popular critic and scholar Adilifu Nama claims, "Without a doubt, superheroes have played a significant role in presenting often idealized projects of ourselves as physically powerful, amazing and fantastic, but superhero comic books also function as more than a roadway to escapist fantasy or funhouse mirror reflections of our desires to create bigger-thanlife personas that can exert our will and power in the world" (33). Nama's statement leaves us with one question: if graphic narratives are supposed to be a place of fantasy and escape, how can one find the Black experience reflected in the superhero genre when it reinforces historically stereotypical ideologies, othering of non-normative subjects, and develops new disturbing ways of thinking about the black body? Fanon seems to insinuate this exclusion is intentional because these comics are "'written for [W]hite men for [W]hite children' and that the 'Wolf, the Devil, The Wicked Genie, Evil, and the Savage are always represented by Blacks or Indians"” (124-25). The late graphic narrative writer Dwayne McDuffie also notes that graphic narratives are no more than a "White-male power fantasy" (Gayle, White Scripts and Black Supermen) and that 
we should not be surprised by the reduction of agency for people who are not considered the mainstream normative (White, heterosexual, and male). This concept of being seen as "othered" in a medium, which is supposed to allow one to escape into fantasy, is considered as a space for critique. If graphic narratives are a "White-male fantasy," what does that mean for Black males or other non-normative subjects who attempt to engage in the graphic narrative and find false representations of themselves present?

Let us consider that one wants an authentic representation of themselves within the narrative context of graphic narratives even though graphic narratives serve as an escape from reality by presenting a fictionalized world. The issue that derives from conflicted authenticity is that, even in this fictionalized realm, there are still stereotypical tropes that manifest themselves in direct conflict with the purpose of literary escapism. How can one escape into a fictional world only to encounter the very image that haunts them in reality? Additionally, this questions whether if this fictional escapism exist in the very first place. If fiction's purpose is escapism, then where does one flee when in the narrative they find the similar perceptive challenges that occur in the real world? Even if the cliché that "art imitates life" is taken into account, this stereotypical emulation is stuck in an inevitable loop; a repeat of art and life which blurs the abdication (divide) that are observed as one in the same. Given this reflection, can there really be a fictional haven? The concept of metanarrative universalization can be even more relevant here. There are worlds and stories within fictionalized worlds (which there are), but let us move these stories to the intersection of reality and tropes. This metanarration then becomes a metanarrative nonfictional conversation - a fictional story about fictional characters that often reflect real world issues or conflicts. One can also argue that this happens already in not only literary genres, but also other multimodal genres such as video games, movies, and television shows. 
Nevertheless, that's not the point. The issue is complex representation of diasporic characters within graphic narrative discourse.

\section{So What's The Fuss?}

A main point of contention that arises from debates regarding the depiction of Black superheroes centers around one thing — stereotyping. For instance, Eisner, revered in the graphic narrative word, contends that stereotypes are just a matter of fact in creative graphic novels. He maintains, "[T]he stereotype is a fact of life in the comics' medium. It is accursed necessity-a tool of communication that is an inescapable ingredient in most cartoons. Given the narrative function of the medium, this should not be surprising" (Eisner 11). It is the same as saying, stereotypes are just easier to draw. He continues, "Comic book art deals with recognizable reproductions of human conduct. Its drawings are a mirror reflection, and depend on the reader's stored memory of experience to visualize an idea or process quickly" (11). Although Eisner (a White Jewish male) grounds his argument in the ease of content development as justification for bringing subjective realism to character through stereotypical depictions, he conveniently neglects to mention the negative effects surrounding explicit portrayals of stereotypes. This evident neglect by Eisner's is also reflected in his Black male character, Ebony White (a buckeyed and big lipped comic-relief/sidekick to his white protagonist in the 1940 graphic narrative series The Spirit) (See fig. 1.2). It is unfortunate that this stereotypical model became prototypical to the development of Black male images in graphic narratives. This "accursed necessity," Eisner asserts, is the reason for tension regarding creation and reception of Black images in graphic narratives. Based on his own subject position as the creator, Eisner claims that any stereotypes drawn from graphic narratives are simply in the eyes of the beholder. Although Eisner says that graphic narratives depend on the stereotype, he relinquishes the responsibility of 
depiction because it is up to the reader to determine if the image is an irresponsible one. Yet, these images are based on the negative aspects of the character created for convenience.

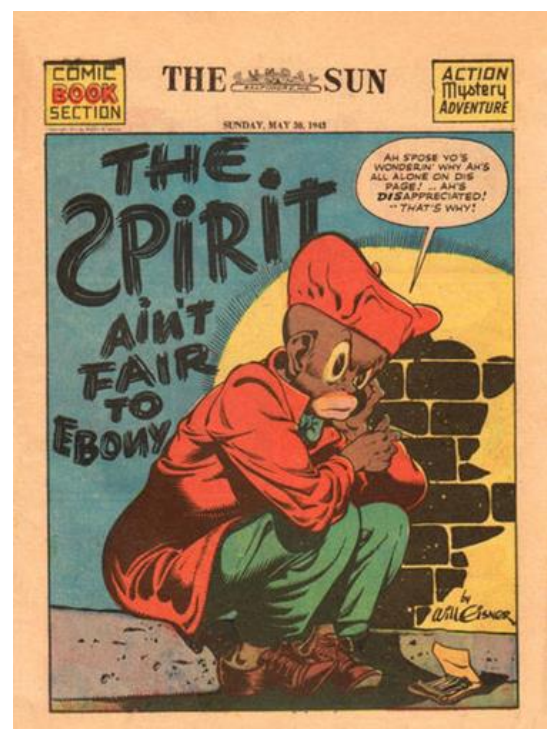

Fig. 1.2. Will Eisner's character, Ebony White.

Stereotypes are dangerous because they are powerful cultural tropes and we should not just accept them as convenient tools in the hands of cultural producers. The recursive images, presented to us, continue to develop meanings. Hall also argues,

But at the broader level of how 'difference' and 'otherness' is being represented in a particular culture at any one moment, we can see similar representational practices and figures being repeated, with variations, from one text or site of representation to another. This accumulation of meanings across different texts, where one image refers to another, or has its meaning altered by being 'read' in the context of other images called intertextuality. We may describe the whole repertoire of imagery and visual effects through which 'difference' is represented at any one historical moment as a regime of representation. (222)

The importance of this project to understand the meaning making of these intertextual images transmitted and for whom do they empower or remove power in identity. Notably, the power of 
racial identity transferred through the stereotype. Hall, in "The Spectacle of the 'Other,"' considers stereotyping as a tiered binary structure:

Stereotyping as a signifying practice is central to the representation of racial difference...Stereotypes get hold of the few 'simple, vivid, memorable, easily grasped and widely recognized' characteristics about a person, reduce everything about the person to those traits exaggerate and simplify them...stereotyping reduces, essentializes, naturalizes and fixes 'difference'...Stereotyping, in other words, is part of the maintenance of social and symbolic order. It sets up a symbolic frontier between the 'normal' and the 'deviant', the 'normal' and the 'pathological', the 'acceptable' and the 'unacceptable', what 'belongs' and what does not or is 'Other', between 'insiders' and 'outsiders', Us and Them. (247-248)

It is not simply a matter of labeling, but the power connected to stereotype is neglected in terms of easily accessible ideas. Halls insists:

Power, it seems, has to be understood here not only in terms of economic exploitation and physical coercion, but also in broader cultural or symbolic terms, including the power to represent someone or something in a certain way - within a certain 'regime of representation'. It includes the exercise of symbolic power through representational practices. Stereotyping is a key element in this exercise of symbolic violence... Power not only constrains and prevents; it is also productive. It produces new discourses, new kinds of knowledge (i.e. Orientalism), new objects of knowledge (the Orient), it shapes new practices (colonization) and institutions (colonial government) (Hall 249, 251). In essence, power exudes influence on the stereotype past racial tropes to a matter of financial exploitation. This profiteering happens through prevention and production. Specifically 
preventing new non-dominant voices, but producing new images and voices that does not disrupt the dominant culture or economic gain circulated through various multimedia avenues.

Considering Hall's position on stereotypes, Eisner fails to recognize this power. Even if Eisner's actions were consciously or unconsciously, author and scholar Consuela Francis interprets this act as a lack of accountability in the role of perpetual cultural political distribution of images due to White privilege of not having to care. Francis posits, "[T]he ways that the idealized fantasy of the superhero reinforces particular racist constructions of [B]lackness may be invisible, and thereby irrelevant, to nonblack readers because race cognizance is not one of the interpretive frames they use when reading comic books" (Francis 141). Perhaps in further contestation of Eisner's notion, Leonard Rifas in "Race and Comix" argues:

Cartoonists often defend the stereotypes in their work by saying that the art of cartooning fundamentally relies on simplification, generalization, distortion, and exaggeration. Caricatures become racists' stereotypes, though, when instead of exaggerating an individual's particular features to bring out his or unique humanity, the cartoonist suppresses the individuality of a person's appearance to bring the portrait into conformity with a preexisting racial stereotype. (Rifas 33)

Eisner's neglect of his role in perpetuating stereotypical images is an act of microaggressive racialization that's all too common coming from creators of graphic narratives. There is power in suppressing the notion that stereotypes are wrong in general, but they are convenient for the narrative. This idea is easy to consider when one has control of the narrative, but this also contributes to the continuity of the neglect when it comes to Black images in graphic narratives. It is hard to label blame when your own perceptive subjectivity is the cause. 
What Eisner's stance on stereotypes also neglects is the historical context of Black images in comics. In the introduction to The Blacker the Ink: Constructions of Black Identity in Comics and Sequential Art, critic Francis K. Gatewood and artistic/critic John Jennings argue that "one thing is true when it comes to the politics around representation concerning Black people: no aspect of it can be taken for granted. There simply are not enough images of Black people in the mainstream not to be critical of the way they are constructed and portrayed" (7). This is true. The lack of Black graphic narratives characters in mainstream representation also enhances the monolithic depiction of these characters. If there are polyphonic representations of the Black image, one will not struggle with the notion that "one represents many," but will allow for the complex representations that are being articulated through this analysis. These visual representations are perverted in graphic narratives because the Black male images ${ }^{7}$ portrayed in these stories are of second-tier heroes who fall victim to either second-hand narratives and/or cancelled series. Black superheroes in mainstream narratives do not have the fortune of complex narratives, but that of strategically replicated images that leave Black consumers of graphic narratives on the outside of their own collective cathartic experience. The lack of complex Black male superhero and narratives denotes a problem because as we want to engage into intergalactic crimes, most Black superheroes are left to fight tertiary-tiered characters in the suicide slums of the ghetto - the very place that some Black people are trying to escape. These visual narratives (dis)allow Black readers to envision themselves as heroes and/or superheroes and must turn to consistent and mass produced images of the White-male superhero.

\footnotetext{
${ }^{7}$ Fredrik Strömberg's Black Images in the Comics: A Visual History (2012) and Professor William H. Foster's Dreaming of a Face like Ours: Collected Essays, Articles and Scholarly Presentations on the Changing Image of Blacks in Comics (2010) and Looking for a Face like Mine: The History of African Americans in Comics (2005) offer excellent visual and historical research into the Black image in comics.
} 
The other issue in how these depictions operate revolves around Black superheroes that are written by White writers in an attempt to fill the void of the missing diversity. However, they end up participating in a benevolent paternalistic discourse, which further contributes to what I liked to call cultural-literary cosplay. This term derives from cosplay (short for costume play) literally means to dress up as a favorite character from popular culture. Cultural-literary cosplay could be defined as a writer's ability to implore cultural identity for the sole purpose of acting out one's interpretation of said identity. This cultural-literary cosplay allows White writers to create characters for the sake of temporality embodiment in order to produce said work. Arguably, White writers use cultural-literary cosplay while costuming Black bodies and other people of color when writing narratives. It can also be argued that most writers perform this same feat when writing characters outside of one's socially constructed identity. This does not mean White writers cannot write about others lived experiences in narrative, but it is highly problematic when they continue to recycle the same tropes whether it is out convenience or irresponsibility. Regardless, this type of literary embodiment can embolden White male writers to feel comfortable writing from a Black male perspective. It is this particular disillusion that Black graphic narrative scholars know that "[e]ven though the words were echoing from a pair of Black lips, a Black man's voice was not being heard" (Gateward and Jennings 1). Again, this argument is not to say that White writers cannot write or create Black graphic narratives characters at all, but we need to question the lens in which this process takes place, specifically how this authorship removes the agency of Black creators to develop their own material when it is being written for them and distributed as "authentic" portrayals through mainstream avenues. Thus, the graphic narrative remains a site of contestation and reclamation for agency. In this contentious space, we must question this notion of what is an "authentic" Black experience. 


\section{Black Is, Black Aint...}

Stuart Hall cautions us to critique our own idea of what it means to be Black in popular culture spaces. Hall argues:

Black popular culture, like all popular cultures in the modern world, is bound to be contradictory, and this not because we haven't fought the cultural battle well enough. By definition, [B]lack popular culture is a contradictory space. It is a sight of strategic contestation...Moreover, we tend to privilege experience itself, as if [B]lack life is lived experience outside of representation. We have only, as it were, to express what we already know we are. Instead, it is only through the way in which we represent and imagine ourselves that we come to know how we are constituted and who we are. There is no escape from the politics of representation, and we cannot wield 'how life really is out there' as a kind of test against which the political rightness or wrongness of a particular cultural strategy or text can be measured.” $(26,30)$

There is a concern in pinpointing authentic "Blackness." If "Blackness" is a social construct developed by the dominant culture, how can we expect to find the true Black experience in a text? Can we do so in form that does not present its own version of ethnic absolutionism? For instance, does this critique embody its exceptionalism? Can the displacement of one power structure result in another that may replicate the equal oppression? What is not true is that even as Black creators of graphic narratives arise they somehow diminish the presence of their White counterparts, that somehow they will be excluded from the dialogue altogether. If popular culture serves to reify notions of representations, then how can there be a zero-sum game of oppression when some Black writers often find themselves writing in resistance of and healing from historical atrocities and experience? 
The creator of cultural representation, in any literary text, must also be conscientious that this self-representation does not also serve the master narrative of tropes within their own work. I am referring to the dismantling of foreign perspectives for one's own, but forgetting that at the very foundation of this destruction and rebuilding lies the very oppressive forces that need to be attacked. For example, if Black artists decide to push for more complex representation of Black characters in texts, but use the same hypermasculine and hypersexual images that they originally critiqued is that hypocritical? This is the hegemonic danger of commenting on and replicating systems of oppression. Nonetheless, this construction can be empowering even with the presence of tropes in the text by reclaiming and rewriting negative images. Tropes are perhaps less dangerous if they are also surrounded by more complex and rounded characters, since Black creators want to fill the void left by flat characters, which, as Eisner suggested, was the preference for a long time. When does a character become a character and not a trope? After all, a fully developed character might also be a trope - a figure that is also indicative of being accused as one who epitomizes conflicting authenticity.

The picture we get from the world of graphic narratives is saturated with contradictions. By "conflicted authenticity," I mean that there is a self-identifiable ambivalence in the reception of Black identity and narrative. We need to consider the limitation of authenticity. How does one identify the authentic self when the self is often a result of cultural habitus? It can also be stated that the self cannot reflect all unless one identities with a collective identity. This observation also calls into question the credibility of a collective identity especially if this identity has been developed and cultivated through visible and systemic forms of ideological and cultural oppression. Obviously, this critique does not mean that this culture (Black culture) does not exist but it does bring into question what is true Blackness and if we are to agree on the tenants of 
Black culture what would they entail? It is my belief that this line of inquisition is best suited for another project as to not to detract from the primary of agenda of this work. But, one should be aware that this complex notion of authentic representation could often lead to monolithic or dogmatic perspectives of the Black identity, the very issue that tropes often lead to or what the term authenticity signifies.

These are important inquiries, but for the sake of this dissertation, I want to focus on the articulation and re-articulation of these tropes. I do not want to disengage with the idea of conflicted authenticity, but I want to ensure that this conceptualized idea is not forgotten since it can often lead to questioning of how I came to an accurate representation of Blackness within the confines of graphic narratives. Representation is the crux of the argument about the culturalliterary cosplay and the interchange of identities in fictional and non-fictional space. To critique problematic images in graphic narratives posed as Black authenticity while providing the avenues for which Black graphic narrative creators can develop counternarratives to resist egregious images and stories that have been written in White and posed as (B)lack.

\section{The Blueprint}

My research is an opportunity to discover more literary connections of Black male superheroes through the lens of English Studies. By doing this, I hope to establish a correlation between how Black male bodies have been narrated by stereotypes, commodification, and reimagined through recapturing agency from the masters mainstream producers. I suggest that as Black male superheroes are represented they are often left with the dangerous weight of Blackness that hinders their ability to be vehicles of fantasy for Black readers. Although mainstream graphic narratives have been created for universal audiences, they still bend to the will of a White-male power fantasy gaze. This conundrum has often been dismissed. 
Additionally, the goal of this research is to make specific links between representations of Black male superheroes and hegemony and the other avenues of expression that replace the void left by these displaced images. It is my belief that Black graphic narrative creators revise these images (like Black Kirby) and other cultural genres to compensate for the lack of literary agency within graphic narrative texts and popular culture when it comes to the characterization of the Black male superhero. For the purpose of this research, I focus on mainstream graphic narrative characters Black Panther, Luke Cage, Black Lightning, and the classroom space as semiotic subjects for hegemony, racial rejection, and revision.

The second chapter, "Capes and Curriculum: Black Pedagogical Superheroism," addresses the conflict of teaching Black literature at a predominately White university. By focusing on being a Black male teaching Black literature within the presupposed color-blind nexus of students and educational departments, I contend that these spaces are also interlaced as a place of power and resistance between faculty-to-faculty and faculty-to-students who do not assume the normative idea of collegiate instruction. Critical race theory's use of personal narrative challenges the pragmatics that is often used to silence Black instructors and students whose agency are attacked by microaggressive acts of dismissal or microaggressive acts of enforcing the status quo. This burden of "representation" correlates with the burden of Black superheroes that are often placed in positions of facing racial oppression in the midst of altruism.

“Surface Race Relations: Racial Commodification of Marvel's Black Panther," chapter three, analyzes Black Panther by using a postcolonial lens to scrutinize this character as a colonized intellect. ${ }^{8}$ Black Panther is caught in the cognitive dissidence of protecting his kingdom of Wakanda, but he is also the Black totemic figure who serves the Fantastic Four. This narrative subjugation seemingly opens the door to pinpoint the theme of modernity in Fantastic

\footnotetext{
${ }^{8}$ Theory developed by Frantz Fanon in The Wretched of the Earth (1961).
} 
Four \#52 and \#53 (Marvel 1966) as a Black superhero is relegated into a sidekick. Additionally, this chapter seeks to analyze Black Panther's role in fighting racism that becomes false reconciliation in the graphic narrative Marvel Premiere: Black Panther series (Marvel 1979-80). The second analysis, with Black Panther as the subject, will engage in critical race discourse linking interest convergence ${ }^{9}$ to Black Panther as a racially commodified subject. This series needs careful critique due to the anemic narrative plot of racism and old Black tropes of modernity that reify images of African exoticism.

Chapter four, “'Sweet Signifying Christmas:' Unchaining Luke Cage,” focuses on how previous stereotypical tropes of Black masculinity in graphic narratives are remixed and reworked through the theoretical concepts "Signification"10 and "retcon" (retroactive continuity). There tools assist in remixing the image and portrayal of Black male superheroes. Dwayne McDuffie intentionally signifies on the character Luke Cage and other Black superheroes from the 1970s in trying to metaphorically kill the old image and/or right/write these stereotypical characterizations as new and more complex images with multifaceted character development. The introduction and death of McDuffie's character Buck Wild in his graphic narrative Icon (DC Comics) becomes a gift to the much-needed collective-catharsis for Black superheroes. This section also investigates how scriptwriter Cheo Hodari Coker rearticulates the Luke Cage character in the Netflix series to be more altruistic and one who engages in Black respectability politics while revising negative stigma of the hoodie on a Black body to a tool that becomes synonymous with a superhero costume.

\footnotetext{
${ }^{9}$ Theory that initiated Critical Race discourse by Derrick Bell

${ }^{10}$ Gates, Henry L., Jr. The Signifying Monkey: A Theory of Afro-American Literary Criticism. 1988.
} 
Chapter five, “Just 'Us' League: Racialized Exclusion in the Recruitment of Black Lightning into the Justice League," analyzes the narrative surrounding Black Lightning while he is facing unknown recruitment to the Justice League America (JLA) in Justice League America \#173 and \#174 (DC Comics 1979-80). Black Lightning is literally split between fighting crime and proving his self-worth as a Black male superhero by the White gaze of JLA. Here, I argue, that instead of just fighting crime, Black Lightning is fighting for his superhero agency in this metanarrative stereotyping and racial exclusion by some of America's iconic heroes (Superman and The Flash) through microaggressive encounters and by his written narrative.

The final chapter, "I, too, am America," addresses rewriting the narrative of the Black male superhero through various genres for reclaiming agency for Black writers and artists within graphic narratives. Black Kirby (from John Jennings and Stacey Robinson's collective group), as the result of remixing Jack Kirby's work, controls the narrative of the Black body as it is visually being written and drawn by their collective. This chapter advances the thought that Afrofuturism is one of many conduits through which Black writers and artists have begun to develop their own titles and superhero characters to combat the mainstream through such narratives such as Kid Code (2014) and Black (2016). Additionally, I also argue for spaces left for exploration in this subject.

In conclusion, this project serves as the foundation for the academic work that bridges the metanarrative universalism, cultural-literary cosplay, and conflicting authenticity theoretical concepts with Black performance theory, postcolonial theory, critical race theory, and literary theory. Again, I find it best to work with Black Lightning, Black Panther and Luke Cage, but I acknowledge there are multiple characters that also deserve analysis. It is my belief that we can use multiple avenues of intellectual work to develop new perspectives and analysis of texts. This 
is the epitome of my ideological roots in hip-hop: the cultivation of an artifact by mixing and matching differentiating texts to find a common link and develop a new style. This style is a new literary theoretical mixtape - a symphony of intertextuality to which sampling in hip-hop is derivative. A mixtape dedicated to examining and problematizing the use of image and narration in texts involving Black male superheroes. These superheroes who have originally been read as Black when written by White writers and then remixed as tools of agency reclamation and resistance by Black authors and artists through the blended genres of Afrofuturism, hip-hop and Black speculative fiction to disarticulate fictional representations and develop a collective catharsis that at least appears to be more real. So let us start the show. 


\section{CHAPTER II: CAPES AND CURRICULUM: BLACK PEDAGOGICAL SUPERHEROISM}

We were taught that education was the surest route to freedom. The teachers were there to guide us, and show us the way to freedom. bell hooks, Teaching Critical Thinking

Oh, you alone understand that if we gonna win We've got to get together, stay together, be together, stick together So tell me why can't you understand That there ain't no such thing as a superman

Gil Scott-Heron, "Ain't No Such Thing as Superman"

\section{One in a Million Questions (The Introduction)}

Can a Black professor be a superhero? According to the lyrics of Gil Scott-Heron's selfsufficiency anthem in the epigraph, the answer is no. We do not need to wait around for a teacher to save us, we have to save ourselves. I know this inquiry appears hyperbolic because when we envision superheroes we think of capes, superhuman strength, or the ability to fly. We fail to think about teachers who stand in front of classrooms and are responsible for the cognitive and educational well-being of students. The context of waiting around for someone to save you can be considered paternalistic at best. In fact, superheroes in the Black community have often been political figures who have fought for the inalienable rights of all human beings (such as Martin Luther King, Jr.). These real-life superheroes have often found themselves in a shrine of some Black homes next to Jesus and now former president Barack Obama. When it comes to Black superheroes, in Damian Duffy and John Jennings'Black Comix: African American Independent Comics, Art and Culture Black academic and artist Stacey Robinson suggests that, "Our heroes don’t wear masks. Why? Simply put, our heroes represent realistic ideals. Justice, freedom and equality don't wear masks" (Duffy and Jennings 163). Black superheroes are those we encounter in our lives that stand up for us. Yet, does being a Black professor automatically mean I have an 
obligation to serve just the Black ${ }^{11}$ community? In a predominately White institutional space, the answer to that question is complicated.

The late Black graphic narrative writer, Dwayne McDuffie, posits that Black superheroes have the added burden of race, but is this Blackness also a burden to academic faculty? I argue that it is both a blessing and a curse. In the article "Toward a Race Pedagogy for Black Faculty" educators Rosemary Closson et al, argue that, "Black faculty teaching race-based courses often do so because they can teach from the authority of experience as well as from the academic preparation" (Closson et al. 84). What they mean is that the embodied experience plus the expertise through the research and scholarship creates the ultimate authority of a race-based subject $^{12}$. This statement is not to denote that White faculty cannot access such expertise through the research, but the tangibility of experience in items that you research adds to the credibility of race-based dialogue. In this sense, being a Black faculty member is heaven. There is an academic street cred that is signified through the Black identity.

The curse, however, lies in the burden of skin color. Rodney K. Hopson reflects on his experience of being a young Black faculty member in "Towards the Language and Scholarship of Freedom and Resistance: Coming to Terms with Being a Young, Black Male Academic in America." In the essay he proclaims, "I would have to realize that my success in the academy depended on my ability to wrestle with the tradition within the largely White, male-dominated professor that had historically manifested discriminatory policies and racism" (Hopson 75). This tradition, of which Hopson speaks, is the ambivalence of being Black in a largely White space; the cognitive dissonance of teaching texts traditionally used to combat the very institutions that contribute to marginality. You can also consider this academic method as "throwing rocks in a

\footnotetext{
${ }^{11}$ Black here insinuates all individuals who assert that they share an African Diasporic experience.

12 One can assume that this theory can apply to other faculty of color, cultures, and genders as well.
} 
glass house." Why? Because even when enlightening our students with the powerful rhetoric of Black aesthetics and theory it contributes to the retaliation that occurs within subversive tactics by administration, students and/or faculty who perceive you as a threat. Nevertheless, altruism still derives from doing what's right in the face of danger.

Given this, I have come to the realization that the added burden of Blackness impacts how I am seen or - at times - unseen in the Department of English. Being seen is encountering micro-suggestive statements such as how I may be interested in teaching urban education classes although I have no history with teaching educational classes in urban communities. I wonder how I get relegated to just teaching Urban education writing courses. Does it have something to do with the fact I am from Chicago and a product of the Chicago Public School system? Is it that my Blackness automatically directs me to urban-based courses by the symbiotic attributes of being African American, urban, and Black? Recently, I found a copy of Twelve Years a Slave in my office mailbox with little explanation other than "maybe someone thought you would be interested in it." As a lover of books I can appreciate the gesture, but I'm also disappointed by the connotation of the book choice. As much as I'm interested in Afrofuturism I find myself presented with the history of my ancestors as in a psychological game of \#NeverForget \#YourPlace. Being seen is being the resident expert of Black talk, but also the conundrum of making sure that its' spoken and taught correctly. Being unseen is walking through the hallway and speaking to faculty members who either a) look right through me only to have a conversation with someone right behind me or b) put their head down. Of course these are just a few examples of many, but they are presented for a purpose. The embodiment of my being does come at the cost of my psyche even though my presence has purpose. 
Let us return to this idea of a Black professor as superhero. If we are to consider that Black instructors, regardless of the blessing and curse, are heroic by their presence and endurance of cultural hegemony, it also denotes a binary between good and evil. If there are superheroes, then there must be super-villains. This notion posits the question, who are or can be super-villains in a classroom? Are they educators who, mad with power, reduce the agency of the students in their classroom? Are they instructors who grade based on racial or intellectual assumptive ability or pose as liberals with subconscious colonial modernity tendencies? I often get asked how do White students and professors take the content of my course material and scholarship since it does not deter from attacking and addressing the issues of Whiteness as normative, Whiteness as essentialism and politics, Whiteness as pre-, present, and postmodernity normative in graphic narratives against the identity of Blackness and the male body. More often than not, I am usually met with microaggressive comments such as "that seems nice," "oh, okay, let's see what we can do with that." To be fair, I noticed that many faculty in my department are not equipped to handle my topic because of its intersectional nature. Also, one can make the argument that some professors are so self-indulged in their own research that they may only assists students who materially benefit their own cause. Nonetheless, my racial microaggression x-ray vision allows me to read in-between the lines since "cultural insensitivity may stem from ignorance and innocence, and may be less overt, and appear to be less offensive and seemingly less harmful than racist acts, it effects cannot be underestimated" (Thompson and Louque 106). Is it fair to say that this ignorant innocence is foul or provided by that assumed privilege? I find this approach problematic as well since I have encountered students (of various cultural backgrounds) who are going into urban teaching (within my English 101 course) thinking they can save the children of these poor and disadvantage communities. This is multicultural 
benevolent paternalism at its best. Yet, as these students want to truly do something to make a difference who am I to snatch their proverbial educational capes? I believe that at times when it comes to being a superhero one must also be the villain (sometimes I call this being realistic). However, I contemplate this villainous approach when it comes to evaluating my presence in the classroom. Who am I here for? What am I teaching? Do the students care? I have all this knowledge, but I reserve it because I'm often at odds of showing too much caring for the love of my subject matter when students just want to past the class and move on. Some of my students do not want to decontextualize the racial undertones of Black Panther's uncolonized country since it does not have any tangible weight for them. I just want to say that's because you have all been colonized. \#StayWoke

Before we embark on my pedagogical experience it is important to note that my own passage as a Black student has molded my teaching style. In his infamous essay "The Furious Passage of the Black Graduate Student,” David Davidson argues, “The Black graduate student usually reaches his most intense anger at the departmental level because it is here that he is most intimately exposed to the workings of institutional racism in the university in particular and, by extension, white institutions in general" (Davidson 197). My pedagogical endeavor is the result of silencing that I have experienced as an undergraduate and graduate student. I wanted to create an experience for my class that I did not consistently receive from courses based in multicultural issues or race-based topics. I chose to proclaim that my subjective and lived experience would not serve as the essentialist ideal for all Black students (or people in general) and that this professorial position would not be one of power mongering in educational spaces.

For this reason I chose to implement an "engaged pedagogy" that bell hooks refers to within Teaching: Critical Thinking (2010). hooks defines engaged pedagogy as "a teaching 
strategy that aims to restore students' will to think, and their will to be fully self-actualized. The central focus of engaged pedagogy is to enable students to think critically" (Teaching Critical Thinking 8). It is this engagement that hooks pushes the communal responsibility of education. hooks further declares Teaching to Transgress:

To begin, the professor must genuinely value everyone's presence, there must be an ongoing recognition that everyone influences the classroom dynamic, that everyone contributes. These contributions are resources. Used constructively they enhance the capacity of any class to create an open learning community... Seeing the classroom always as a communal place enhances the likelihood of collective effort in creating and sustaining a learning community. (Teaching to Transgress 8)

Paul Gilyard, in his CCCC chair address "Literacy, Identity, Imagination, Flight," challenges educators to think of a progressive pedagogy that does not silence or neglect students. Gilyard states, "For any progressive pedagogy to achieve respectable results, students, among whose ranks are some of the important outsiders we need, have to feel invested in the roles they play in the process" (Gilyard 144). Additionally, noted pedagogy scholar Lisa Delpit confirms Gilyard's declaration in practicing a progressive pedagogy that the teacher should experience vulnerability in the classroom. She contends, "The teacher cannot be the only expert in the classroom. To deny students their own expert knowledge is to disempower them" (Delpit 131) and concludes that "[e]ducators must open themselves to, and allow themselves to be affected by, these alternative voices" (Delpit 141). It is then this moment "when everyone in the classroom, teacher and students, recognizes that they are responsible for creating a learning community together, learning is at its most meaningful and useful" (hooks, Teaching Critical Thinking 11). During the course, I made sure to incorporate this notion of an open community in 
the classroom; a space where students felt comfortable voicing their concerns or disagreement with the literature or texts brought before them. This ambition resulted in a conundrum based on the resistance content of Black literature or thought.

As a graduate student, at the time of this internship, I also reflected on the silencing as a student. In numerous courses, my comments have often been reduced to the monolithic experience of myself. Although I was speaking from the intersectional subjective position of a Black-male, it was as if I had no agency on other insights into Black culture. The instructor would became defensive and clung closely to the "research." This research that s/he emphasized automatically made them the expert on the Black experience in speech, literature, privilege, and history. Delpit posits this discrimination in indicating the silencing that occurs during this type of experience, "However, either by virtue of their position, their numbers, or their access to that particular code of power of calling upon research to validate one's position, the White educators had the authority to establish what was to be considered 'truth' regardless of the opinions of the people of color, and the latter were well aware of that fact" (Delpit 127). My experience did not merit the same weight as the "research." Instead of combining the research and my lived experience to develop a dialogue between us, there was a now a border of resistance placed between the instructor and myself. There is an irony here since, in some respects, the syllabi did indicate these classes were "safe spaces." Safe for whom though? I did not perceive my safety here. Experiences like these also indicate the importance of why Black graduate students and faculty are needed in these academic spaces to contest the cultural politics of the classroom space that is often labeled as liberal and free with the caveat being as long as you agree with the instructor. 
Insights such as the "research" and problematic pragmatic dialogic trump all lived experience, surely a subconscious or conscious act of agency reduction. It is as if the physical presence of that being talked about dangers the narrative of the educational experience of that White instructor who is trying to imply that they are the expert of all. We can truly account this pedagogical exceptionalism and essentialism for what it is - colonial modernity in practice - the struggle for Whiteness to affirm itself against the Black body. With that being said, I have encountered too many times where I have experienced what Jay-Z said in accepting an American Music Award in 2009 for best rap album award: "Men lie, women lie, numbers don't." If this is the case, then my lived experience is monolithically subjective or an anomaly no matter how antiquated and disillusioned the context of said research presents. I felt what these instructors wanted was not democratic discourse in how this research may have evolved, but that this was the stone cold truth. At times I chose to be a good "boy" and silenced myself so I can pass the class. I told myself that did not want my students (regardless of their cultural background) to experience the type of silence where the resistance was not in rejecting the work, but rather in minimizing participation in class. The work is to be only seen, not heard.

For this pedagogical reflection, I chose to utilize a self-reflexive method of personal narratives that is often used when engaging a critical race theoretical discourse. I use this method for two reasons. First, "Self-reflection is a significant part in the development of praxis. Selfreflection allows instructors to become sensitized to their influence on the teaching and research environment" (Closson et al 88). I want to reflect on any role that negatively and/or positively influenced the environment of analysis. Lastly, scholarly personal narrative (SPN) serves as a counternarrative to traditional pragmatic research. The SPN recognizes and affirms my subjective experience as a Black educator at a pre-dominantly white institution (PWI) teaching 
African-American literature (AAL). We should consider this pedagogical inquiry one that is both informative and counternarrative. I believe that the hybridity of problematizing my pedagogical experience with SPN enlightens my pedagogical choices for the courses I have taught and addresses the issues of resistance, resilience, and renaming. This is important because "victims of racial discrimination suffer in silence or blame themselves for their predicament. Stories can give them voice and reveal that others have similar experiences. Stories can name a type of discrimination; once named, it can be combated" (Delgado and Stefanic 48). Again, I have selected this pedagogical reflection to take place through a critical race theoretical lens that uses narratives as a counter to cultural and educational pedagogical hegemony, microaggression, macroaggression, and silencing in hopes that I can connect with others who have this shared experience. I find this beneficial in addressing the unique circumstances of my English 165: Introduction to African-American Literature experience.

\section{The Structure (Course Content)}

In the fall of 2015, I had the opportunity to teach English 165: Introduction to AfricanAmerican Literature for the English Studies department at Illinois State University. I titled this course, ““And I Heard'Em Say': Contextual Cyphers in African-American literature.” The purpose of this course was as follows:

This course seeks to help student make intertextual connections between historic and contemporary themes in African-American literature. The prominent themes of this course are resistance, resilience, and counternarrative, which will be analyzed by observing how humor, autobiographical narratives, socio-political criticism, and hip-hop are used in African-American literature. Students will experience basic theoretical 
concepts such as intertextuality, double-consciousness, and signification as they engage with the course material. By the end of this course, students will be able to answer the following questions: What is African-American literature? How did African-American literature create a voice for African Americans? What does African-American literature speak against? What are some recurring themes in African-American literature? Is African-American literature still relevant? Selected readings will focus on comedy, comic books, poetry, rap, and prose of (in)famous African-American authors in attempt to answer the aforementioned questions ${ }^{13}$.

Students would navigate these inquisitions through the following textbooks:

- $\quad$ The Fire Next Time by James Baldwin (1993)

- Between the World and Me by Ta-Nehisi Coates (2015)

- for colored girls who have considered suicide when the rainbow is enough by Ntozake Shange (1977)

- Sister Citizen: Shame, Stereotypes, and Black Women in America by Melissa HarrisPerry (2011)

- Dear White People by Justin Simien (2014)

- Icon: A Hero's Welcome by Dwayne McDuffie (2009)

- To Pimp A Butterfly by Kendrick Lamar (2015)

The content of this course derived from two specific influences. The first influence was the result of my Education and Foundations (EAF) course "History of Educational Thought: Education, Liberation, and the Black Radical Tradition" instructed by Dr. Pamela Hoff (a Black faculty member). This course focused on resistance, resilience, and liberation of African Americans

\footnotetext{
${ }^{13}$ Taken directly for the course syllabus. More details can be found in Appendix A which contains the course syllabus.
} 
through education in the United States. The second was a confluence of research on Black male superheroes and Black identity in graphic narratives ${ }^{14}$. This class would be grounded in the fight for Black identity and agency through the use of literature, poetry, graphic narratives, and humor as sites of hegemonic resistance and African-American empowerment. I also wanted to reflect this empowerment by hopefully operating as the physical embodiment of these principles and ideas through humor and critical discourse for the students.

Preparing for the internship, I was concerned how to teach the negation of Whiteness in a PWI-based course, while respecting the agency of all students regardless of their cultural background. I figured that too much radicalism within the text and content of the course would defeat the purpose of engagement across the board for all students. However, I wanted to distort and challenge students' concepts of race and how these cultural assumptions affect us. English instructor Ann Louise Keating argues that "[A]t the very least, we should complicate existing conceptions of 'race' - both by exploring the many changes that have occurred in all apparently fixed racial categories and by informing and by informing students of the political, economic, and historical facts shaping the continual reinvention of "race"' (207). It is this challenging of race and introductory understanding of Blackness that this class could be a space where liberality and diversity is truly discussed and embraced. In Prophetic Insight: The Higher Education and Pedagogy of African Americans, educational theorist Earnest Bracey accuses higher educational institutions of their inability to be the liberal spaces that they profess and that they often appear as pseudo-liberal spaces for marketing spaces. Bracey asserts, "The contemporary university, with all its faults, ambiguities, preoccupations and predictability, has often been accused of reneging on the promise to equip the modern-day student with a truly liberal education" (Bracey

\footnotetext{
${ }^{14}$ Graphic narrative is a technical term for comic book
} 
57). I wanted this course (and future courses) that address this subject matter of race needs to be a truly liberal space.

When it came to selecting the text for the course, I struggled with trying to provide the balance of proper introductory material to AAL. Upon research, I have found that this is not an unusual experience for Black faculty. Professor Rodney Hopson states, "We, as African American faculty and educationists, make epistemological decisions when we assess what is knowledge in order to determine if a particular piece of information should be included in a syllabus or curriculum, or how our own beliefs are central to and influence classroom methods" (Hopson 74). I think the argument can be made that all instructors consider their values and the students when developing course materials. We must also consider that text selection is an act of cultural politics. By selecting texts to teach we recognize that there is a silencing of voices when allowing other texts to speak based on the books subject matter and authors we choose. Also in doing this we bring in the authors politics through the shared ideology of their work. In addition to Hopson's critique of epistemological connections to our selected text we must also consider our own values. Selecting books became a deeply meditative activity that made me question who did I feel was important to Black Feminism and Masculinity while neglecting others.

Considering the content, there was little to address LGBT issues in course. This was not intentional, but I used the segment dealing with Baldwin's The Fire Next Time to have a (albeit brief) discussion of intersectionality of LGBT issues within the Black community. Next time I will make sure to have a better space for this conversation. Even though this appears neglectful in reflection for the priority of this instructor, I do understand the difficulty of selecting texts. This is even more evident in choosing a course that is specialized for majors as opposed to a 
general education class where students may lack the background knowledge of theory or context to specialized content that requires more basic material.

In a recorded office conversation with his student Chang Chun Tao, famed rhetorician Keith Gilyard reflects that there is a purposefulness to which we select out texts for the course. Gilyard says, "Our choice of materials and our classroom concerns communicate messages as well, largely about whom we value" (Gilyard 141). Unconsciously, we, as faculty, do create a subjective selection of content. I did take precaution by selecting text that encompassed the Black female and male perspectives that addressed (directly or indirectly) gender, sexuality, and class. With that being said, the texts represented in this course reflect a resolve of aligning the past (Baldwin's The Fire Next Time) with the present (Coates' Between the World and Me) to the future (Lamar's To Pimp a Butterfly).

In hindsight of course materials and assessments, I noticed that James Baldwin's The Fire Next Time was the most referenced book in literary analyses and reading response assignments. It is also no coincidence since this text did a great job of introducing and intersecting other material in the course. I also believe that the students enjoyed and connected with Baldwin's narrative style the best. The second most referenced text was Ntozake Shange's for colored girls who have considered suicide when the rainbow is enough. I would like to attest this to two things a) that it was the most poetic and emotive of the texts that we covered and b) that the class gender majority was women. The guest speakers I invited for this section created a practical bridge to the theoretical material in the section dedicated to Black Feminism. For this unit, Black Art graduate student Venise Keys and doctoral studies colleague Flourice Richardson spoke regarding the Black woman experience in its complexity through their lived experience as they both create scholarship that intersect their Blackness and gender (women). It was important for 
me to reduce my role in this unit to show the students that, instead of speaking for them, I wanted to empower these women to speak themselves. This statement is not to indicate they lacked empowerment since such statement can be received as chauvinistic. I wanted to make sure that texts were discussed by those who may have a better grasps of the lived experience of what it means to be both Black and a woman while considering other intersectionality. As we continue to engage whether a Black professor can be a superhero, I want to present several scenarios that I had encountered during my internship. The first scenario deals with having to acquire students for taking the class. Far too often, in conversations with Black faculty mentors and staff members, there is fear regarding acquiring students for a class to "make." This trepidation puts added pressure on Black faculty to utilize recruitment efforts to convince students to take their courses - a burden that is not often shared with their White counterparts if classes do not appear as a requirement or the instructor lacks popularity within the department. This statement would indicate an issue with politics of course registration and advisement that we will later address. The next scenario deals with resistance of the course material, but not from the source that you would expect. The third scenario concerns itself with when White students check out of the course based on race-based content. Lastly, the final scenario addresses the internship's class conversation on reverse racism within context of the Black community. I felt these four scenarios highlight my pedagogical experience during the fall 2015 internship. It was my hope that my course (and all others) would serve as a safety net for those seeking knowledge of Black culture. It was my civic duty as an educator... an academic hero. 


\section{Dig, If You Will, The Picture (Demographic and Logistics of the Internship)}

Here is demographic breakdown of the course participants. This information was provided by the students in a voluntary self-identifying survey taken during the course ${ }^{15}$. These numbers are based on the pre-first week enrollment and enrollment after the first week:

Original enrollment

- 26 students originally enrolled

- 20 women and 6 men

- 13 black students (11 women and 2 men)

- 3 bi-racial women

- 2 Hispanic men

- 8 White students (6 women and 2 men)

Enrollment after the first week of classes

- 23 students

- 19 women and 4 men

- 13 black students (11 women and 1 man)

- 3 bi-racial women

- 1 Hispanic men

- 7 white students (5 women and 2 men)

The demographics for this course can be considered as an anomaly. At Illinois State University, one does not expect to have a class where the majority of the students in the course are Black at a PWI — even for a class that is AAL. Reflecting on my own experience as an undergraduate and graduate student in AAL courses, there were only a few students of color enrolled in these spaces (most of which were Black, Latino, and Asian). However, this number could be no more than 8 total in a class of 23 or more predominately White students. I speculated that this rare instance — where the Black students outnumbering the White students in the classwould provide an interesting balance of perceptions and not leave the Black students with the weight of interacting with the class. This cultural allocation also presented new and interesting

\footnotetext{
${ }^{15}$ Students also voluntarily information regarding their gender and racial identity that was covered under the approved IRB. Also, for the sake of consistency, I have changed the names of the students involved.
} 
challenges in how to make sure that White students were not the cathartic figurative punching bag for the angst and frustrations of the Black students, but also allowing Black students to voice their much needed frustrations. I hoped that, given the topics of discussion and number of shared cultural identity, would have led the students to speak with no fear of angst or retaliation and that my presence would allow them to be unafraid. Additionally, the bi-racial students also provided an interesting perspective because of the dual-cultural context of their background (two being Black and White and another student being Hispanic and White). I wanted to make sure that this space allowed them to navigate the cultural identities without having to bifurcate their perspectives to whichever side of the class was the least hostile due to controversial topics.

The most active participants in the course were the women. Of all the women the only quiet student was one a young White woman named Sally. Sally did participate, but she was the least active of the women participants. One of the most active participants was Symone, a Black woman. I found her to be the most active and responsive as it came to course content, subject matter, utilizing her subjective experience to understand new concepts and ideas as well as engaging respectfully with her peers. Of course, Symone and Sally represent two binary differences, but their cultural backgrounds do not seem to be coincidental.

I wondered if the gender dynamics affected the masculine influence of the course. Of the four men in the course, (two White, one Black, and one Latino), they spoke the least in the course. In fact, one Black student named DJ and one White student named Andy missed four classes each. Based on the inactivity of both students previously mentioned, they suffered low grades, attendance, and participation. Alan, the one Latino-male student in the course, only participated if called upon, but not voluntarily. However, Jordan, a White male, was the most 
engaging of the least engaging group of students. He at least asked questions and participated in class discussions. Yet, all four male students were reluctant to reinforce their ideas or comments. Most, if not all, of these students came across very cordial in conversations that organically manifested. This respectability can be contributed to an insistence that we listen to each other speak to be understood, regardless of perspective, before responding. This rule was established during the first day of class. Setting this foundation allowed for respectful conversation once students began to dialogue. Although I tried to refrain from being authoritative in my classroom management, I only intervened when I felt students were being disrespected or accusatory without cause. By doing this I was making sure that each student was being protected but allowed to speak their peace. This peace was important for creating an atmosphere of trust and critical thinking because it hopefully allowed students to process thoughts and emotions and to articulate without fear of retaliation.

For example, Brittany, a White woman, brought up the fact that she was called "the most ghetto white girl that someone knew." She said that a Black male acquaintance told her this since she liked to hang around Black people more so than White people and exhibited Black traits in her speech and musical selection. After this comment, Lina (White woman) followed up with the comment about "what does 'ghetto' mean" and asserted that it is basically an insult. Instead of attacking Bridget or Gina's statements, Symone (Black woman) inquired about how "Blackness" and ghetto became synonymous. This questioning led to a class conversation on racial identity and how Blackness is often equated with poverty, struggle, ghettos, low education and crimeessentially the opposite of what we would consider the sanctity of Whiteness. I thought this was fascinating because, instead of shutting the conversation down, we began to address topics such 
as Black authenticity, racial identity exchange, cultural influence, and how things are signified to create stigmas. Peep the following scenarios.

\section{Scenario 1: Hustling for Classroom Quotas}

One would think that there is a consistent push for at least African-American students or students in general to take an AAL course at a PWI. What became problematic was the fact that I needed to do some recruiting for this particular course. I was concerned that I would not get enough students so that my class could "make." As stated earlier, even as I spoke with other instructors who teach or taught race-based courses in literature or education, there always seems to be the fear that their classes will not "make" based on low enrollment or interest. I can honestly say that I did a lot of hustling to recruit students (for the course). I primarily focused on recruiting Black students because I felt that they would benefit because of the course's commitment to being an open space for healthy dialogue and processing contemporary issues that appear as reoccurring problems within the Black community. This assumption also derived to meet the needs of Black students who were previously protesting about the lack of academic curriculum addressing their identity and identity and recent social political death or attacks taking place on Black bodies nationally.

For class recruitment, I attended Black-based student organization programs, introduced myself, and described what type of class I was teaching. I think this served two purposes. The first purpose was that students who never physically been introduced to Black instructors or faculty could visually see one. Lastly, my class participant hustle was important to establish relationships with programs and departments who connected with students who are usually not academically pursued. For example, I visited Vince Cunningham, coordinator of the Trio (SSS- 
Student Support Services) Department. I constantly contacted Cunningham to get students who might otherwise be discouraged by participation in such courses. I sent Vince Cunningham my course syllabus and he (in return) encouraged his counselors to register students for my course. ${ }^{16}$ This networking would form an academic bartering system for future class enrollments.

Other avenues I used to recruit students were local Facebook pages of minority-based groups at Illinois State University. Social media, like the aforementioned, were a great way of connecting with other students who I could not reach at meetings. Traditional tools I have seen for advertising courses were either listserv based or by flyers in random department boards. However, I advertised my course through dialogue and pictures of the course textbooks on Facebook. Through this method, I found students liked and shared my posts to their own timeline or tagged students in the post so that they were aware of the course. I wanted to max out every available possibility to engage students to let them know that a) I was here and b) here is a class that may interest you. What I found from this academic hustling was that my class literally filled up three days later to reach the capacity for the course. The final course roster bolstered students from across disciplines and cultures that each brought in different perspectives. It should also be noted that since AAL 165 is a general education course I was able to pull students from these various disciplines and justify its' requirements for students meeting resistance through advisement.

As we consider the sensitive nature of an AAL course, we need to also consider how these courses are being advertised to students and more importantly, especially those students of color. Why should such academic hustling be done for any course or class whose substance and

\footnotetext{
${ }^{16}$ Vince Cunningham, after reviewing the course syllabus, also wanted to take the course or sit in a class. I told him he was more than welcome to come and visit. Although I also encouraged any faculty and staff who had taken an interest in my course to attend, I wanted this remain a student-based course. However, this begs the question of why faculty (more importantly faculty of color) do not have this type of professional development space to address these concerns at Illinois State University?
} 
liveliness depends upon a traditionally marginalized or underrepresented population? I posit that more often than not, some students of color are persuaded not to take these types of courses in pursuit of "easier" or more "beneficial" classes. For example, I had one student recount her registration experience and how the counselor tried to dissuade her from taking the course for something else that may interest her. Coincidently this student was one of my best students. However, this student had to fight for her choice to take this course. Why is this the case? One can consider that either counselors believe there is no merit in these courses, maybe perceived as academically challenging to students in dire need of boosting their grade point average or both. You can also make the argument that counselors are not fully informed on the content of these classes and may not serve their value system of academically rigorous considering the categorization of placement in general education. There also needs to be awareness that instead of appearing cultural selective (e.g. "you might like this class because of your culture") there is a hesitation to promote such multicultural classes. We need to really engage with the politics of curriculum placement and class selection at the undergraduate and graduate advisory level. There are consequences from the guidance away from these courses because the lack of attendance affects the future availability of these courses. If students of color are being dissuaded from such course, one can only surmise what White students encounter in their advisory periods for course selections. Faculty and administration need to consider the university's support in recruiting students for these types of courses so that not only do they "make," but also make a difference in influencing the cultural appreciation of Black literature and culture (or culture in general) on campus.

Additionally, I would like to see more options available to students. From my experience as an undergraduate and instructor of AAL, English 165 is only offered once a year (at best) and 
limited in its student capacity. If we feel that diversity is an imperative element within the university, we should offer more of these classes. ${ }^{17}$ During the mid-point of the semester, one of the students asked if I will be teaching this course again. I told her that I did not know because it was my internship and it is only offered in one section once a year, and there must be a rotation of instructors and other graduate students to have an opportunity to teach this course. She became visibly upset and asked who did she need to talk to have more courses like this and not only did she want more courses like this, but she wanted me to teach them. I found this moment empowering since the student was appreciative of the cultural space that I carved out in this course. This moment was also fulfilling experience because I felt was appreciated and reified my path to teaching is correct. This compliment was also bittersweet. The student, also a senior, felt that she never had this type of engagement until this class in her last semester and it makes me wonder how many of our students feel left out or have no space to speak in classes.

\section{Scenario 2: Black (Angry) Lit}

Before teaching my internship course, I wondered if I would encounter any intellectual resistance. Would there be resistance to the content of Baldwin and Coates as they navigate their racial imprisonment through their self-reflexive experience of the Black-male body? I also wondered if there would be resistance to Harris-Perry and Shange's reaffirmation and recapturing of the Black woman's body that would cause dissonance to the White women in the class. Interestingly enough, none of these things occurred. In fact, the White women in the course connected to Shange's cry for self-love and acceptance in for colored girls. Sean, one of the White males in this course, even began to question how his Black male friend struggles with

\footnotetext{
${ }^{17}$ I am cognizant that courses are also dependent on fiscal flexibility, but that also find this allocation and course availability process quite "interesting."
} 
double consciousness based on place and space similarly to Coates' examination of the Black body seeking to cultural assimilate and still remain demarcated as a space for destruction. One thing to note is that the White students were not openly resistant of the course material. I never questioned why the White students did not resist. I wonder if they felt my agency was justifying my mastery of the subject and thus essentializing the Black experience through my Black body or was it that I did a good ass job teaching the material and they were eager to learn. You can also assume that students may have been struggling with a feign comfort in my presence and that I would automatically marginalize them because of their cultural identity. Out of all the thoughts I had concerning these students it was comforting in the aspects that most of the White students in the course were fully engaged in the class content and discussion. However, one openly defiant Black student would eventually drop the course before the first assignment was due.

I found Jameer's (Black male, name made-up to protect his rights) openly inquisitive stance interesting. Why I posit this as interesting is that within the first week of the course, presented himself as openly assertive. This hostility did not derive from anything his peers said, but from me and the content of the course. On the first day of the class, after introducing myself and course material, I invited inquisitions regarding the content, syllabus or whatever the students wanted to address. It was then the student rose his hand and asked this question, "Why is African American literature so angry?" I was taken aback by the question and other students in the class appeared visually disheveled by their facial expressions as well. These students were either shocked by the statement, considered this inquisition on the first day of class disrespectful or both. I can say that I did not expect such a question early on without reading and comprehending course material. It was if the student generalized a body of literature based on subjective experience with the genre or even perceived the texts for the class as instantly 
radicalizing anger. I politely answered that AAL is not angry, but is speaking back against what has resisted the African-American agency in society, history, and literature. If you detect hostility in the writing, it is only an urgency to reclaim agency and/or is reflective of a cathartic process for the author. As the Black experience is not monolithic so is the same for the content of AAL.

After my response, Jameer went silent and I continued to answer additional questions regarding the syllabus and course content. A few questions later, Jameer asked another inquisitive question with a scowl on his face, "Why does African-American literature always try to change you?" It became evident to me that this was not an openly hostile student, but one struggling with his own reception of this material. It appeared he was more so concerned that the material in this course would adjust his current consciousness. I simply responded that all education should be transformative and if you are not transformed by your encounter with a course then what value does it have? Jameer appeared thrown off by the response. I have learned in my encounters with students to not respond to hostility with hostility, but by grace and enthusiasm. This response seem to temper Jameer for the time being... until next class.

On the second day of class, I had students watch writer Chimamanda Ngozi Adichie's “Danger of a Single Story," a TED talk analyzing how monolithic narratives shape people's encounters and ideas regarding other cultures through her personal narrative. After viewing, we began discussion on how people view the Black experience in conjunction with Adichie's narrative. We also discussed how this type of assumption can endanger perceptions of other cultures based on a single encounter or experience. After the class conversation, from which Jameer was noticeably silent, I asked if there were any more questions about the class or the course at this point. Jameer raised his hand and said (with a scowl on his face), "I have one 
question. What are you trying to do in this course?" I was confused so I asked Jameer to elaborate. Jameer, hesitant at first responded, "Well, what is that you are trying to do with this class and course content?" One of the students, Makayla (Black woman), behind him was noticeably annoyed by his question. ${ }^{18}$ I too paused in an effort to collect myself and figure out how I was going to approach this subject. I eventually told Jameer that my goal was to provide content to critically engage African-American authors who were writing for agency and if you are transformed by the content that is great, but that it is ultimately up to you how you receive and process that information. My overall concern is that students show some in-depth thought in assignments or discussions about these topics and ideas academically and respectfully. Jameer, appearing annoyed by my response, prompted me to inquire if he needed more clarification to which he responded "no." This follow-up question was not to be petty or to cause him to be contrite, but I wanted to make sure I fully answered the question with respect to his understanding. Before the first assignment was due, Jameer dropped the class and there were no more assertive attempts at resistance for the remainder of course. I appreciated Jameer's attempt to ask these questions because it also gave students struggling with my politics an opportunity to understand what I was doing with this class. In short, he assisted in affirming my claim for the importance of the course with his resistance.

After the student dropped the class, I took this intellectual disengagement personally. As excited as I was to have a Black male in my class, I never considered that he would also be the strongest to resist the content. I began to seek an understanding from fellow Black faculty and colleagues to process this confusion. I was prepared to be confronted by White students who may feel threatened by the course content because it reduces the Whiteness that may be pervasive

\footnotetext{
${ }^{18}$ Not simply because it was the end of class, but she shared with me after class that she felt he was being openly disrespectful.
} 
through most of their other collegiate experiences. I never expected to be pedagogically challenged and accused of intentional transformation by a student of color, let alone a Black student. The student seemed to be preoccupied with the content that was purposely supposed to "change him." According to pedagogical scholar Maryemma Graham in the introduction to Teaching African American Literature: Theory and Practice, "To question the legitimacy of African[-]American literature is to continue to render African[-]American people invisible in literature as well as in life" (Graham 8). Maybe this transformative content was deemed too radical and thus discovered that his best option was to drop? Maybe my Black body did not align with his perceived idea of Blackness or educator? Or maybe Jameer wanted to render this experience invisible or silent and, by dropping the class, was able to do so.

I've deemed that the Jameer may have suffered from what is referred to as false consciousness and also that he, on the scale of racial identity, may be static at the preencounter phrase. False consciousness can be defined as the "phenomenon in which oppressed people internalize and identify with attitudes and ideology of the controlling class" (Delgado and Stefanic 162). It is this process in which the oppressed or marginalized adopt the consciousness of their oppressor. To be considerate, let's assume here that the term oppressed is defined by those who are historically conscientious or remain ignorant of said oppression. Whereas the course had no overt resistance by White students (men or women) who were in the course, the most resistance was raised by a Black student unwilling to be "transformed" by the content of the class. It was as if this course was supposed to institute a hatred for Whiteness which would in turn threaten the status quo of his familiar world. Jameer, possibly unknowingly to himself, was becoming the gatekeeper for maintaining Whiteness uninterrupted and reifying his own cultural hegemony within this space (before dropping). 
In regards to his racial identity stage, Jameer would be best described as being in William Cross' preencounter stage of Black racial identity. According to Beverly Tatum in "Talking About Race, Learning About Racism: The Application of Racial Identity Development Theory in the Classroom,"

In the first stage of Preencounter, the African American has absorbed many of the beliefs and values of the dominant White culture, including the notion that 'white is right' and 'Black is wrong.' Though the internalization of negative Black stereotypes may be outside of his or her conscious awareness, the individual seeks to assimilate and be accepted by Whites...This de-emphasis on one's racial-group membership may allow the individual to think that race has not been or will not be a relevant factor in one's own achievement, and may contribute to the belief in a U.S. meritocracy that is often a part of Preencounter worldview. (277)

What I, and the other students in the course, encountered was Jameer's reluctance to move outside his preencounter stage even at the cost of learning more about African-American literature and culture. By deeming this class consciously manipulative to his ideal world he chose to resist against it. I found this interesting since (based on the class roster) Jameer was an English major and I would have assumed that having an Black English instructor would serve as a sigh of relief or mentor experience because of the lack of Black faculty in English. Yet, it became more of a "what are you doing here and why are you trying educate people" accusatory experience. I know that I sought out Black professors as an undergraduate and graduate because they may have the lived experience of my journey, but Jameer and I did not have that shared lived experience. I recognize that the instructor and student may not have the same lived experience, but in this case I was more-so a threat to his experience. This is why we should engage in the 
complexity of the Black experience in classroom because it reflects a complex pattern of agency and experiences. Referring back to idea of conflicting authenticity, I made an assumption that our skin color bonded our experience, but it did not. Jameer and I, although similar in melanin, had different cultural politics. We can conclude that not all Black people want to be "woke" to cultural indifferences or issues.

Later on in the course this particular incident did raise a discussion on what is deemed as the Black wake-up call. A Black wake-up call can be considered the experience where someone of the African diaspora encounters the limitation, insinuation, and experience of their skin color or racial difference. We were guided into this conversation by China, a Black-woman student who was frustrated by Jameer's (now a former student at this point of course) hostile inquisition. So much so that she decided to share with the class that she saw Jameer at McDonald's with his "White" girlfriend. Additionally, with conversations about the Black wake-up call, this also prompted my first experience with policing the classroom. Although I understood the student's angst with the situation, I found it unfair to hurl accusations at a student not present, even when they did not agree with the content of the class. Yet, is that not what superheroes do at times? Save the thanklessness and thoughtlessness.

Scenario 3: The Checkout (Engaging in non-White literature with White students)

In addition to my AAL internship, I was also teaching a general education interdisciplinary course entitled "IDS 121: Graphic Narratives as Sites of Social Justice and Responsibility.” Themes in this space focused on graphic narratives as sites of social commentary on historical and political trends. On this particular day we were focusing on the image of Black-male superheroes in mainstream graphic narratives. We watched the 
documentary White Scripts and Black Supermen by Dr. Jonathan Gray. This documentary critiqued popular Black male superheroes such as Black Panther, Luke Cage, Falcon, etc. Ironically I was also showing this film in my AAL course. Of course the results from viewing the documentary differed drastically based on the class audience.

In the AAL course, students were engaged with the documentary; some taking copious notes and nodding their head in agreement to the commentary by scholars and artists regarding the role of Black-male identity in superheroes roles and graphic narratives. There were some students who were not taking notes, but were content watching the film for enjoyment. Since the documentary had no logistical benefit to the course grading, I did not take offense because it still provided an avenue to further investigate how Black identity is rewritten and recaptured in the avenue of graphic narratives. This documentary led to some interesting discussion regarding topics that appeared in the class discussions about the Black graphic narrative text Icon: A Hero's Welcome that immediately followed since students never considered graphic narratives as a site of power, identity, and resistance. I have found that providing students with an intellectual foundation to approach texts allows them more opportunities to engage with the information in front of them. This schematic structuring is important when dealing with concurrent texts whose themes influence the understanding of the next book in the course.

However, while viewing this documentary in my IDS 121 course, I noticed that the majority of the students not paying attention. They were so disinterested that some could be seen doodling, texting, passing notes, or doing other work. Demographically, this class was $98 \%$ white and the $2 \%$ were bi-racial (one Korean-German woman and one Black and White male) ${ }^{19}$. Unfortunately, neither of the bi-racial students were present this day. I bring this attendance up

\footnotetext{
${ }^{19}$ These students self-identified during discussion post conversations about race and identity and were often unafraid to write about their experience.
} 
because the bi-racial male became heavily engaged in the course content and would have loved this documentary based on after-class conversations regarding race and politics. As a Black professor whose research is based on the content of the documentary, I felt highly insulted. Although there was a displeasure in witnessing this disinterest, I was not surprised. I have noticed when it comes to discussing notions of race, gender, sexuality or class in a predominately White class all engagement stops.

I believe this disengagement was the result of my physical presence, which reifies the notion of race and also the content that immediately engages the White students into conflicting material. Closson et al contend:

In some instances when teaching controversial nonwhite material that speaks back against racial injustice, White students experience feelings of shame and guilt. These white students then utilize silence, pedagogical questions, devaluation, and open challenges to the professor's integrity. In fact, by the mere presence of Black faculty, in the classroom space the [W]hite students' sense of safety is fractured and causes dissidence to the subject position of power dynamics within the classroom. (Closson, et al 83-84)

From my experience teaching race-based material, some White students react as if this particular section of the course material does not pertain to them. It's as if the privilege of their position automatically negates the acceptance of cultural material that they deem not a part of their academic experience-marginalization in practice. One can also assert that some students just did not care for the course in general, but it is interesting that on this particular subject matter they appear less engaged. 
Recently, in an English 125 (Literary Narrative) course based on Afrofuturism, while reading 47 by Walter Mosley, multiple White students expressed in their discussion posts that they were afraid that they were reading another book about slavery. It was as if they had been already inundated with the subject so many times that this was just another depiction of what they knew from research or other classes. ${ }^{20}$ I actually had one White student confess that at the beginning of the class she considered herself well informed regarding the Black plight after reading articles online regarding the Black Lives Matter movement. Another white student chose to state that the she really learned how slavery was based on just reading 47 alone. This student essentialized the Black slave experience through a fictionalized book about freedom and fantasy. Cleary a problematic read. While I applaud the notion of fiction as a change agent regarding the inhumanity of slavery, I reminded the student that this is only part of the story and that some Black communities as still suffering the effects of what noted Black scholar Dr. Joy DeGruy describes as post-traumatic slave disorder (PTSD). The resistance in this text is fictional, but the real effects of slavery are evident.

This essentializing and marginalization provoked one of the Black students in the English 125 class to publicly address her concerns regarding the language within some of the discussion posts that summarily dismissed the lived experience of traumatic and institutional destruction of Black people caused by slavery. I appreciated that this student felt empowered enough to raise the issue within this class because it also allowed me, as the professor, to support her position and challenge her White peers to understand that this material is not distant culturally for some people in the class, in particular the Black students and myself. After this class discussion, the Black student came up to apologize about causing an outburst, but she felt compelled to address

\footnotetext{
${ }^{20}$ Reluctantly I hold the same view when it comes to movies depicting slavery because it appears that Hollywood cannot get enough of the pre-and-post Jim Crow era for Black folks.
} 
this issue. I told her that she need not apologize and that I encouraged her to say more because far too often students are acted upon in a class setting and not allowed to react to the class material. She appreciated that I offered her a space to express her concerns and supported her in what she felt was an injustice of the space. It is this type of interaction between Black students and professors that reaffirm our purpose as instructors and how our presence alone can be a huge advantage in giving students the opportunity to speak their minds without repercussions or silencing. Sometimes saving the day is having a student's back when individuals feel outnumbered and speaking one's peace/piece...

\section{Scenario 4: Reverse Racism}

The topic of reverse racism came up in AAL during our discussion of Ntozake Shange's for colored girls. Layla (black-woman) decided that this was an opportunity to bring up a concern that was bothering her. She said, "Professor DC, can Black people be racists?" I thought this question would come up in a later discussion on humor as a form of resistance and regaining agency, but I could tell that Layla really wanted this question to be answered. I don't know if this was a test or not, but I decided to use the combination of my subjective experience, research and class texts to discuss this matter. I did not want to discourage this type of inquisition and felt that this was relevant to our conversation of resisting Whiteness and patriarchy, given that some of Shange's language and other course material can be intentionally read as anti-White.

It was also imperative that this conversation take place because I also realized that students usually do not have a venue to address this type of content in other classrooms. One of the more active students, Ciara, Black woman, had often expressed her disappointment with other courses where conversations about race and class were automatically castrated at its inception because 
the White instructor did not want to engage in the conversation. I responded to Ciara, that although we preach liberalism and idealism in classes, some instructors do not wish to address the intersection of race and class in their course because they are either (a) ill-equipped to handle the conversation because they may never had pedagogical training in conflict management or (b) that the instructor is losing their authoritative control of the course due to the controversial nature of the topic and to relinquish control is to relinquish power where the instructor can never feel powerless. I would also like to posit that another reason can be that professors just do not want to address it because they feel like it is not important to the pragmatic and descriptive discourse that they have set for the class pushing these "taboo" topics at hand to the margins of the syllabus and sometimes out the door. Fortunately, I embrace controversy and inquisition in the class. If we embrace difficult questions it allows for the professor and students collaboratively develop answers to issues at hand. This process also allows students to see the professor as someone not all well knowing and now removes the position of academic delegator to academic collaborator. It does take finesse and sensitivity to navigate this space, but it should be something educators should be unafraid of addressing.

Kendall, Black woman, proceeded to say that Black people can be racist because of how they comment on other people's culture. Mackenzie, a bi-racial woman, followed up Kendall's comment with her experience of being disliked in high school because she was accused of being a "White girl" who was taking away the "good Black male students" by Black women students. I asked the class to define racism and most of the class defined or agreed that racism was the extreme dislike of someone from another race. I instructed them to research prejudice. I then posed the following question, "What is the difference between racism and prejudice?" The students stopped to process my question. I then provided the students with a cumulative 
definition of racism (based on the text we read and some sociological and historical examples) that stated racism is prejudice placed into praxis; prejudice is theoretical or the idea that someone is disliked based off of difference, but racism is when you put that prejudice into action to limit someone's economic and educational advancement thus reducing their agency while harnessing ways to enact physical or psychological violence. The students stopped to process these thoughts.

I think we came to the consensus that Black people lack the political and cultural capital to be racists ${ }^{21}$; this is true even if they operate in hegemonic practices very similar to those imposed by the dominant culture. However, Black people can be prejudice based on the definition that we created in class. It was important that we used this class space as time to address the assumption of racism and how it functions systematically and influence societal norms. We used this as an opportunity to also discuss how this knowledge helps counter narrate the claim of reverse racism and how that term in itself is used to relinquish the responsibility of systemic racial practice. This is why it is important to take time to address the students' inquisitions while making it relevant to the content of the course-erasing misconceptions of self-identity seeks to absolve how dominant cultures operate.

\section{As We Proceed (Further Investigations)}

Referring back to Tatum tells us that the role of racialized curriculum should not be seen as the sole weight of the African-American literature or education courses. In fact, we should have a campus-wide based curriculum that deals with how students understand or utilize racialized identity. Tatum argues:

\footnotetext{
${ }^{21}$ Well, at least when pitted against White collectively. Arguably, even racism is situational and contextual since race is a construct as well.
} 
Campus communities with an understanding of racial identity development could become more supportive of special-interest groups, such as the Black Student Union or the Asian Student Alliance, because they would recognize them not as 'separatist' but as important outlets for students of color who may be at the encounter or Immersion stage of racial identity development. Not only could speakers of color be sought out to add diversity to campus programming, but whites who made a commitment to unlearning their own racism could be offered as models to whose White students looking for a new ways to understand their own Whiteness and to students of color looking for allies. (Tatum 291)

Tatum uses scales of racial identity in her "Psychology of Race" courses which prompted her to make the aforementioned cited comment. So, for future investigations, I would like to utilize William Cross' scale of measuring Black racial identity ${ }^{22}$ and Janet Helms White racial development scale within future African-American literature to gauge how the literature makes students react. More importantly, these scales require a metacognitive process to assist student in culturally locating themselves at the beginning of the course and reflect on how course material affected them at the end. I hope the use of scales will also assist me in gauging the psychological and cognitive impact of the course material and if the engagement pedagogical process works.

I would also like to see how the content of my AAL internship is received within a predominately-White classroom. One could assert that the reception of the course material to go remotely uncontested (outside of the one student early on) can be the result of the large Black population in the class, great instruction and pedagogy, fear of not being the dominant culture in the class or all of the above. Again, given that there is rare occasion at a PWI that Black students out number White students in a class can skew the results of my self-reflective narrative on the

${ }^{22}$ It was prefaced in the essay that Cross scale is also good for measuring the identity of other students of color. 
course. In fact, I had to draw on other experiences of other courses where White students became resistant to the course material than my own internship. Perhaps for my next course assignment I will intentionally try to recreate the same topics when White students outnumber students of color in the class to assess the conversational outcomes of the course. However, from my experience, I have found in these scenarios (outside the pure AAL content) that these conversation often end in silence or the students of color carrying the weight of the course discussion because White students may feel inclined to defer to them due to the racial embodiment of the students or through marginalization. However, this is why I chose to enact the engaged pedagogy in my class - to open spaces for conversation that is often difficult to have any give all the students a voice. It also helps to make participation required for the course through a point-based system.

\section{\#TheAcademicClapBack (Conclusion)}

In his reflective essay on teaching experience, "Hey, I'm No Superman: The Teacher as Hero" by Alan Block, he states:

Few consider teachers as anything but technocrats and poorly prepared lackeys. But it might be that teachers could be known as artists and revolutionaries, to be a teacher means to possess beliefs on which to act and to have the courage to act upon those beliefs. To take such a stance today and always enacts a quiet and mostly invisible heroism that seems to go against the very nature of the American psyche. Perhaps though not supermen, teachers might begin to think of themselves as revolutionaries and artists... heroes. (Block 37) 
Block, like Stacy Robinson's quote on superheroes, feels that teachers, by their very presence, are heroes. I would add that Black educators are also Black superheroes and tangible beings inside and outside of the Black community. We can find their superhero feats in the chronicles of history and the present and not have to look to the pages of Marvel or DC Comics. Was it not Ida B. Wells and Ella Baker who wrote about oppression and trained generations to protest and march effectively as Black superwomen? Even our youth now have taken up the iconicity of self-love and affirmation thought the \#BlackLivesMatter movement.

Yet the question still remains, is the Black professor a superhero? I think a more pertinent question to ask is are you educating to empower or enslave? What are the cultural politics of the Black professor? When it comes to Black faculty, often like commercial Black graphic narratives superheroes, we operate at the margins; somewhere in this space of getting students to shed the mythos that Black professors hardly exist at PWIs. We are not multi-melanated university leprechauns that ride on multicultural unicorns in the fields of diversity rhetoric. Our presence brings merit to true inclusion in the class with the ability to leap interdisciplinary boundaries and move beyond race in pursuit of politics. We are tangible beings whose presence provides access and voicing through curriculum and for students. The burden of educational and academic decolonization should not solely fall on the shoulders of the core/elective course that is scarcely offered, but as a collective curriculum-based response to embrace traditionally marginalized voices. Without AAL some students would struggle to access the language to address the things that bother and/or empowered them. I believe this empowerment is what makes the argument of Black instructors as literal pedagogical superheroes true. We, like other instructors that teach White and nonwhite literature, have lived experience and (with respect to the research) can provide the literal space to open minds and decolonize the false consciousness of those who 
suffer from cultural and class hegemonic notions of the White experience (students of color or White). hooks states, "College professors have tremendous freedom in the classroom. Our major difficulty is sharing knowledge from an unbiased and/or decolonized standpoint with students who are so deeply mired in dominator culture that they are not open to learning new ways of thinking and knowing" (Teaching Critical Thinking 27). In turn, this makes the Black faculty seem even more like a superhero when one is able to break down hegemonic barriers and make her/his appearance in the classroom.

So where does that leave me? I believe as a reluctant hero professor who is both blessed and burdened by Blackness at a PWI. I'm not bulletproof, but I often have to utilize thick skin to bounce off "forced- liberal agenda" accusations and cultural denouncements of my character or marginalization of race-based conversations inside and outside of class. A masked smile hiding the hurt and disappointment of politics at the local, national, and course level so that I may do the job that is required of me. I can't fly, but I can carry students to new cognitive direction with a single book. My responses are faster than a speeding bullet and my words evoke thoughts more powerful than a locomotive. My physical and intellectual presence is a counternarration to Black archetypes. My goal is to make more academic and pedagogical superheroes. More importantly, to get students to think critically about the world around them and see themselves as change agents.

Unfortunately, due to budgetary constraints, I do not have a costume. However, I often fluctuate between business-casual (in tie that binds) and casual attire to determine if there was a difference in the way that I was treated as a professor and also inform my students that a fittedcap does not reduce my intelligence or agency but combats the negative perceptions of how Black men dress. The purpose is to disrupt the normative narrative that my clothes don't reflect 
the "styles upon styles upon styles" that my intellect and pedagogical wisdom have that may be reduced by my skin color or attire. Can I save the entire population of Illinois State University with a single class? No. However, if I empower students to save themselves they can do the work of enlightening others. Having the super powers of presence and voice is a pedagogical heroism all in itself. 


\section{CHAPTER III: SURFACE RACE RELATIONS: THE BODY POLITICS OF}

\section{BLACK PANTHER}

I saw him, later for several days, sitting in a bit of shade looking very sick and trying to recover himself: afterwards he arose and went outand the wilderness without a sound took him into his bosom again.

Joseph Conrad, Heart of Darkness

As signs, their power to ignite critical consciousness is diffused when they are commodified. Communities of resistance are replaced by communities of consumption.

bell hooks

Race in contemporary comics proves to be anything but simplistic. If some titles reveal deceptively soothing stereotypes lurking behind their veneers of diversity, then others show complex considerations of identity.

Marc Singer

When Jack Kirby and Stan Lee created the Black Panther character in 1966 the intent was to breathe new life into the graphic narrative industry. This multicultural inclusionary process was not unique since co-creator Jack Kirby was known as being on the cutting edge of incorporating diversity into his amazing artistic work. He was the one "who was drawing most of Marvel's cityscapes, occasionally inserting a [B]lack spectator pointing up at the Fantastic Four's Baxter Building” (Maslon and Kantor 169), especially at a time where people of color rarely appeared in this medium outside of being stereotypical caricatures. However, Black Panther, at times, was a supplemental character in comparison to his White counterparts (Fantastic Four, Captain America, Avengers, Daredevil, etc. $)^{23}$ until receiving his own series with Marvel Comics’ Jungle Action \#5 in 1973. After a brief hiatus, due to low sales, the Black

\footnotetext{
${ }^{23}$ Black Panther would interact with these characters through guest appearances for short issues. This is why I am only focusing on solo titles where Panther is the lead character.
} 
Panther character was reintroduced to the Marvel universe in Marvel Premiere ${ }^{24}$ series issues \#51, 52, and 53 by Ed Hannigan (writer) and Jerry Bingham (artist) in 1979. Nonetheless, in his reappearance, writers Hannigan and Bingham continued a Jungle Action storyline that contained similar themes of race and superheroism signified by historical visual rhetoric. This racialized address only proved that the Black Panther's adventures were limited to repetitive content. In fact, despite Lee and Kirby's valiant effort, Black Panther remained tied to issues of modernity and primitivism in his origin story, through Jungle Action, to the Marvel Premiere written by Hannigan and Bingham. If we consider the well intentions of Kirby, Lee, Hannigan and Bingham, they were simply not enough to surpass the commercialized intent of selling Black Panther. Even at the core of Black Panther's creation, lies the malice of false commodified inclusion.

Despite the large criticism of the mainstream graphic narrative industry for being poor practitioners of diversity, this chapter analyzes ethical representations of Black Panther confronting issues of race and identity in Fantastic Four \#52 and Marvel Premiere \#51-53 featuring the Black Panther. In comparing Black Panther against his White graphic narrative superheroes, who, despite being a reflection of dominant culture, do not deal directly with race, one could argue that their outsider status allows them to be "othered" (not normative, non-super powered standard). What if we complicate that notion of stacking the "otherness" of superheroes with the complexity and historical context of race? White graphic narrative characters, being a part of the dominant culture, do not encounter "othering" in race nor have to address racial issues. However, we battle these issues more overtly in Marvel Premiere \#51-53: Black Panther. This three-part series focusing on Black Panther thrust us into a murder mystery that runs

\footnotetext{
${ }^{24}$ Marvel Premiere series brought new characters into the Marvel continuity and reintroduced characters that no longer had their own titles ( "Marvel Premiere")
} 
parallel with an eventual confrontation against the Ku Klux Klan and a religious zealot. Black Panther faces these particular situations of otherness: Being Black, African (Un-American), and confronting - racism through fictional representation of the Ku Klux Klan ${ }^{25}$ and Soul Strangler (this series supervillain).

The larger questions at hand are what does it mean when graphic narratives ${ }^{26}$ are created by White artists who focus on social-political issues through the bodies of Black superheroes and what happens when we have issues of race or cultural discrimination written by those who the hegemonic system privileges? I hope to address this through a rhetorical analysis of audience and symbolism in these selected Black Panther titles. Additionally, I will critically analyze the shattering of the fictional escapism that derives from graphic narratives by taking out the fantasy of situated action in favor of contemporary social issues of racism. Once initiated, we can deduce that Black Panther becomes nothing more than a commodified character whose Africanist presence/identity offers some problematic depictions of Africa and superficial racial commentary.

The problematic Panther should be considered intentionally complicated when noting that the majority of readers and writers for graphic narratives are White males. And to these White males, as Dwayne McDuffie states in the documentary White Scripts and Black Supermen, “Comics are a White-male fantasy lived out through fictional characters" (Gayles). McDuffie's statement then posits the question, what interests do these writers have in portraying Black characters confronting issues of race if this gaze is based in White fantasy? Is the purpose to be

\footnotetext{
${ }^{3}$ I briefly want to state here that there have been instances where superheroes have addressed issues of social justice, but more so from the perspective of political propaganda (Captain America versus the Nazi) to which graphic narrative distributors wrote and created stories in support of the war efforts of the United States in World War I, World War II, and the Cold War especially. There is also an instance of Superman taking on the Ku Klux Klan ("Superman vs Ronald Reagan and the Ku Klux Klan" from War, Politics, and Superheroes by Mark DiPaolo (2011), but here I am focusing specifically on when the comic book industry started to focus on national social justice issues.
} 
culturally progressive so that the content is easily digestible by a majority White audience? If so, does this make an abrasive assumption that Black writers and authors' content maybe fueled by White male-bashing? Can this cultural-literary cosplay act be a subliminal cathartic justification for battling racism or a narrative of battling one's own subversive privilege?

Stuart Hall in 'Notes on Deconstructing 'the Popular' argues, “The cultural industries do have the power constantly to rework and reshape what they represent; and, by repetition and selection, to impose and implant such definitions of ourselves as fit more easily the descriptions of the dominant or preferred culture. That is what the concentration of cultural power - the means of culture-making in the hands of the few - actually means" (Hall 447). Here, Hall calls attention to the often-ignored cultural power that comes with cultural production as a constitutive process that defines our identities as social beings. In agreement with Hall, we need to think about how cultural productions shift and transform to develop theories/concepts and identity models that shape the cultural imagination of any society. We need to consider that when artists and writers have the opportunity to rewrite or implement new ideas or cultural perceptions they often replicate the negative normative depictions of the non-dominant cultures. But the crucial point here is not just the simplistic replication of old stereotypes of Black Panther in the new series, it is how the old racial models work in new contexts. Francesco Casetti in his essay “Adaptions and Mis-adaptions: Film, Literature, and Social Discourses” argues,

We are no longer confronted with a re-reading or a re-writing: rather, what we are dealing with is the reappearance, in another discursive field, of an element (a plot, a theme, a character, etc.) that has previously appeared elsewhere. A reappearance is a new discursive event that locates itself in a certain time and space in society, one that, at the same time, carries within itself the memory of an earlier discursive event...There is 
something else going on, something deeper: the fact that the source text and its derivative occupy two entirely different places in the world scene and in history. Therefore, when we talk about adaptations, transformations, remakes, and so on, we should not simply focus on the structure of those texts - their form and content- but on the dialogue between the text and its context (82-83).

What Casetti claims is not that old models being reworked, but the discourses embedded in the newer version of the texts that proves problematic. Given the opportunity to engage in new material the reappearance of old tropes and motifs buried in previous texts still find their way into current versions. One way this happens is through the necessary use of these images to sell and benefit the producer. For instance, Black Panther's presence in his origin narrative and also return in the Marvel Premiere series is the by-product of what, in critical race theory, is called differential racialization. Differential racialization is best defined as when the "dominant society racializes different minority groups at different times, in response to shifting needs such as the labor market" (Delgado and Stefanic 9). Black Panther is the by-product of the Civil Rights and Black Power movement increasing presence, but also a commodified conduit to procure more readers of color leaving the purpose of this character shallow and misleading. It is also this (mis)use of Black Panther that haunts his return in the Marvel Premiere series by the poltergeist of modernity's past. The point here is that old practices of modernity find themselves transplanted from European modernism into American texts. In this chapter, I argue that due to differential racialization, earlier depictions of Black Panther are fraught authentic representation of Blackness and often present Black Panther in ambivalent circumstances of modernity, servitude, and superficial racial address. By analyzing the different racialization presence in 
Black Panther we can gaze into this subject as a complex site of identity and power to be read through the multiple contexts as both hero and subversive villain.

\section{Commodified Colonized Intellect from the Jump}

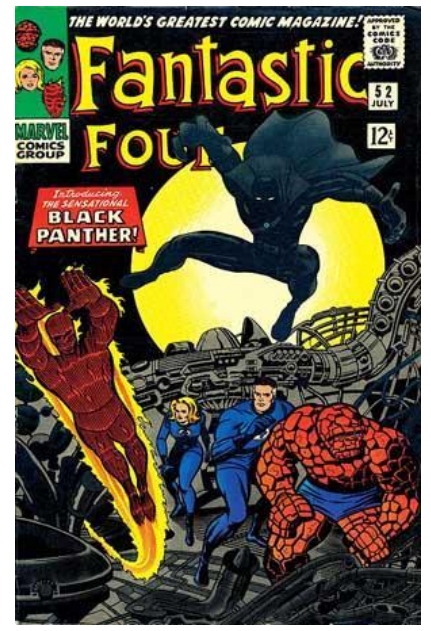

Fig 3.1. Black Panther arrives on the scene in Fantastic Four \#52.

Black Panther — the first Black graphic narrative superhero-when unmasked, is known as T'Challa, king of an isolated fictional African nation known as Wakanda. In an interview with the Huffington Post, Stan Lee lets us know why he and Jack Kirby created the character:

At that point I felt we really needed a [B]lack superhero...And I wanted to get away from a common perception. So what I did, I made him almost like [Fantastic Four's] Reed Richards. He's a brilliant scientist and he lives in an area that, under the ground, is very modern and scientific and nobody suspects it because on the surface it's just thatched huts with ordinary 'natives.' And he's not letting the world know what's really going on or how brilliant they really are. (quoted in Ostroff, "Stan Lee On Superhero Diversity: 'A Lot Of People Are A Little Bit Bigoted"').

Neal Kirby (son of Jack Kirby) recalls his father's influence in the creation of Black Panther: "I really think my father created and introduced the Black Panther because it was the right thing to do at the time. It broke all the stereotypes - a [B]lack super hero with a scientific brain. It's no 
secret that my father was very socially liberal, and I think he saw this as his personal way of making a statement and 'joining' the civil rights movement” (quoted in Beard, "Jack Kirby Week: The Black Panther'). And just like that, Black Panther made his arrival into the Marvel universe through a guest appearance in Fantastic Four \#52 (1966).

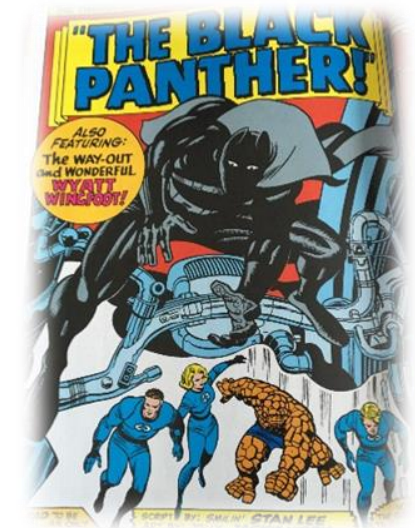

Fig. 3.2. Black Panther is seen looming over the Fantastic Four in Fantastic Four \#52.

Before Black Panther becomes the ally for Fantastic Four he is viewed as a deceptive foe facing the Fantastic Four (Fig. 3.2). Although Black Panther is king of the fictionalized noncolonized and technologically-advanced nation of Wakanda, he is relegated to foe and then sidekicked in his first appearance with the Fantastic Four superhero group. BP becomes a supplemental figure to the background and perception of this fictional African nation as his presence is reflective of previous Black characters before him — seen and not heard or mere graphic narrative fodder. It is this type of Western exoticism with Africa that is the subject of criticism by Chinua Achebe regarding Polish-born British author Joseph Conrad's enthnonarrative of Africa in his essay, "In Image of Africa: Racism in Conrad's Heart of Darkness." Let's consider Achebe's comments about the perception of Africa in Conrad's text. He claims:

Quite simply it is the desire — one might indeed say the need — in Western psychology to set Africa up as a foil to Europe, as a place of negations at once remote and vaguely 
familiar, in comparison with which Europe's own state of spiritual grace will be manifest ...Heart of Darkness projects the image of Africa as 'the other world,' the antithesis of Europe and therefore of civilization, a place where man's vaunted intelligence and refinement are finally mocked by triumphant bestiality. (3)

Achebe's main criticism is the displacement of the African in their own homeland and relegated as the other. Cultural voyeurism and misinformation has thus replaced the African in their own ability to speak. Even in Lee and Kirby's noble endeavor to create characters reflective of everyone in culture, they still manage to emulate the same benevolent paternalistic practice as Conrad in their depiction of Black Panther in Fantastic Four \#52and \#53. Black Panther is a product of American creation, the colonial tropes of modernity and primitivism that manifest themselves in Conrad's Heart of Darkness permeate through the context of Black Panther's first appearance, his fictionalized kingdom and how his body is being read as fictional third-world superhero in the eyes of white writers and global audiences. It is this visual narrative, metafictional displacement of Africa, and the fraught characterization of Black Panther that lends itself in fully examining the Marvel Premiere series. The point here is to show that although his creators claim a progressive 'liberal' agenda as Kirby Jr. tells us, this character consistently disappoints as the first Black superhero through silencing. This silencing happens to Black Panther in four ways: dialogue, embodiment, location, and ideology.

The first is through a dialogue encounter between Black Panther and the character, The Thing. The Thing decides to interrupt Black Panther's narrative of his origin by insinuating that he's heard all of this before and compares the on-going narrative to Tarzan movies (Hudlin). This reduction of metanarrative agency is problematic. Lee and Kirby (the creators of Fantastic Four) could be using this as a satirical reading to signify on redundant narratives situated in 
Africa. So Africa is the place always already known for which outsiders may never learn anything new. In a moment where Lee and Kirby could change the narrative they contribute to Black Panther's silence at the expense of humor. Yet, the humor here also contributes to the violence of silence. This silence is a form of violence because it is an act that reduces the fictional autonomy of Black Panther through a microinsult. Even in a fictional world, "our" hero is overtly told his beginnings do not matter. This rhetoric harkens on the history of racialized silence.

The second silence comes on the cultural embodiment of the character on the part of Lee and Kirby. Part of what is at stake in my analysis is the cultural-literary cosplay committed by Lee and Kirby, i.e., what this Black-body embodiment means for non-White readers and also the affect that it has on the psyche of the voyeuristic white cultural commodifier who uses the Black body as a sight of action. This concern is addressed by writer and theorist Toni Morrison in Playing in the Dark: Whiteness and the Literary Imagination. Here Morrison alludes to not only the Black body being a site of play, but also a surface upon which deceptive language is being deployed against. So not only is the Black body a surface on which White creators write, it is made to be read by White readers as well. So it is doubly appropriated to yield multiple meanings for the White audience. Morrison states, "The ability of [white] writers to imagine what is not the self, to familiarize the strange and mystify the familiar, is the test of their power. The languages they use and the social and historical context in which these languages signify are indirect and direct revelations of that power and its limitations" (15). So not only is the Black body being used, but the language is also manipulated in the process, which Morrison frames as "the self-evident ways that Americans choose to talk about themselves through and within a sometimes allegorical, sometimes metaphorical, but always choked representation of an 
Africanist presence" (17). In short, White Americans use Black bodies as costumes while limiting the Africanist presence. This is where issues of authorship become evident in graphic narratives, because of who is writing and voicing these bodies as simply instruments of play, which limits the effect of cultural dialogue around race. The act Africanism serves two purposes here. The first is Africanism is a way to limit agency of African people and also police power and retaliation for cultural irresponsibility. Secondly, to quote Morrison, "American Africanism makes it possible to say and not say, to inscribe and erase, to escape and engage, to act out and act on, to historicize, and render timeless. It provides a way of contemplating chaos and civilization, desire and fear, and a mechanism for testing the problems and blessings of freedom" (Morrison 7). Morrison is proclaiming that this act of writing authorizes racialized use of culture without fear of retaliation. Essentially, exploring Black bodies in narratives is an act possibly conveyed through good intentions and commodification, but also can be abandoned without respect and recourse.

Thirdly, Wakanda's location has been problematic because it resides in no specific place. Even within the Marvel universe the cartological inconsistencies makes this difficult to find. Is it on the West coast of Africa near the Atlantic as reflected in the cinematic universe and or in variant locations as it has been distinguished within the Marvel graphic narrative? Also others have argued that by displacing the first Black superhero in Africa and not in America, there was also a disenfranchisement with the character (White Scripts and Black Supermen; Narcisse, "The Politics of Marvel's Black Panther"). I contend this placement happens for two reasons. The first reason is that maybe Lee and Kirby were paying homage to the origin of the African American by placing a Black hero in the "motherland" as some sort of diasporic shout out to a lost history culture; a pan-Africanist dream to overshadow the nightmare of the Trans-Atlantic 
Slave trade. The second reason is the cultural weight that comes with placing the first Black superhero in America. It can be argued that by placing Black Panther in Africa allows Lee and Kirby to not confront the reality of American culture during the Civil Rights and pre-Black Power movement for people of African descent. This textual act of distancing puts the space between to the discrimination faced by people of color and others and places the focus on fictionalized nation in Africa therefore alleviating the creators of addressing hardcore historical issues of racial exclusion.

The last act of silencing transpire within Black Panther's psychological state. Black Panther is considered what Frantz Fanon in The Wretched of the Earth (1961) calls a colonized intellect. The colonized intellect is defined as one who is educated in the colonial ways, but struggles in their cultural allegiance. This individual also becomes a threat to the colonial power since s/he is the byproducts of colonialism (being educated and trained in the colonial ways), but chooses to serve their native nation. Fanon states, "When the black wo/man, who has never felt as much a 'Negro' as he has under white domination, decides to prove his culture and act as a cultivated person, he realizes that history imposes on him/her a terrain already mapped out, that history sets him along a very precise path and the s/he is expected to exist in of a "negro" culture" (150). Fanon challenges us to think of colonized intellects as natives who have been educated in the ways of the colonizer. This education causes one to have conflicting ideologies in challenging the system of indoctrination. What derives from this education is also a hybridity of cultures where one can also learn how to change the system, but that does not take place with Black Panther. What makes Black Panther such an interesting read is that T'Challa has been educated in Western universities (later alluded to in other works) and also finds himself conflicted between serving his kingdom and also protecting the West. Wakanda is supposedly a 
fictionalized non-colonial African state, but its superhero is a colonized intellect. Despite the fictional nation is free from colonial rule, the subversive Western education of Black Panther/T'Challa is rooted in colonization. This claim makes sense because of Black Panther's internal conflict with servicing the needs of his native kingdom of Wakanda and his conflicting allegiance to Western culture by his educational background, which subconsciously influence his decision to work with the Westerners (Fantastic Four). We can also point to the cognitive dissonance of the White writers writing Black Panther as another level to the colonized intellect. The dissonance of providing a Black superhero who attempts racial empowerment, but not at the stake of disrupting the entire status quo of White-male fantasy.

Although Black Panther is introduced as the first Black superhero, he is only known as this after we receive him as an enemy of the Fantastic Four, in a fictionalized nation. Kirby and Lee embody Black Panther to live out the oriental fantasy of an African kingdom in an uncolonized civilization as atmosphere instead of using this to empower the Black superhero through his presence. Again, I point to my idea of cultural literary cosplay that weighs heavily in this text. It is this limitation that Black Panther is subjected to in his written narrative in the origin story. An image of Africa that burdens him in the Marvel Premiere series.

\section{Same Ol’ Song: Marvel Premiere featuring Black Panther}

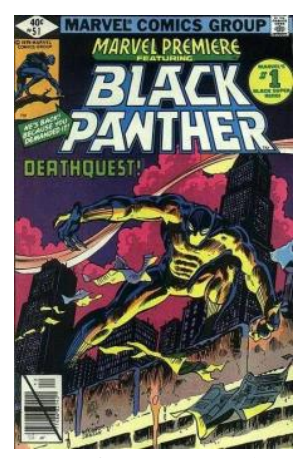

Fig. 3.3. Cover art for Marvel Premiere \#51. ${ }^{27}$

\footnotetext{
${ }^{26}$ Cover art images for the graphic narratives originate from the website, Comic Vine (2014).
} 
The Marvel Premiere featuring Black Panther issues \# 51-53, written by Ed Hannigan and drawn by Jerry Bingham (Marvel Comics, 1979-80), conflate issues of interracial relationships, religious zealots, and racism in a murder-mystery framework. In Issue \#51 (see fig. 3.3), "The Killing of Windeagle," Black Panther has returned to the United States for reasons unknown and is attacked at his Wakandan consulate by a supervillain named Windeagle, who is Latino. The issue here is minority versus minority. In Black Panther's return he faces a marginalized person of color as a super-villain. A steady trope of minority versus minority in graphic narrative texts. This battle is a continuation of Black Panther and Windeagle's encounter in the Jungle Action (Issue \#24) series. Windeagle refers to Black Panther as the "devil" multiple times, but is quickly defeated after engaging in hand-to-hand combat with Black Panther and captured (see fig. 3.4). While addressing responsibilities within the consulate, Black Panther has a brief meeting with Monica Lynne, a Black female affiliate from the past, and her associate Kevin Trueblood (a White male news reporter). Trueblood's purpose in these texts appears to be a voyeur of Black Panther's actions and nothing more.

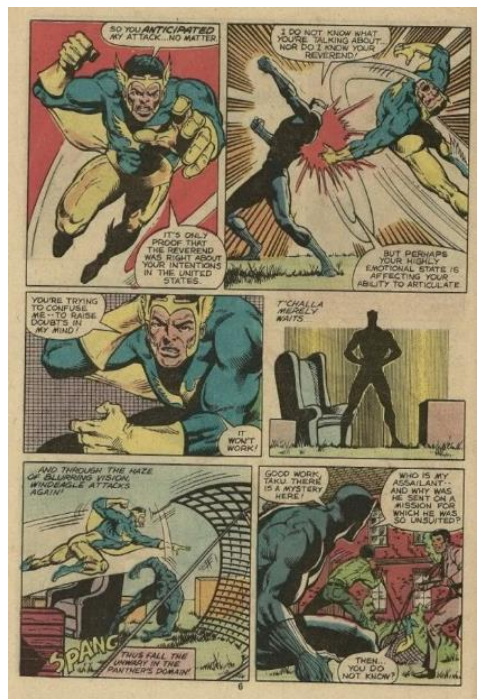

Fig. 3.4. Black Panther battles Windeagle in Marvel Premiere \#51. ${ }^{28}$

${ }^{28}$ Taking from the website Scan Daily (2015) 
This conversation takes the reader through a flashback that Black Panther cannot recall. ${ }^{29}$ For the rest of issue we continue through a series of flashbacks from Jungle Action issues \#20-21 where Black Panther confronts the "Dragon Circle" disguised as the Ku Klux Klan trying to incite riots and gain power. After the flashback ends, Windeagle confronts Black Panther again only to be defeated once more and then assassinated by a mysterious sharpshooter whom Black Panther cannot locate after the said shot $(27,30)$. Even in his return to the Marvel continuity, Black Panther's narrative heavily relies on previous plots instead of moving forward and exploring new territory. Although one can argue that this reductive narration method is problematic, the purpose is to foreshadow Black Panther's current mental condition. However, this narrative choice is also interesting since graphic narratives usually use a content block to direct the reader to referenced material by footnote and do not take up most of an issue to relay previous content. There is an obvious ploy to use this issue to catch up on Black Panther and not bring much more to the narrative.

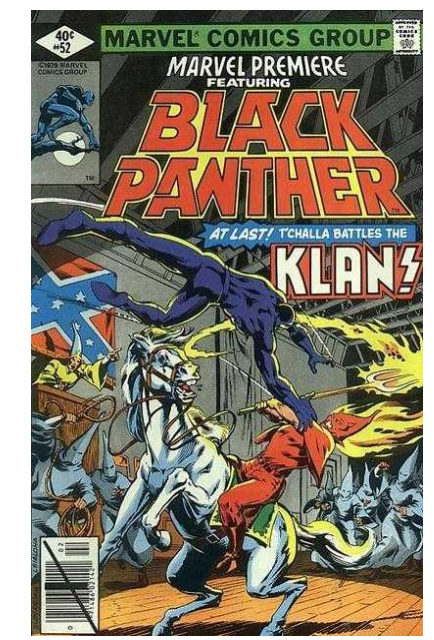

Fig. 3.5. Cover art for Marvel Premiere \#52. ${ }^{30}$

\footnotetext{
${ }^{28}$ There is a lot of intertextual referencing to Jungle Action \#19 where this story takes place.

${ }^{30}$ Cover art taken from Comic Vine (2014)
} 
The next issue provides context to the problematic nature of Black Panther's series. The visual cue from the cover art of Issue \#52, "A Journey to the Past," (see fig. 3.5) insinuates that Black Panther, first Black superhero, is positioned to battle the "Klan." This reference is the Klu Klux Klan, a notorious white-supremacist group, being reworked into the Marvel Universe. This racial conflict is interesting because of the "At Last! T'Challa Battles the Klan" rhetoric on the cover for two reasons. First, we can assume the writers are trying to excite readers and reinforce this cathartic notion that a Black superhero finally "laying hands" on a hate group that often eludes non-fictional justice. Secondly, by this time in the Marvel universe, we have AfricanAmerican superheroes such as Luke Cage and Falcon, yet it takes a global African superhero to do what local superheroes lack the ability to perform. Yet, upon further investigation we learn this location is not the case. Issue \#52, "A Journey to the Past," continues the investigation of Windeagle's death from the previous issue.

In the storyline of Issue \#52, Black Panther and his associates are involved in a car chase which results in an informant being assassinated by a mysterious sniper (once again) who leaves behind a clue which implicates the Ku Klux Klan as the perpetrators of the murder. Black Panther then proceeds to infiltrate a Klan meeting where one of the members insinuates that there is a pact between the Klan and Dragon Circle which has been violated because of the Reverend's (leader of the Dragon Circle) smear tactics and framing the Klan for crimes it did not commit. It is at this point the villain, known as the "Soul Strangler," cast in a red-hooded outfit similar to the Klan, on horseback and armed with a noose and pitchfork covered in flames as weapons, disrupts the Klan meeting. Soul Strangler, then, states, "Hear me, men of invisible empire- heed the words of your master! I have come in your hour of need to lead you into sacred battle" (23). When one of the Klan members doubts this appearance, Soul Strangler 
quickly responds "Hah, mortal fools! I am no costumed pretender-I am the embodiment of your living past! You have chosen the path of hate - it is only firing that I lead you on that path!” (26). This phrase "embodiment" articulated by Soul Strangler demarcates the beginning of this Black Panther series as a superficial text. Continuing the narrative, Soul Strangler flings his pitchfork at a hidden Black Panther and a battle ensues between Black Panther and Soul Strangler. During the confrontation, Soul Stranger disappears and leaves Black Panther to fight Klan members. With all the hype articulated by the hyperbolic subtext of the cover art, there is not a true "battle" with a Klan. It's a brief scuffle left devoid of any racial redemption. This disappointment does not cohere with the next superficial racial occurrence in these texts. After quickly defeating the Klan, Black Panther chases after the Soul Strangler, but does not catch him. Black Panther decides to go back to where this all starts-Georgia. ${ }^{31}$

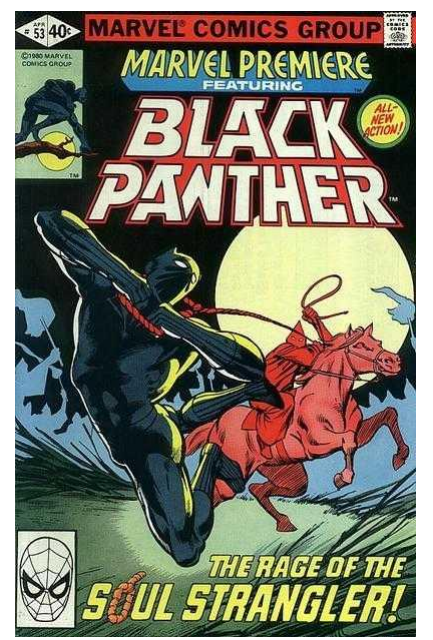

Fig. 3.6. Cover art for Marvel Premiere $\# 53{ }^{32}$

Before we address the final issue, we need to critique how the overt symbolism of the cover art will contradict the content in Issue \#53 (see fig. 3.6). From an initial gaze, one would see that Black Panther (the hero) is endangered by Soul Strangler (villain). Moving beyond the veil of a surface reading, we see an explicit historical reference for lynching. This disturbing

${ }^{30}$ Referring back to Jungle Action \#19-24(Marvel Comics, 1973)

32 Cover art taken from Comic Vine (2014) 
depiction carries the reminder of slavery and Jim Crowesque retaliation of hatred, law, and death felt by the necks of Black bodies. Heroes win, and one hopes that by the redemptive qualities of graphic narratives and the premise that the hero overcomes, maybe, just maybe, Black Panther is finally able to achieve what countless other Black victims of racial violence had not—escape the noose. This idea is a large burden to place on a fictional narrative, but the cover art creates this expectation. However, the narrative that follows, again, does the opposite.

In the final issue of the three part series Issue \#53, "The Ending, in Anger!," Black Panther and his affiliates return to Georgia searching for answers to the sniping murders and track down the mysterious Soul Strangler. After arriving on the farm of Monica Lynne's parents, Black Panther has a dizzy spell and recalls being kidnapped and brainwashed by the Dragon Circle during his battle back in Jungle Action \#20 (Marvel Comics, 1976). In a separate panel we are introduced to "mysterious individuals" who are at a country club discussing the series of events that have taken place between the Black Panther, Ku Klux Klan and Dragon Circle. It is insinuated that the White males are members of the Klan and are plotting to kill the leader of the Dragon Circle, Reverend Blackburn, since he is in the way of "progress." ${ }^{33}$ The next scene is located in a swamp during a meeting of the Dragon Circle and Reverend Blackburn. Blackburn is preaching about killing all the members of the Klan and Black Panther. In a plot twist, one of the members speaks and reveals himself to be Monica Lynne's father (who only goes by Lynne). Lynne speaks up regarding the Dragon Clan being nonviolent and relinquishes involvement in this war. During an attempt on Lynne's life, after his verbal mutiny, Black Panther rescues him from Dragon Clan assassins (14-15).

After the rescue, Black Panther follows Reverend Blackburn into the woods where he is apprehended by the Klan. One of the Klan members calls Blackburn a "nigra lovin carpetbagger"

\footnotetext{
${ }^{11}$ This is not elaborated further and must be tied to a future story arc in the Marvel universe.
} 
and declares they will kill him using old "tried and true methods" (16-17). This moment is where the plot veers into sensationalized racial conventions to convey a sense of "authenticity." Here we see the rhetorical implementation of racialized and referential language through the use of the word "nigra" (a linguistic deviation of the word "nigger") and covert reference to lynching in "tried and true methods." In this exchange we also encounter the Klan's plan for killing Blackburn over property investment and not necessarily race or politics. The text appears to be making commentary that racism, at its roots, is all about economic power. The Klan does not care about Blackburn's racial inclusion, but protecting their financial interest is the priority. As members of the Klan take Blackburn into a river boat down the swamp stream, they are transported, through a mysterious mist, to swamp land where they encounter a shack of slaves from the antebellum era. Black Panther observes this conversation in the distance as an elder Black male slave tells Blackburn (who runs to them for help after jumping out the boat) that "he is a brother of hate" (22) and his kind has no use for truthful ways and he is brother of another kind which brings the appearance of the Soul Strangler (22). Soul Strangler tells the Reverend that "men of power make their own truth and any dare disagree with our truth—-the die!" (22). Out of the shadows emerges the Black Panther who attacks Soul Strangler and easily subdues him (see fig. 7). While holding Soul Strangler in his hands, Black Panther watches the villain dissolve. Black Panther then says, "Gone! Was it a Phantasm, a left over reaction to the cult's brain washing? Black Panther knows better. The hate was merely reverted to its old form and still holds sway over the part of the world that lives by fear instead of thought...” (27). At the conclusion of this text the slaves disappear, Black Panther punches Blackburn before he and the Klan members are arrested (27-30). 


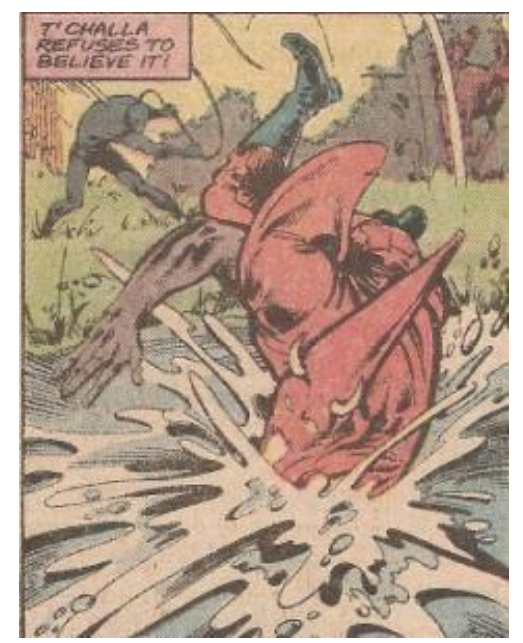

Fig. 3.7. Black Panther defeats Soul Strangler in Marvel Premiere \#53. ${ }^{34}$

Given the context of the cover art and narrative of Black Panther's storyline we are left cathartically hanging (no pun intended). With the heavy reliance on racialized material to propel Panther's story, the text works in a way where the villain literally dissolves away and becomes this after-school special generalized commentary on the spirt of hate; a hate that influences and pervades us all. The text, instead of addressing the historical weight of that hate, absolves itself by dissolving the villain. Initially we can deduce that Black Panther life matters, but more so \#AllHateMatters as well. We can also assert the judicial justice is served by the arrest of the Klan members and Reverend Blackburn, but I refer back to the section where these unknown men are plotting to eliminate Black Panther. They too, in a way, are absolved by their visual invisibility and also signify the unknown motives of hate. However, what can one expect by the motivation of the writers whose use of weighted racial symbolism would be a racial implication that affects readership.

Marvel Premiere series fails on the narrative front, and through visual artwork we see that even here, there is a rehashed narrative. Let's look at the cover art for Jungle Action \#19, 21, 22, and 24 (see fig. 3.8).

${ }^{34}$ Image taken from Comic Vine (2014) 


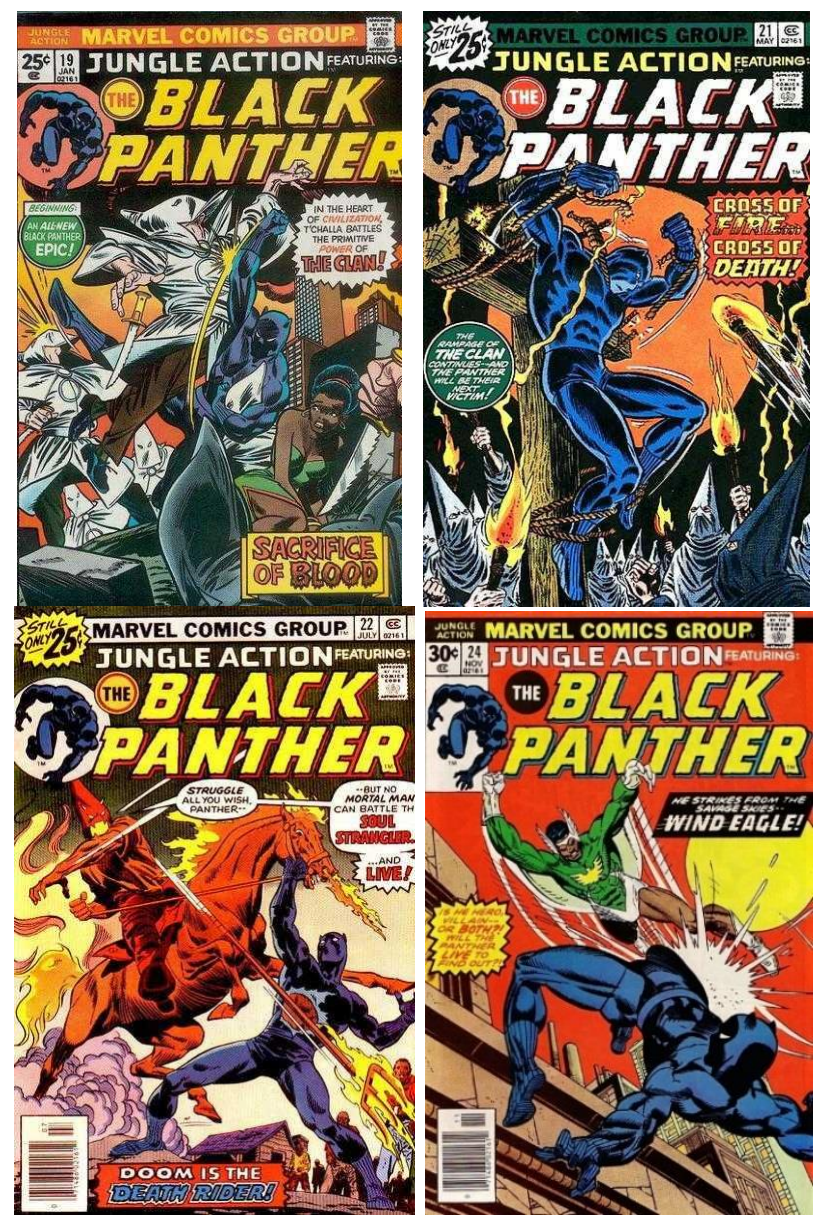

Fig. 3.8. The covers of the Jungle Action featuring Black Panther \#19, 20, $22 \& 24 .{ }^{35}$

Even the issues Jungle Action (written by Don McGregor) from 1976 shows us that this content has already been addressed in previous Black Panther texts. Black Panther has already battled the "Clan" (Jungle Action \#19), but in this issue it's the Dragon Clan and not the Klu Klux Klan. However, the hooded robes allude to the costume of a Klu Klux Klan member. Black Panther has already escaped a symbolic racialized moment of danger -this time a burning crossanother symbol of the Klan and racial terrorism (Jungle Action \#21). Black Panther has already battled Soul Strangler and Wind Eagle (Jungle Action \#22 and 24). Instead of reintroducing Black Panther into the continuity of Marvel universe with new enemies and plots, Hannigan and Berrimen reinforce the static representation for Black Panther in the Marvel Premiere series by

\footnotetext{
${ }^{34}$ Cover art images for the graphic narratives originate from the website, Comic Vine, (2014)
} 
looping an old narrative. This plot device cannot even be considered a reboot since this "new" take on Black Panther is also connected to old texts. Black Panther, in this case, is still weighted in and by past narratives. This blatant repetition of superficial racial relations is indicative of the repetition in cultural representations that Stuart Hall calls attention to: "[ $[$ ]he cultural industries do have the power constantly to rework and reshape what they represent; and, by repetition and selection, to impose and implant such definitions of ourselves as fit more easily the descriptions of the dominant or preferred culture" (Hall 447). Yet, historically, issues of race and social justice have always been problematic in the graphic narrative, but how did we get to this complication?

\section{Opening Doors to Difficult Conversations in Graphic Narratives}

According to Derek Parker Royal in "Introduction: Coloring America: Multi-Ethnic Engagements with Graphic Narrative,"

Comics are a composite text made up of words and images that, taken together, can have an impact far different from that produced by more traditional modes of narrative such as the short story or the novel. Much like film, comics rely on a visual language that encourages a more immediate processing time within the reader and, on the level of interpretation, a more "efficient" exchange between author(s) and audience-at least when compared to purely language-based mediums. (7)

This immediate action takes place within the limits of a graphic narrative to be more concise in with messages, metaphors or analogies. We can also observe the visual rhetoric of the texts by their physical and narrative limitations. In regard to the limitation, it merely means that the physical structure of the work (comic frames, artwork, etc.) and also narration (who speaks in 
which dialogue and also silenced) all are due to the spatial demarcations of the text. Royal elaborates on how graphic narratives are further affected:

Nonetheless, there is something relatively 'direct' about an image's ability to affect reader response. The figures that make up the comics rub up against reality in ways that words cannot, revealing the various assumptions, predispositions, and prejudices that authorillustrators may hold...This power underlying the comic image becomes all the more evident when placed within the context of race and ethnicity. (7)

Royal implies that graphic narratives, although already powerful in their fantasy storytelling, can create visual canvases of influences where art, commentary and culture collide. However, graphic narratives are also influenced by the creators and distributors of that medium. This concern also connotes that racial issues are more digestible if the protagonist is White or not addressed. In order to understand this we must look at one of the most referenced texts that addresses this matter: Green Lantern \#76 (DC Comics, 1970) because of its stance on social issues.

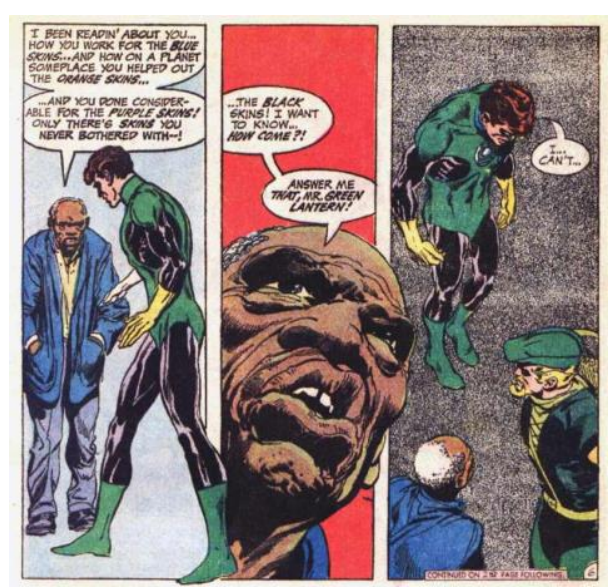

Fig. 3.9. Green Lantern/Green Arrow $\# 76$, Green Lantern is challenged on race. ${ }^{36}$

\footnotetext{
${ }^{14}$ Image taken from Green Arrow/Green Lantern Vol.1.
} 
In the introduction to the Green Lantern/ Green Arrow Volume 1 (2004) writer Dennis O'Neil reflects on how and why he and artist Neal Adams chose the narrative of Green Lantern and Green Arrow as a platform to take on social justice issues:

For a while, I'd been wondering if it might be possible to combine my various professional and personal concerns...Could a comic-book equivalent of the new journalism be possible? Probably not. But something—? Not fact, not current events, presented in panel art rooted in the issues of the day? Now there was a possibility...It was an opportunity to stop lurking at the edges of the social movements I admired and participate by dramatizing their concerns... What would happen if we put a super-hero in a real-life setting dealing with a real life problem. (5)

O'Neil and Adams place Green Lantern in the complex context of having to physically confront the issue of race and economic disparity by having this cultural issue embodied through a Black male who is having issues with his slum landlord (see fig. 9). Here is an example of being responsible in content and using the graphic narrative as a space to engage the lack of racial inclusion within graphic narratives. In this specific episode, Green Arrow is the one who eventually confronts the landlord since Green Lantern is bound by a code that does not allow him to exact justice. One could interpret this text in one of two ways. On one hand, this moral conflict can be commentary regarding the limitations of artistic and cultural exploration by the Comic Code Authority signified by Green Lantern's plight in participating in this moment of justice prohibited by societal laws and proper procedures. On the other hand, Green Arrow could symbolize the artists and writers expressing their own vigilantism against the restrictions of the graphic narrative industry. O'Neil alludes to this later in the aforementioned introduction of Green Lantern/Green Arrow Volume 1. He states, "I would be able to put into Green Arrow's 
speeches some of my own feelings, some of the pain and bewilderment recent events had caused. The comic-book form could be, for the duration of the assignment, a means of self-expression, as well as a means of amusing strangers" (6).

Graphic narrative historians, Laurence Malson and Michael Kantor in Superheroes!: Capes, Cowls, and the Creation of Comic Book Culture ${ }^{37}$ shed light on the historical significance of this particular text:

Still in its time, Green Lantern/Green Arrow, a contrived title if ever there was one, attained an exceptionally high standard as a groundbreaking work of art. Far more explosively than Green Lantern's power ring and for more incisively than Green Arrow's weaponry. O'Neil and Adams had used their narrative powers to destroy the wall that arbitrarily separated comic book fantasy from the real world. The shockwaves that reverberated when fantasy combusted with reality would be felt for the next four decades (179).

O'Neil and Adams allowed others to begin experimenting with contemporary issues in the realm of the graphic narrative. However, the silenced or reduced voices of Black characters confronting issues of race were still rendered invisible. White writers assuming cultural "authority" elicits concern for the dissemination of narratives being told. This position of power causes us to question if these are truly issues are social justice, then why the racialized silence? As the old Black man in the Green Lantern and Green Arrow previous stated, "What about the Black Skins?" (13).

\footnotetext{
${ }^{37}$ A companion text for the three-part PBS Documentary Superheroes: A Never-Ending Battle.
} 


\section{Conduits for Commodification}

Although O'Neil and Adams created a venue for social justice issues to be addressed in graphic narratives, it also raises certain crucial questions: why did it take so long and what does this new direction have to do with the Black Panther series? The ability to be relative or address issues of social justice in graphic narratives did not come from place of liberalism, but more so due to publishers' (Marvel and DC Comics) search to battle declining sales of graphic narratives that started to occur in the 1970's (Wright 234). To be fair, O’Neil and Adams' effort deserves some salutations for the ability to use the graphic narrative as a medium to bring forth such social concerns. However, through Marvel's capitalism, use of Black superhero vessels that allowed them to engage more specifically with issues that would be otherwise limited when using White superheroes. Nickie Phillips and Staci Strobl support this premise in the chapter “Aren't There Any Brown People in this World” from Comic Book Crime: Truth, Justice, and the American Way stating, "Comic books featuring Black superheroes explore race relations and social justice in ways not possible in books that render race 'invisible' through the exclusion of superheroes of color" (178). According to Phillips and Strobl, it makes sense for graphic narrative distributors to anchor these racial discourses in Black graphic narrative superheroes to appear "authentic." However, is it safer for a story of race relations to be written by White writers and does White creativity covertly and overtly reinforce the status quo of White hegemony? We must remember the audience being addressed and how does that effects the reception of social justice conversations regarding race?

In the introduction to the Black Panther Vol.1: The Client (2001) Christopher Priest (Black writer for Marvel) discusses his thought process as he was contemplating which angle to approach Black Panther in another reboot solo series greenlighted by Marvel Comics: 
The problem with race and popular media is, in most every 'Black' movie or 'Black' music CD you see or hear, there is some hostility directed towards Whites. Now were I a White male, I certainly wouldn't want to spend eight bucks to go see a film where males are portrayed as stupid and are the butt of every joke or where I am made to feel guilty about things I had nothing to do with, or prejudices I don't actually have. (1-2)

Corroborating Priest's thought process regarding the main audience in the essay "What's Going On? Black Identity in the Marvel Age," Michael Van Dyk reflects on his youth purchasing graphic narratives and why he chose his superheroes based on their cultural ethnicity:

Not surprisingly, most of the superheroes I chose to idolize were White and male. I was, after all a White middle-class kid growing up in a predominately White neighborhood. Sure, there were superheroes of other races and genders, but I was not interested in their exploits. I did not identify with them: I did not want to be them, and, as a result, I did not comics about them. My cultural surroundings and the color of my skin dictated what I read and who I emulated. (466)

If the audience, artistic development team, distribution and financial benefactors are White, it would only make sense to still cater to issues of social justice to that audience and "mask" it as a way of selling to an entire audience claiming to focus on group of readers. For instance, Priest, being Black, also anchors Black Panther in a superficial narrative in his run of the series from 1998 to 2003. He utilizes a White character named Ross to narrate Black Panther's story. We can assert that Priest uses this method as a way of subversively critiquing White writers of Black Panther by the narrative choice that also provides access to the majority of readership; a reading arguing that Black Panther can only be truly read through the White narrative. This approach 
marks the ideology of the universal audience for the differential racialization that occurs in the Black Panther texts.

What is this universal audience? According to Chaïm Perelman and Lucie OlbrechtsTytecha in the section "The Universal Audience" from The New Rhetoric, "[T] is regarded as a model to which men should conform in order to be worthy of the name: in other words, the elite audience sets the norm for everybody. In this case, the elite is the vanguard all will follow and conform to. Its opinion is the only one that matters, for, in final analysis, it is the determining one" (34). The alignment of graphic narratives industries, content universal audience readership and economics, is a clear example of what critical race theorist Derrick Bell refers to as interest convergence, which is " $[\mathrm{t}]$ he interest of Blacks in achieving racial equality will be accommodated only when it converges with the interest of Whites" (523). The "interest" in particular are the companies (Marvel in this instance) using Black superheroes in battles with overt references to racial overtones to sell more graphic narratives in an effort to address culturally specific content. We must consider the way the Black Panther text resolves itself to sustain the White hegemonic structure since it would require a massive overhaul to the Marvel universe that relies on the complexities and diversity of its characters and ideas grounded in the cultural politics of dominant culture. Bell further elaborates:

Whites simply cannot envision the personal responsibility...that true equality for Blacks will require the surrender of racism-granted privileges for Whites...Racial remedies may instead be the outward manifestations of unspoken and perhaps subconscious judicial conclusions that the remedies, if granted, will secure, advance, or at least not harm societal interests deemed important by middle and upper class Whites. (522-523) 
If the universal audience regarding readership is White, then in the case of Black superheroes (Black Panther) there can be no full resolution to the race issue in graphic narratives because it would disrupt the "natural" order of things. Considering how the Black Panther miniseries is resolved, there is no true change besides the arrest of the pawns (a couple of Klan members and Reverend Blackburn) and an evil villain that turns out to be nothing more than a figment of Black Panther's imagination. So, even though Marvel Premiere promises a focus on Black Panther battling the Klan and Soul Strangler, all racial challenges occur on an artificial level through a brief encounter with the Klan and disintegrating villain. This interest convergence of race and graphic narratives is where differential racialization takes stage. Companies, like Marvel, make commercial motives their reason for racial inclusion rather than obtaining a multicultural audience with promises of racial justice without closure. Once again, economics factors trumps over the racial awareness in the texts.

One could argue that graphic narratives are just simple devices with which people live out their fantasy, but I would argue that is not the case. Graphic narratives are the synthesis of entertainment, corporate agendas and dissemination of material that reiterates a specific ideology concerning racial attitudes that play a part of a hegemonic platform of control. Even if graphic narratives play a minor role in the grand scheme of this suppression, they still have an effect on what messages are distributed to an audience and how they are received and thus should not be dismissed (Van Dyk 467). Dyk reiterates this particular point, "[T]his is the privilege of White patriarchal capitalism, its ability to produce and distribute images it deems acceptable, regardless of accuracy and free of consequence. In this environment, Blackness, like any other commodity, is manufactured, marketed, discarded, recycled, repackaged, and resold all in an effort to maximize profits. These profits, however, come at the cultural expense of Black people" (483). 
Using historical context of racial hatred (Ku Klux Klan, noose, the use of the word "nigra") as devices to sell more issues borders on irresponsible — especially if the results are a shallow attempt to address racial issues that still linger and haunt in contemporary times ${ }^{38}$. The cultural politics of Black Panther often neuters his power and cultural importance because he has been strangled in an avarice noose by the souls of the corporate writers in pursuit of C.R.E.A.M ${ }^{39}$. Attacking notions of race in a graphic narrative through the embodiment of Black superheroes allows White writers to use Black characters as a way of resolving and/or dissolving, racial issues on an artificial level. Royal states that a "[g]raphic narrative, in allowing the reader to "mask" him- or herself in its non-mimetic figuration, invites empathy with the nondescript "Other" on the comic page, thereby encouraging the reader to connect to other experiences and other communities that might otherwise have been unfamiliar" (10). Royal is referring two types of embodiment: the writer creating the character and audience receiving the story. In this specific medium the writer (Ed Hannigan) is White and the larger readership is White. When writers create these kinds of stories, they do so through the "other." The "other" in this case refers to the conduit of the Black superhero, Black Panther. The Marvel Premiere series offers a White (or, any other culture that is not specifically Black) reader a gateway into Black superheroism in the form of commodified social justice voyeurism or what I like to call "diet protest" narratives.

bell hooks, in Black Looks: Race and Representation, provides a framework in which this voyeurism affects reception when issues of race and ethnicity are introduced in a commodified venue. hooks contends, "When race and ethnicity become commodified as resources for pleasure, the culture of specific groups, as well as the bodies of individuals, can be seen as

\footnotetext{
${ }^{37}$ I recognize that the Black Panther miniseries was created in 1979-1980, but the racial connotations were still relevant as this was at the down slope of the Black Power resistance.

${ }^{39}$ Cash rules everything around me.
} 
constituting an alternative playground where members of dominating races, genders, sexual practices affirm their power-over in intimate relations with the Other" (23). Considering hooks argument, Hannigan and Marvel are the architects of this pseudo-address of race. They prove a White author can jump into Black Panther and physically embody the fight of racial issues and then leave as part of some sort of temporary graphic narrative possession. Yet, by doing this, Hannigan creates an appropriation of heavy race issues that are conveyed to be nothing more than just entertainment. hooks continues, "Currently, the commodification of difference promotes paradigms of consumption wherein whatever difference the Other inhibits is eradicated, via exchange, by a consumer cannibalism that not only displaces the Other but denies the significance of that Other's history through a process of decontextualization" (31). The power of production removes and devalues the historical significance of racialized content in the Black Panther. This political and economic act dematerializes the racialized overtones and importance of visually witnessing these symbols of hate battled and defeated by reconstructing them into superficial markers for advertisement. Since audience plays a large role in the reception of a text, we can than start to look at how it further affects the symbolism in Black Panther's miniseries.

\section{Power to the People: The Conflict of the Black Panther Character and Symbolism}

Evaluating audience also causes one to consider the symbolic nature being represented in the Black Panther graphic narrative mini-series. This examination is especially important since "[t]he ways in which we conceptualize, represents, and consume our superheroes, for instance, can speak volumes about the ways we frame the ethnic subject" (Royal 16). How we receive these transcribed images of commodification and hegemonic reinforcement can have a profound 
effect on what superheroes represent given the color of the character and what issue or enemy they face. The psychological effects of racial tension, when placed in the context of a medium of fantasy automatically alters the perception of how the symbolism of social justice is received. The symbols of Black Panther, Soul Strangler, and the Klan in the- three-volume miniseries all play a role in creating the context for symbolism and reinforcing the status quo which is praxis of graphic narratives that are created by hegemonic establishments.

According to academic Marc Singer in “'Black Skins” and White Masks: Comic Books and the Secret of Race":

The stereotypes through which American popular culture often interprets and represents racial identity operate not only as tools of defamation but also as vehicles for far more subtle manipulations of race... Whether those stereotypes assume the form of unrealistic portrayals of racial minorities or an equally unrealistic invisibility, they often fulfill this double function of oppression and reaffirmation. (107)

Singer suggests that these images, created for consumption in pop culture, can also serve a dual function of silencing and affirming stereotypes. Black Panther gives us multiple symbols of hate without any true resolution. Villains are arrested in the end, but the system itself remains intact. For example, consider the villain, Soul Strangler (see fig. 3.10). 


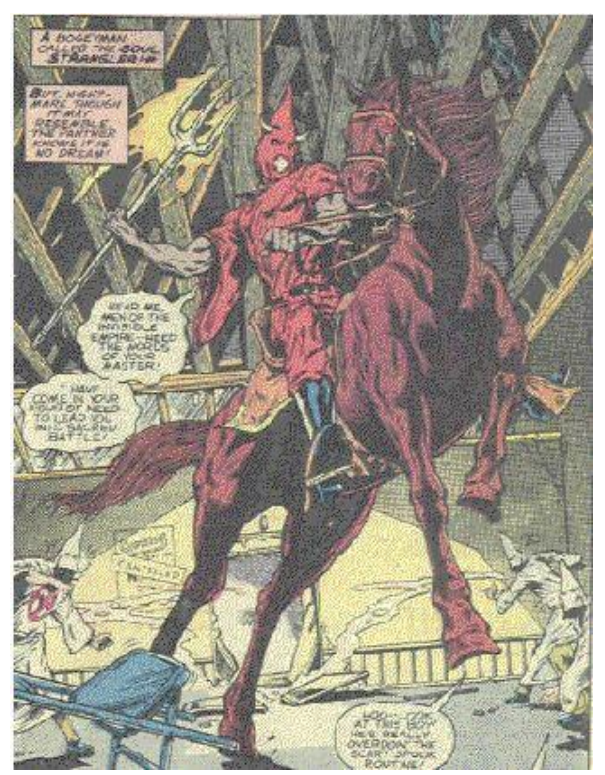

Fig. 3.10. The Soul Strangler from the Marvel Premiere series. ${ }^{40}$

Soul Strangler is a metonymical device of hate within a racially-charged society in this Marvel series. This symbolism is problematic because, rather than have the Black Panther fight a physical being (in a fictional sense), he engages with a metafictional entity inspired by hate that manifests itself as a clone of a Klan wizard. Sadly, the graphic narrative offers an "out" for racism. Soul Strangler cannot be merely defeated because it's only a spirit absolving man from accountability of his action in this text. If Black Panther cannot defeat Soul Strangler because it is a spirit, then that would make him powerless to defeat said foe. In essence, this ambiguous conflict is the antithesis of super heroism. We understand that superheroes do suffer defeat and this does not indicate their inability to be un-super, but, with Black Panther's foe only being an apparition, the typical conflict between hero and villain is removed and replaced with a lethargic and meaningless climax. About this narrative injustice, hooks argues, "Exploring how desire for the Other is expressed, manipulated, and transformed by encounters with difference and the different is critical terrain that can indicate whether these potentially revolutionary longings are ever fulfilled" (hooks 22). Although Black Panther does eventually conquer Soul Strangler (the

\footnotetext{
${ }^{39}$ Image taken from Comic Vine (2014)
} 
symbol of hate), it disappears and absolves any true enemies of their racial injustices. When given the opportunity to address matters of race in the text the graphic narrative series absolves itself by providing a phantasmal out - a proverbial metafictional racial scapegoat.

In the essay "Some Varieties of Heroes in America," Roger Abrahams indicates how narration of the negro as a hero usually plays out when provided the opportunity to confront symbolic evil. Abrahams asserts, "[T]hey [Blacks] seldom get a chance to fight their real enemy openly, and consequently their heroism (both physically and fictionally expressed) often is misdirected, self-defeating, and only temporarily effective in dispelling fears of the loss of masculinity. Their expressions of manliness are therefore often exaggerated" (344). As Abrahams suggests, Black Panther (in this series) fights an apparition of his own mind —an exaggerated battle. Since Black Panther is a commodified character aligned with corporate interest that serves the majority of its White audience should was there ever going to be a true resolution to matters of race if it alters the privileged in this text? This conflict is indicative of the manipulation of symbols. One could also read the metaphysical representation of hate as symbolic of Black Panther's own hate that he is battling as problematic. It too not only absolves the physical symbolism of racism, it also creates a blame-shifting paradigm by making Black Panther the thing he hates. The writers essentially move the spirit of racism into Black Panther upon his stating he also can be consumed by the spirit of hate. Technically, this would confuse a reader by insinuating that the result of hate is a combination of history and a figment of Black Panther's own imagination. In this instance, racism can happen to anybody by anybody. This concept oversaturates the specificity in confronting issues of race in these texts and oversimplifies the power of racism. Unfortunately, this narrative choice works in diluting the symbolism of racism by insisting that hate can happen to anyone and that, because of this 
phenomenon, we (the audience) cannot pinpoint the responsibility of historical or religious hate mongering groups on them. Such a position is the equivalent to saying "forgive them, father, for they know not what they do." The problem is that this figurative and literal "them" are the same perpetrators who benefit from this system. Although it appears that Marvel and their creative staff do not condone racism in these texts, the resolutions of these narratives are contributing to the ideology of hegemony through audience and symbolism that serves a systemic racial structure. By having racial context placed in the realm of text that is solely focused on getting more readers and consumerism into this series we, the audience, are denied a true connection with the hero, social justice, and equality. The Black Panther loses again.

\section{Conclusion: With Great Power...}

In final thoughts, at the end of introduction in Green Lantern/Green Arrow Volume 1, O’Neil states:

We would dramatize issues. We would not resolve them. We were not in the polemic business. I was smart enough to know enormously complex problems couldn't be dissected within the limitations of a 25-page comic book and humble enough to know that I didn't have solutions anyway. Still I cherished the notion that the stories might be socially useful; I could hope they might awaken youngsters, eight- or nine-years olds, to the world's dilemmas and these children, given such an early start might be able to find solutions in their maturity. My generation, and my father's, had grown up ignorant; my son's didn't have to. Maybe I could help, a little (6)

Although there is a small attempt to bring diversity to graphic narratives by addressing issues of discrimination and race, the monetary compensation from the presence of the inclusion of Black superheroes becomes the real point here. White authors and artists can enter the body of 
a Black Panther for the love of money and also sketch issues of race, but at the cost of profit does this occur. At the heart of inclusion lies economics. This disillusion causes these writers to miss an amazing opportunity that provides conflict resolution in the world of fantasy that one may not experience in the real world. To repeat, although there are limitations to graphic narrative work, doing racial exploration with a sense of purpose is a start.

In conclusion, Kirby and Lee embody Black Panther to live out the oriental fantasy of an African kingdom in an uncolonized civilization as atmosphere instead of using this to empower the Black superhero. Black Panther has been conflicted between the service of his kingdom and assistance to his White allies. The nature of the imagery of Africa through the eyes of White subjects. Although the Black Panther is a product of American creation, the colonial tropes that manifest themselves in Conrad's Heart of Darkness permeate through the context of Black Panther's first appearance, his fictionalized kingdom and how his body is being read as fictional third-world superhero in the eyes of white writers and global audiences.

To expect a graphic narrative to serve as a solution to racism is a bit overzealous, but to expect that the issue be handled with more concern for sensitive racial symbols is not. Although Hannigan may not have felt his world was at risk by guising himself behind the helm of the Black Panther, it was a missed opportunity to address social issues of that era. Hannigan could have also been stuck in the stress of gathering more of a Black audience by trying to reinvigorate interest in a Black superhero. By shifting from fantasy to magical realism, these authors (unlike O'Neil and Adams' sincere effort to incorporate these issues) could have used this avenue as a way of fighting the powers that be, but they choose to absolve the demons of the racism metaphysically and figuratively so as to not affect their readership. It is unfortunate that this type of resolution can be more so done with White superheroes. In Black superhero narratives, the 
ability to operate outside of Whiteness still relies on Whiteness. The Marvel Premiere series does not shatter fantasy by delving into magical realism. The graphic narrative merely reverts back to its' subversive roots through absolving the imaginative antagonists of responsibility. This series offers the opportunity for Black Panther to confront the Klan and tackle social issues of race, but it rescinds on its social justice crusade by desiring a resolution that maybe only some White readers would deem to be a dream ending. 


\section{CHAPTER IV: "SWEET SIGNYFYIN(G) CHRISTMAS”: UNCHAINING LUKE CAGE}

The Black response to [W] hite imitation has been to ignore it, to tolerate it, to show [W] hites what the real thing is by appearing to share it with them, to go back to the original basic meanings involved, to invent new meanings which defy [W]hite acceptance, or to discard the expression altogether and take up another.

Stephen Henderson

Black people, the evidence suggests, had to represent themselves as 'speaking subjects' before they could even begin to destroy their status as objects, as commodities, within Western culture.

Henry Louis Gates, Jr.

Way down in the graphic-narrative streets, two signifying writers stepped on a pseudo-

Black superhero's feet! To destroy a stereotype one must embrace, destroy, and rewrite the history of that trope. Revisionism is a political act-especially if the trope in question is symbolic of one's own historical representation. A history so weighted with negative connotations and archetypes that continue to evolve visually yet still contains the same troublesome ideologies. The politics of revisionism is clearly demonstrated by late Black graphic narrative creator/writer Dwayne McDuffie and noted television director and co-writer Cheo Hadari Coker who utilize different avenues to resignify the Black-male-hypermasculine image portrayed by the graphic narrative character, Luke Cage. Although male superheroes are considered hypermasculine by nature, the historical aspects of hyper-racialized violence adds another level of masculinity to the Black body. It's like a hyper-hypermasculine idea that moves it past a humanistic element to one that is primitive in nature. So even if the fantasy idea of superheroes is contingent upon they hypermasculine principle, if we align hypermasculinity with racial stereotypes post-Civil War (Brutes, savages, etc.) and the primitivism of modernity we get the over-hypermasculinated Black male body; one deficient of intellect and feeling, one that is both a distributor and recipient of violence. I argue that McDuffie and Coker rewrite the monolithic image of the Black-male superhero through Luke Cage. McDuffie reintroduces the 
Luke Cage trope embodied by the Icon series character Buck Wild as a retcon to the familiar image of African Americans as superheroes in the graphic narrative, carving out an alternative space for more complex images; Coker reconstructs Luke Cage's character to make it culturally relevant and symbolic of contemporary social justice issues in the Netflix series, Luke Cage.

The Signification referenced in this chapter derives from Henry Louis Gates Jr's The Signifying Monkey in which he states, "[S]ignifyin(g) is the figure of Afro-American literary history, and revision proceeds by rifting upon tropes" (124). It is with this process that "[w]riters Signify upon each other's texts by rewriting the received textual tradition. This can be accomplished by the revision of tropes. This sort of Signifyin(g) revision serves, if successful, to create a space for the revising text" (124). Signification is not only imperative in revising history, but also propelling beyond static representations of Black males in graphic narratives. Signifying the stereotypical trope allows one to comment on a skewed perspective of representation and rewrite one's fabricated image in their voice. Signification is important for identity reclamation of constructed images with the intent to render negative perspectives or images void and turn a new page to complex narratives. In short, Signification is the space where cultural political resistance occurs and reimagined. This process is essential to retroactive continuity.

In Frank E. Tupper's book The Theology of Wolfhart Pannenberg, the process of retroactive community is described as "[u]nforseen contingent events [that] are retroactively joined to the past, transform it, and thereby restructure history's continuity... Hence the continuity of events is actually visible only in retrospect... retroactive continuity ultimately means that history flows fundamentally from the future into the past, that the future is not basically a product of the past" (99-100). Retroactive continuity, referred to as "retcon" from hence forth, is the literary concept that history can be revised to suit the future. In his explanation 
of the term, Tupper references the New Testament section of The Bible as a retcon to the religious rules of the Old Testament. The Bible thus revises itself in the later half to fit the needs of future interpretation of scripture. This exegesis then falls on the redemptive qualities of the future as no longer bounded by the past while changing it. This process frequently occurs within graphic narratives in order for writers to rejuvenate story lines or rework characters to fit in to current narratives that they have been originally written out. I also contend that retcon works through Signification as a way of not only rewriting the narrative, but also the self represented through literal and figurative presentation. If revisionism is where cultural self-representation takes over in the cultural struggle for meaning and the constitution of identity, retcon is integral in the politics of the text to reclaim one's fabricated and replicated identity by rewriting the self through literal and figurative presentation.. Based on these concepts, McDuffie and Coker create their own literary and visual rhetorical catharsis in the texts by using [S]ignification in two different retcon experiences through the fictional body of Luke Cage. McDuffie utilizes his character Icon to commentate on the Luke Cage character (and other Black superheroes created in the 1960s and 70s) who associate with the Buck stereotype, which can often hinder the positive effectiveness of the first solo African-American graphic narrative superhero Luke Cage. Coker uses Signification by retconning Cage's origin and personality to address current sociopolitical issues. Coker presents a conservative-minded Cage who emphasizes altruism and respectability thus revising Cage's former costume and mercenary ideology. Both McDuffie and Coker reconstruct the semiotics of Luke Cage's body by rewriting his purpose through their own cultural politics of representation in order to regain control of their fictional visual identities. 


\section{"It's About to Get Ugly!" The Problematic Luke Cage}

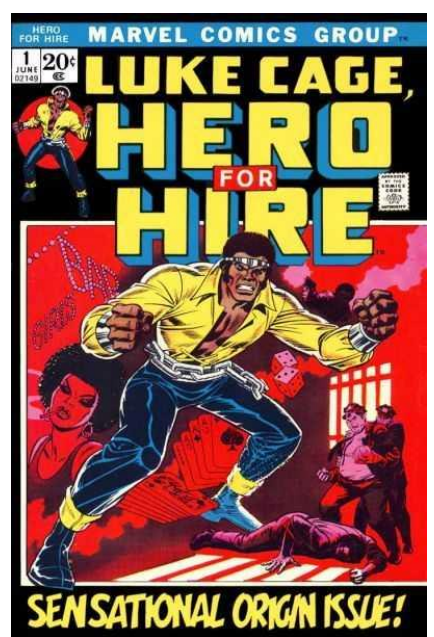

Fig. 4.1. The cover for Luke Cage, Hero for Hire \#1 (Marvel, 1972)

In order to understand the importance of these revisions, we must address the complicated character that these literary political acts of Signification entail (see fig. 4.1). In 1972, in conjunction with the influence of the Blaxploitation film era, Archie Goodwin, Stan Lee, and John Romita Jr. created the first African-American graphic narrative superhero with his own solo series, Luke Cage: Hero for Hire for Marvel Comics. Scholar Adilifu Nama in his book Super Black: American Pop Culture and Black Superheroes indicates that Marvel creators probably used this film genre because "[B]laxploitation films increasingly relied on sensationalistic depictions of racial strife, wherein crazed and corrupt [W]hites appeared to live only to plot for the [B]lack protagonist's death and by symbolic extension, [B]lack peoples' defeat in the struggle for racial justice" (19). So even though Blaxploitation films were created as a counterculture to images of racial discord and powerlessness by providing action-oriented rhetorical response to [W]hite hegemony, these films also reinforced stereotypes perpetuated through images of hypermasculinity in the Brute/Buck hero (Shaft, Super Fly, The Mack, etc.) and the hypersexual Black vixen (Foxy Brown). Nama contends that Cage's origin extends beyond Blaxploitation and adds, "Consequently, Luke Cage is a [B]lack superhero that 
symbolizes the cresting prison reform movement of the early 1970s and possibly the righteously defiant image of his namesake, Cool Hand Luke, more than the Blaxploitation film craze he's often credited as solely representing" (56). Nama posits that Cage is more than just Blaxploitation, but also symbolic of prison reform and experiments.

This symbolism is in the very nature Cage gains his powers. According to graphic narrative historians Laurence Malson and Michael Kantor, "In homage to Captain America, a stubborn [B]lack prisoner named Carl Lucas, stuck in an impenetrable penitentiary where he is constantly victimized by white guards, agrees to participate in a strength-enhancement experiment in exchange for parole. When the experiment goes horribly awry, he is transformed into a being of incredible power and invulnerability" (172). Luke Cage gains impenetrable skin and enhanced strength because of this failed experiment that metaphorically reads "as what was meant to kill him, only made him stronger," physically. One can also construct the argument that Cage's experiment also justifies the idea of a "hardened criminal" through the representation of his insensate skin. Cage is also problematic because he utilizes his brute strength and invincible skin over his brain, which contributes to the Buck/Brute stereotype of a powerful, but brainless Black menace. Comparing Cage with his superhero colleagues, we need to consider the idea of Captain America volunteering for the experiment that gave him his powers to serve his country. However, Luke Cage uses the experiment to reduce his prison sentence. There is nobility in Captain America's purposeful serving, while Cage received his powers by happenstance, in jail, and early release.

In an interview with Alex Pappademus for $G Q$ magazine's discussion on Black superheroes, graphic narrative writer and academic John Jennings reflects on how Cage appears to be representative of the Black audience. Jennings contends, "I think Cage kind of was the 
[B]lack audience in the Marvel Universe for a while. The different incarnations mirrored how [B]lack people were being portrayed in media. And there's stuff like Brother Voodoo, too. And even characters like Iron Fist, or Shang-Chi: Master of Kung $F u$ - that's them capitalizing on all those B-movie stereotypes" (Pappademus, "Collecting Black Comix: African-American Superheroes and the Luke Cage Problem"). Based on this error of using the monolithic image to represent all, the stereotype trope of Luke Cage becomes further problematic by its Blaxploitation (mis)use of Black masculinity merging with the graphic narrative to become an ambassador for Blackness in comics.

In a critical essay concerning images of Black superheroes "What's Going On? Black Identity in the Marvel Age," Michael Van Dyk argues that "Luke Cage becomes Power Man, drawing further attention to his militant roots and making the [B]lack male stereotype complete...Created from the perspective of middle-class [W]hite artists and backed by a mainstream [W]hite company, Luke Cage seemed the very definition of problematic" (Van Dyk 473). Van Dyk insists that although Luke Cage is a Black character supposedly outfitted for success, his authenticity is compromised by the ideology of his White writers. Van Dyk further criticizes Cage's origin to a level where seemingly character cannot be repaired by being " $[\mathrm{t}] \mathrm{he}$ result of overzealous creators, Cage is an amalgam of characteristics found in current media portrayals of black masculinity. Intellectually guarded, physically intimidating, and behaviorally violent, Cage represents, however misguided, Marvel's vision of what it is to be authentically [B]lack in America today" (Van Dyk 488). Counter to that stance, Nama believes that "the character's [Luke Cage] greatest contribution was representing a real African[-]American superhero that spoke to all audiences, even though it was a risky choice to render him as an unapologetic troubleshooter who charged for his services" (Nama 172). How real was Luke Cage 
if he garnered criticism for his lack of authenticity? This reading of Cage does more to reify the commodification of the Black experience through the fraught lens of Blaxploitation. Nama attempts to redeem some of Cage's criticism for being what hip-hop academic Jelani Cobb refers to Cage as being a "mercenary for hire with bulletproof skin" who projected the mentality "cut me a check and I'll be a superhero" (Cobb, White Scripts and Black Superheroes). This assertion complicates the notion of being a superhero for a righteous altruistic cause since what we technically have is a Black superhero who is a hustler for heroics or a bulletproof goon.

Jeffrey Brown in the essay "Panthers and Vixens: Black Superheroines, Sexuality, and Stereotypes in Contemporary Books" states the reason these images need to be destroyed is because "[i]t is this reliance on stereotypes that makes truly progressive depictions of Black superhero characters difficult within mainstream comics from industry giants like Marvel and DC Comics" (Brown 136). Since Cage's character represents a racially stigmatized staple in the Marvel universe, it also creates the standard image for Black male superheroes. This construction complicates the ability of future Black-male superheroes to be viewed as authentic since Cage is the lens through which all other Black superheroes are judged. Yet, Nama further argues, "Power Man is a radical signifier of the troubling intersection of racism, institutional authority, and broader themes associated with black political disenfranchisement" (Nama 56). If Cage is this radical signifier, then why does his image need revision? In order to decontextualize the ideology of Black graphic narrative superheroes we must change what he symbolizes. This is where McDuffie's satirical character "Buck Wild” becomes applicable. McDuffie employs Buck Wild as a visual representation of Signification in order to criticize the Luke Cage genre (and others) and remix the concept of a Black superhero and radically Signifies the signifier. 


\section{Out of Satire - A Fool is Born!}

Derek Dingle, Michael Davis, Denys Cowan, and Dwayne McDuffie founded Milestone Comics in 1993. Although the staff was mostly African American, they centered their stories in diverse worlds. Milestone Comics, under DC Comics, became the first Black nationally distributed franchise in the nation. However, after a strong start (selling five million books in its launch), Milestone Comics only managed to survive from 1993-1997 (Dauphin 32). Later, its titles and characters merge with the rest of DC Comics universe. Yet, during its run, McDuffie (the series writer for Icon and Hardwire), who served as editor and chief for Milestone Comics, had a different idea how Black graphic narrative superheroes should be represented. He, as well as the other founders of Milestone, wanted to create alternative representations of Black superheroes. As a former editor of Marvel Comics who wrote comics to supplement income (Dauphin 32), McDuffie experienced multiple negative encounters with the portrayal of AfricanAmerican images while writing for Marvel series DeathLok. Based on these conflicts, McDuffie chose to manufacture heroes that were more personable rather than a binary trope to counter the negative images. McDuffie, on the image of Black representations, noted, "We are people, not an image, and it doesn't really solve anything to replace a negative stereotype with a positive stereotype. No human being is going to live up to that. I just want books that break the monolithic idea of what [B]lack people are" (34). McDuffie sought to redefine or in this case, retcon appropriated concepts of African Americans in the graphic narrative.

In a deleted scene from Jonathon Gayles' documentary White Scripts and Black Supermen, McDuffie recalls a story on how the creators of Luke Cage, Archie Goodwin and John Romita Jr., developed his dialogue. McDuffie stated that the purpose was twofold: one being "a well-intentioned attempt to make the language real" and "that they wanted to curse like 
Shaft did, but couldn't because it was for comics." McDuffie also said Marvel was oblivious to the authentic portrayal of Black language and decided to muse this character's dialogue based on Chester Himes' detective fiction. However, unbeknownst to the writers of the Luke Cage series, McDuffie asserts that they were actually appropriating a fictional work as the real deal due to the satirical nature of Himes' character's language (“Dwayne McDuffie on Chester Himes, Luke Cage and "SWEET CHRISTMAS!" 2011). In essence, the origin of Luke Cage's language was metafictional and received as authentic Black dialogue by White writers trying to emulate the "real."

McDuffie's character "Buck Wild" from his Icon graphic narrative series serves as the embodiment of Signifyin(g) Marvel Comics' Luke Cage. He makes overt intellectual critiques of the problematic characterization of Luke Cage in Icon \#13 "It's Always Christmas" (DC Comics, 1994) and Icon \#30 “The Buck Passes” (DC Comics, 1995). In Icon \#13, we are introduced to the character named "Buck Wild" in a similar fashion to how Luke Cage is introduced in his own graphic narrative series. The difference is in Icon \#30 we are taken to the funeral of Buck Wild where there is reflection of his life told by a preacher, Icon, and past enemies. It is here we see McDuffie play with using the Buck Wild character as a conduit of his criticism for historical ${ }^{41}$ Black superheroes through the process of Signification and retcon.

As one of Milestone Comics premiere characters, Icon is the racial remix of DC Comics' popular superhero Superman. Icon's origin is similar to Superman's—a child stranded from an alien planet who lands on to Earth. The difference in this text is that Icon's [B]lack skin is the result of a camouflage protection process by which he replicates the melanin of his first human contact. Icon is discovered by a [B]lack slave. So even though Icon is not [B]lack, "Icon experiences [B]lackness as just an arbitrary state of mind, his African Americanness [sic] locked

\footnotetext{
${ }^{41}$ I must state that this is contemporary in terms of the 1990 s.
} 
in by the accident of initial discovery by a slave" (Dauphin 33). Although this is an interesting remix to the Superman narrative, there are those who do not agree with this character. Nama argues that "the imitative elements were so much a part of the Superman universe that they significantly diminished Icon's Afrofuturistic originality. Moreover, Icon's origin narrative was extremely problematic, given that he comes of age as a [B]lack slave and does not use his superior abilities to free [B]lack folk from enslavement" (Nama 96). He further elaborates, "Given that virtually all superheroes are victorious because of their moral determination, concern for others, and notions of justice, what does Icon articulate about racial justice?" (Nama 97-98). I argue that Nama misses the point of this remix. McDuffie chooses this narrative to demonstrate the power of retconning superherorism in the Superman genre. Although the concerns are understandable, Icon still provides a template for which McDuffie does his best work in remixing the narrative of the Black superhero since it helps establish the counternarrative of Black images that are at play in and out of the Milestone Comics metafictional universe.

In Icon \#13 "It's Always Christmas" we are immediately introduced to the character Buck Wild aka "Mercenary Man" in the first panel. Even in naming, McDuffie intentionally attacks the image of the Black Buck/Brute stereotype (see fig. 4.2). Buck Wild visually looks like a combination of Luke Cage and $\operatorname{Tyroc}^{42}$ with his one-piece leotard, chest-exposing gold leotard, golden tiara, wrist bracelets, and matching boots. Luke Cage's original costume design has often come under heavy scrutiny. Communications professor Blair Davis in the essay "Bare Chests, Silver Tiaras, and Removable Afros: The Visual Design of Black Comic Book Superheroes" makes the argument that "As such, the various depictions of black characters created by comic book writers and artists—especially such elements as dress, accessories,

\footnotetext{
${ }^{42}$ Tyroc is a Black DC Comics superhero outfitted in a white one-piece leotard with the power of flying and amplifying his voice.
} 
weaponry, and the like - become signs that convey particular representations of black culture, identity, and/or history" (Davis 195). Here Davis refers to the iconography of the superhero costume. Not only is the heroic act indicative of superhero status, but the costume is just as iconic in representing such a status. Davis continues his argument:

Cage selects his costume from a costume shop; it features a distinctive yellow shirt that opens to reveal his bare chest, a silver headband, and steel bracelets, all of which formerly belonged to an escape artist... By extension, the steel chain (along with is bracelets, which resemble shackles) also serves as a reminder of the heritage of slavery that Cage carries with him as a black male, signifying the chains that bound those who were loaded onto the slave ships to make the forced journey from Africa to foreign lands... Though it is not referred to as such in his earliest appearances, the headband has since become known as a tiara — an item worn by brides and princess and therefore representing intense femininity...Furthermore, his steel wristbands appear strikingly similar to those worn by Wonder Woman, further aligning him with historically feminine costume patterns (Davis 196, 198)

Here Davis provides us with multiple readings of Cage's costume that can best be summarized as direct slavery and prison connotations while propagating effeminate traits. In short, Cage's original costume is an amalgamated hot mess. Davis concludes:

Cage's status as a superhero becomes relatively more limited outside the context of comic book fans, give that he currently lacks the iconographic imagery that the costumes of such internationally recognizable heroes as Superman and Spider-Man provide to audiences. To unfamiliar readers, Cage appears to be just an average man; perhaps this is exactly the point: that the average person can indeed be a hero and make a difference in 
his or her community, an ideal that Cage has sought to uphold since his debut (Davis 201).

Davis is referring to the current reiteration of Luke Cage who only bears a t-shirt, jeans and shoes/boots as a costume. However, one can make the argument that even if Luke Cage now reflects the average man being a superhero it also neglects the conception of superheroes. Maybe anyone can be Luke Cage, but in this case why wouldn't they want to be someone else when your power is connected to the historical atypical representation of Black hypermasculinity and the monster motif of being bulletproof or indestructible? Perhaps the concept here is that you do not need a costume to be a superhero, but isn't that what costumes signify, heroism to a certain effect? However, this costume conflict is challenged by the Netflix reinvention of the "hoodie" as costume for Luke Cage in the current self-titled series that is addressed later in this chapter.
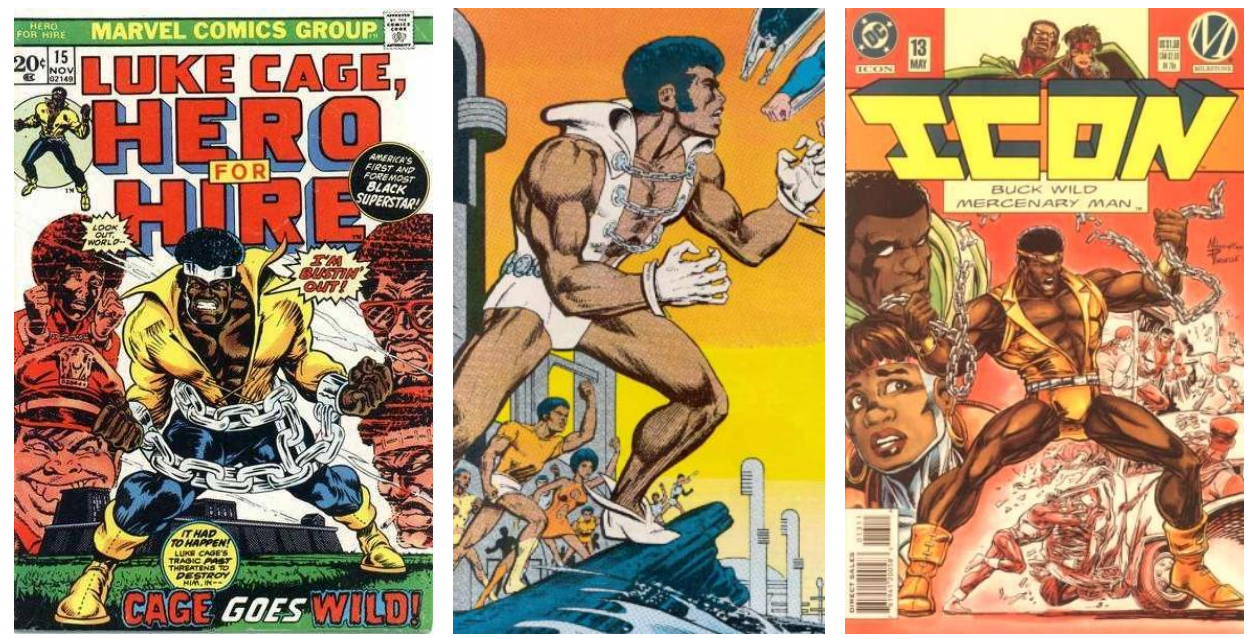

Fig. 4.2. Luke Cage (left), Tyroc (center), and Buck Wild (right).

Linguistically, Buck Wild's dialogue is always self-referential to his powers (similar to what Luke Cage does). In the opening panels he invades a drug houses and tells the criminals that they should be wary of his "tungsten skin" and "belief [-] defying strength" (2). In this allusion, McDuffie plays on the Black Buck trope of physicality and invincibility. According to graphic narrative analysts to Nickie Philips and Staci Strobl in the chapter “Aren’t There Any 
Brown People in this World?" from the book Comic Book Crime: Truth, Justice, and the American Way, "Coupled with structural inequalities, the legitimate avenues of economic and social success of [B]lack men being in the realms of sports and music caused [B]lack men to seek control over their lives through physical strength and sex appeal forced to use their bodies to achieve success rather than their minds. This, in turn, led to American notions that [B]lack men had 'bodies not minds' and were even bodies out of control' (Philips and Strobl 171). This idea of Black bodies being out of control would supplement the notion that Buck Wild/Luke Cage's body is out of control, leaving Buck Wild/Luke Cage with an inability to think and only a desire to act on aggression. Buck Wild, like Cage, is all body and no brains.

Interestingly enough, in a dialogue box that would be the equivalent to a speaking inner conscious (or often referred to as indirect speech), we encounter Buck Wild's thought separated from the dialogue he speaks (also known as direct speech) while fighting. This inner monologue runs parallel to social commentary on the cultural criticism of stereotypical Black images. Buck Wild pontificates (while still kickin' ass over several panels) about “pimps in platform shoes, fat sloppy rag headed mammies..." (2). McDuffie is masterfully drawing references to the quality of Luke Cage's enemies that he has been critiqued for fighting. The "fat sloppy rag headed mammies" refers to foe Black Mariah and the pimps in platform allude to Big Ben, both stemming from Luke Cage's gallery of enemies.

Buck Wild ends his inner dialogue by reflecting on these images stating, "It ain't much, it ain't even good. But it might be all there is. And that's better than nothin' ain't” (3). McDuffie appears to be Signifying on the argument given by Luke Cage apologists who say that, although we did not have many Black superheroes, at least we have some sort of representation. Near the end, we are introduced to a Black female villain named Lysistrata Jones. Her name is a nod to 
the Greek play written by Aristophanes in which the main female protagonist Lysistrata uses the power of abstinence to bring about peace between two warring countries by convincing the wives of the soldiers to do the same (Mastin, "Lysistrata"). However, there is in peace in Lysistrata Jones's presence. Lysistrata Jones is presented in an afro, wearing brown hip-hugging bell bottoms, a tied-up green tube top, and platform shoes. By having both of these characters in the same room, the visual gives a concept that these figures are outdated. They seem to be stuck in the 70s visually but are in the contemporary time of the mid 1990s, a slap in the face to graphic narrative companies using outdated references in the guise of being trendy and current.

Lysistrata's weapon is called a "P-whip," which brainwashes those it touches or ensnares. There are a few implications for her weapon. On one hand, it is a Signification on Wonder Woman's lasso of truth that causes the apprehended to relinquish aggression and tell the truth. On the other hand, it could symbolize the empowerment of Black female sexuality that can tame the aggressive male. In this case, it connects the Black stereotypes of the Jezebel (hypersexual promiscuous woman) and the Buck offsetting each other in some sort of neutralizing cultural criticism connection. Meaning the Black Buck is defeated by the power of the Black woman's vagina. Lysistrata refers to Buck Wild in this confrontation as a "Big old Hunk of Buck" (4). Again, relegating the Black male (and in this instance female) body to one of a physical naturethe Black male body is than epidermilized (and burdened by) sexuality. David Royal, in the introduction essay to the MELUS journal focusing on diversity in graphic narrative, argues: Authors may expose, either overtly or through tacit implication, certain recognized or even unconscious prejudices held by them and/or their readers. In comics and graphic art there is always the all-too-real danger of negative stereotype and caricature, which strips others of any unique identity and 
dehumanizes by means of reductive iconography-the big noses, the bug eyes, the buck teeth, and the generally deformed features that have historically composed our visual discourse on the Other. (Royal 8)

Reverting back to the story line, Buck Wild is entrapped in Lysistrata's p-whip and becomes brainwashed. Additionally, Jeffrey A. Brown in Black Superheroes, Milestone Comics, and Their Fans acknowledges that in order for McDuffie to address the issue in this text he draws up the Blaxploitation stereotype through Buck Wild and Lysistrata Jones. Brown contends:

In this specific case, as with their entire line generally, it was clear that the folks at Milestone were wary of positioning their stories as anything more than good clean hero fun - in fear of being perceived as political rather than entertaining. But it is also clear that characters like Buck Wild and Lysistrata Jones operate as both a node to the troubled history of Black superheroes and as a point of reference against the Milestone characters can be read as reinvention of the heretofore dominant [B]lack superhero type. (Brown 163)

Continuing with the narrative, the focus of the Icon issue then switches to the Black female protagonist named Rocket who is standing on an adjacent rooftop and also having an inner dialogue about being 15 years old and pregnant. ${ }^{43}$ Rocket decides to take out her displaced anger by fighting crime and ends up infiltrating the same drug location where Buck Wild was previously engaged in combat. Rocket subdues the criminals and before she can beat a captured criminal mercilessly, Icon appears. While calming Rocket down and tying up foes, Icon is ambushed and attacked by the "p-whipped" Buck Wild. The punch knocks Icon outside of the

\footnotetext{
${ }^{43}$ One thing I noticed in the research is that McDuffie does an awesome job of incorporating social issues relevant to the Black community in his Milestone graphic narratives. This address of teen pregnancy is one of many examples.
} 
building. McDuffie uses this conflict as an opportunity to Signify more on the character of Luke Cage through a contrived dialogue by Buck Wild that confuses Icon and Rocket (see fig. 4.3).

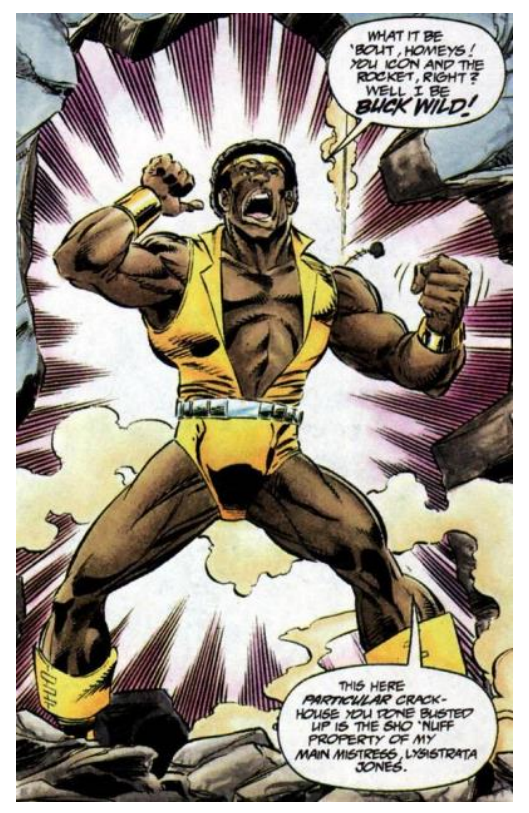

Fig. 4.3. Buck Wild's "groovy rant" from Icon Issue \#13(DC Comics, 1994)

McDuffie addresses the problematic dialogue of Luke Cage's speech through the critique of Buck Wild's language in an exchange between Icon and Rocket:

Icon: "His dialect is unfamiliar."

Rocket: "You telling me. Kinda sounds like Chester Himes meets Amos and Andy. I don't think its slang, though. I think its brain damage." $(19)^{44}$ Again, if the method of Signification is to parody text indirectly, McDuffie uses this situation to indirectly address the inauthentic voice and language perpetrated by the writers of the Luke Cage series and how the some members of the Black audience felt about it. For example, Black graphic narrative writer Michael Sales said, "There was a part of me that wanted to see someone rooted in my reality. And even though Luke Cage was supposed to be that because he was urban... it was corny" (Gayle, White Scripts and Black Supermen). Luke Cage readers have

\footnotetext{
${ }^{44}$ Dialogue is bolded to replicate text emphasis taken from the issue.
} 
reason to feel disconnected from the character because they will immediately recognize that his "damaged" language does not speak to them. In essence, Cage's face was Black, but his voice/dialogue was not. This conflict corroborates McDuffie's criticism about the origin of Cage's speech that was stated earlier. ${ }^{45}$

After the dialogue between Icon and Rocket, Buck Wild attacks Icon, but this time he is subdued by Icon. However, as Icon requests Buck Wild to yield, Icon is accosted by an angry crowd. It is here McDuffie own apprehension regarding authentic Black; the crowd thus mirrors the counter response to criticism of the Luke Cage character. The crowd, which is all Black, chastise Icon to leave Buck Wild alone. The crowd then begins to shout words like "he's one of the good guys," and "he let us pay him on installment" (23). McDuffie is alluding to Luke Cage's hero for hire premise. Then one of the antagonizing members of the crowd tells Icon to "Let go of him. He's the only hero we got" (23). The "we" that the crowd members refer to is the audience of Black graphic narrative readers who, again, decline criticism of Luke Cage character because he is the only representation of Black superheroism; especially since Cage's adventures take place in the "hood" of Harlem. Luke Cage is read as the representative of the lower-class urban community so an attack on him is an attack on them. This is the conundrum that the Luke Cage character creates in its criticism. Black graphic narrative historian William Foster is one of many reflecting on this problematic issue of representation: "We were just so pleased to see people like us, that the role they played was secondary to the fact that they were present at all. So, I think there's still kind of feeling present even today. Sometimes it is better than nothing. I mean, at least we're not totally invisible anymore" (Foster 64). I believe Foster understands the paradox Luke Cage represents but provides a different perspective on the character's importance, which, in this instance, is symbolized by the angry mob.

\footnotetext{
${ }^{45}$ As stated earlier in this essay in the introduction.
} 
Following this encounter between Icon, Rocket, and Buck Wild, Buck Wild hushes the crowd and (still under the submission of Icon) begins to share his origin story. McDuffie literally rewrites the origin of Luke Cage within the origin of Buck Wild. Buck Wild is falsely convicted for a crime he did not commit, but ends up plea-bargaining for a crime he did commit. ${ }^{46}$ While in prison, Buck Wild was abused by a racist prison guard and, in an effort to reduce his sentence, chose to participate in a prison experiment. The variation here is that in Luke Cage's origin story he agrees to participate in an experiment which focuses on electromagnetic cell regeneration in exchange for parole ${ }^{47}$, whereas in the Buck Wild origin narrative Buck Wild agrees to participate in a cryogenic experiment as a way of knocking off time. Here we can see that McDuffie is Signifyin(g) on the idea of Buck Wild losing time off his sentence by being frozen for a few years, which in essence does not reduce his time, but in fact stagnates his life in another way. The outcomes of the experiments vary, by these elements - Luke Cage escapes with super powers, but Buck Wild does not escape. He is left frozen with super powers and brain damage leaving his mind stuck in the 1970s. McDuffie continues to play on the idea of the Black Brute being all physical, but no intellect. McDuffie insinuates this condition of the Black superhero Cage trope has left this character retarded or mentally stagnant - a reflection of his image. Buck Wild concludes this tale by stating that he did not escape prison (unlike Luke Cage) and he got out a few weeks later on a weekend furlough program (25). McDuffie uses this opportunity to provide us with Buck Wild's full name "Buck Wild, Mercenary Man, Hero for Rent” and that he has been fighting evil for folks in the neighborhood for a fee (25). Again, McDuffie is alluding to the problematic issue of Luke Cage being a hero, but only for monetary gain.

\footnotetext{
${ }^{46}$ In the origin story of Luke Cage it is alluded to that he is already a street criminal before he is arrested and wrongfully convicted. McDuffie is spoofing this in the retelling.

${ }^{47}$ Luke Cage, Hero for Hire \#1 (Marvel Comics, 1972)
} 
Resolving their differences, Buck Wild goes back to capture Lysistrata Jones, but with Icon and Rocket in accompaniment. However, Buck Wild's irrationality to attack without a plan of action causes him to be "p-whipped" again and also allows for Icon to be captured. Again, McDuffie emphasizes the Buck/Cage action without an intellectual angle, but it causes the Icon character to be trapped as well suggesting that characterization or association (i.e. Icon is endangered by associating himself with Buck Wild) matters. However, Jones is neutralized by Rocket, and in the last page of this graphic narrative, Buck Wild thanks Rocket and Icon for their assistance that culminates in an insightful exchange:

Buck Wild: Lookin' at you [Icon and Rocket] makes me think mebbe [sic] if I hadn't been frozen, I wouldn't have to be like this. Mebbe I can still be more than what I is now.

Rocket: I wouldn't count on it, Buck. You are what you is. And 1972 was a long time ago. Maybe it's just time to move on.

Rocket's statement about "moving on" refers to how the Buck Wild/Luke Cage character has not evolved beyond his 1972 characterization and that it is time for us to move past this fraught symbolization into something more current and refined. The best way to do that in a story is kill a character in order to evolve the other characters. We can see this foreshadowing occur visually between Rocket, Icon, and Buck Wild in this last scene. Rocket and Icon represent the new image of Blackness and Buck Wild is representative of the past. To complete the retcon signification process, McDuffie must "kill" the old Black graphic narrative stereotype in order for us to embrace new and complex images.

Professor Rebecca Wanzo in "It’s a Hero? Black Comics and Satirizing Subjection" utilizes the concept of critical race humor (a combination of critical race theory and humor) as 
an effective method of analyzing McDuffie's Signification process. Wanzo describes critical race humor as "a primary mode of intellectual intervention into traditional nationalist narratives, and their texts also draw attention to how critical humor can be informed by the affects other than amusement. In the midst of one-liners and punch lines, these are creations of hope and desire, willing into being and proliferation that which was previously unimaginable" (Wanzo 316). Here humor is the tool used by the writer that explicitly challenge previous norms and representation that is indicative of what Wanzo describes as "melancholia." Wanzo also ties this into the concept of racial melancholia, which she derives from Anne Anlin Cheng conversation of racial melancholia (316). Melancholia is where "[b]oth consumers and objects of racial stereotypes are often 'stuck' with the history of these representations, constantly negotiating images that are culturally imprinted. Those who attempt to produce new models of [B]lack bodies are often burdened by a history of stereotype, particularly in genres that have never imagined them as anything other than that" (Wanzo 316). What Wanzo is referring to in this frozen space is often linked to the inability to escape previous cultural signifiers of race. One is often tied to previous cultural representation that proceeds them. In this case, McDuffie, recognizing that the Luke Cage character precedes his Icon character/s complex world, decides to embrace the melancholia and uses humor or critical race humor as a way to confront and destroy the past so that future may be born. This concept is interesting because Black people in popular culture are far too often relegated to hypervisual stereotypical affect, but still manage to use humor as a tool of resistance. McDuffie Signifies the Luke Cage story as preliminary retcon approach for the purpose of rewriting and attacking the Buck/Luke Cage stereotype that later takes place in Icon \#30 "The Buck Passes" (DC Comics, 1995) to move past the racial melancholia Buck Wild represents. 


\section{The Death of a Damn Fool}

Prior to Icon \#30 “The Buck Passes," Buck Wild steps in for Icon while he is away on another mission. In the process of standing in for Icon, Buck Wild battles Icon's archenemy Oblivion and is mortally wounded ${ }^{48}$. In an interesting dynamic, Buck Wild imitates Icon, but is destroyed (by the villain Oblivion) because he is not as powerful as the authentic version of Icon that he is trying to mimic. Incidentally, Buck Wild passes away from his wounds ${ }^{49}$ and sets the stage for a larger platform of signification in Icon \#30 - the funeral. McDuffie seems to be less accusatory in his satirical address of the Luke Cage doppelgänger character in this narrative. In this issue, McDuffie has a funeral for the fallen Buck Wild where even here nothing goes according to plan. Taking place in a Black Baptist church setting, a preacher begins to reflect on the life of Buck Wild, which offers another opportunity for McDuffie to Signify on the past ways we have tended to marvel about our superheroes. During the eulogy, the preacher delivers a quasi-sermon about all of the heroic traits that Buck Wild did not have (immoral, irrational, not charitable, etc.). When the preacher finally gets to the point of mentioning the good that this character has done there is complete silence. One could take this blank expression to mean that upon reflection of Cage's character there is nothing good to say. However, Icon decides to intervene and provide kinder words in respect to the fallen "Buck." Icon's speech symbolizes a more reflective critique of Luke Cage with the Signification in addressing the mourners in the church. Icon, mused by McDuffie, says it all:

My name is Icon, and I have come here today to pay respect. Because Buck Wild, for all of his faults, is worthy of it. I am considered by many to be a hero, an example of possibility and achievement. And recently, Buck has patterned himself after me. But

\footnotetext{
${ }^{48}$ Icon \#26 "Testify" (DC Comics, 1995)

${ }^{49}$ Icon \#29 "Future Shock" (DC Comics, 1995)
} 
years before I arrived, Buck Wild was already here fighting the good fight. Although we may, from our current perspective, have found him crude and ill-informed, we cannot deny his importance. Intentions count as much as actions. And Buck was nothing if not well-intended...Because whatever else he was, he was a hero. A hero for those of us who had no heroes. Were it not for him, we wouldn't be here today. (9-10)

Icon becomes the messenger, delivering McDuffie's unfiltered feelings on this complicated character. Icon now presents a more "coming to terms" with a love/hate relationship for the Luke Cage character. Brown postulates that "[i]n a eulogy for a comics era, thinly disguised as a eulogy for a specific character, Icon's speech sums up the attitudes of both the Milestone creators and many of their fans" (Brown 164). Icon's eulogy attempts to close the door on the stereotypical past of Black-male superheroes to make way for a new era of superheroes that Milestone Comics' Icon is obligated to represent, while acknowledging the historical importance of this character in the lineage of Black representation in graphic narratives.

However, after an eloquent analysis, McDuffie ramps up the Signification by having past metafictional criminals (created specifically for this text) pay their respects to the dead Buck Wild. The first is Lysistrata Jones who reflects on her first encounter with Buck Wild. In this flashback, Jones describes her first attempt to "p-whip" Buck Wild, but he escaped using a formula "created by a white man smarter than him" (15) that transformed him into Buck Goliath. The Signification occurring here is the embodiment of Buck Wild as conduit to address Marvel Comics' superhero "Black Goliath," which was often criticized for being a rehash of "Ant-Man," but a Black version whose series only lasted for five issues. 
Our next villain, paying his respect to Buck Wild, is a Julian Bond-type pimp by the name of "Sweet Stick Mike. ${ }^{50 "}$ In this flashback, Sweet Stick Mike has his flock of "ho hordes" attacking an old superhero dressed in a red, white and blue outfit named "The Patriot." Clearly, this is a satirical reference to Marvel's Captain America (old wartime superhero frozen after the fight with the Nazis only to be resurrected in contemporary times to be a superhero) ${ }^{51}$, but it is also in this scenario that Buck Wild appears as his faithful sidekick "Jim Crow." The Jim Crow character serves as dual-layer symbolism. It refers to the time of segregation where White actors in Black face portrayed minstrels and laws that hindered the progressive life of African Americans post- Civil War. Jim Crow is also an apparent reference to Captain America's longtime partner "The Falcon" who is also problematic due to his subsidiary role as a sidekick to his White superhero counterpart. In one of the panels during this flashback McDuffie has Jim Crow say to Patriot "You okay, boss man?" to which the Patriot responds "You're my best friend" (21). This commentary refers to the often-criticized paternalistic attitude Captain America portrayed to the Falcon character as being "the man standing next to the man" (Nama 67). In reference to this relationship, columnist Matt Seitz describes the stereotypical image of Blacks in movies echoing McDuffie's point about Falcon and Captain America's relationship: Even though the movies take pains to insist that the African-American character is as much a flesh-and-blood person as the [W]hite hero, the relationship is that of a master and servant. And not a real servant, either: one that really, truly lives to serve, has no life to speak of beyond his service to Da Man, and never seems to trouble himself with doubts about the cause to which he's devoting his time and energy. (Seitz, “The Offensive Movie Cliché That Won't Die").

\footnotetext{
${ }^{50}$ Another allusion to the hypersexualized imagery of the Black-male body.

${ }^{51}$ I consider this ironic to referencing Buck Wild's failed frozen experiment origin that gives him brain damage.
} 
The point Seitz makes here is simple. Although Falcon is considered to be the first AfricanAmerican superhero, his status was negated to secondary hero by the reliance and connection of Captain America.

The next villain to speak at Buck Wild's funeral is Cockroach Andy (who is a Signification on the villain Cockroach Hamilton from Luke Cage's early narratives). Cockroach Andy gives a brief speech about his encounter with Buck Wild as the hero, Buck Lightning. McDuffie draws parallels to DC Comics' Black Lightning here (DC's Comic first Black superhero). Nama elaborates on the importance of Black Lightning:

Black Lightning symbolized a critique of [B]lack Americans that had joined the American middle class in the wake of the civil rights and Black Power movements but abandoned their less fortunate brethren still stranded in [B]lack ghettos across America...Ultimately, Black Lightning was a black superhero that symbolically stressed self-reliance, critiqued tokenism, and most importantly symbolized how African Americans were simultaneously insiders and outsiders in American society. (26) This scenario is particularly brief to match the limited series Black Lightning had in the 1970s until he was relegated to what creator of Black Lightning, Tony Isabella, so eloquently states "as Batman's bitch" (Gayle, White Scripts and Black Supermen). We can assert that Isabella's disdain addresses the silencing of more complex and intelligent Black superheroes through reducing their role to secondary assistants of their popular White counterparts, as stated before with the Captain America and Falcon/Patriot and Jim Crow comparison.

Cockroach is abruptly interrupted by another signified character named KingFish (a parody of the evil villain Kingpin from the Daredevil/ Marvel universe). KingFish blurts out a "Buck can't die" (25) and casts a jewel into Buck Wild's casket that transforms him from Buck 
Wild to Buck Voodoo (signifying on Brother Voodoo from the Marvel universe ${ }^{52}$ ). In this brief resurrection, Buck Wild/Buck Voodoo takes over the mind of Kingfish and causes him to jump out the church window, but he does not die since it is the first floor. It is here that Buck's girlfriend Darniece ${ }^{53}$, interrupts an impromptu conflict between Buck and Icon and tells him "I didn't want to believe it, Buck, but you're dead. You don't belong here. You belong in a grave. I love you, Buck, but your time has passed" (28). Following this speech, Buck Wild removes the jewel implanted in his chest, falls to the ground and lets out one last word ... "Christmas" (29). This "Christmas" is a direct correlation to Luke Cage's signature phrase "Sweet Christmas." In the last panel of the graphic narrative, Icon provides this insightful dialogue regarding Buck Wild, "And for all of his failures. He died trying to do what was right. Let us hope that when our day is done, history remembers us as kindly as it remembers him" (30). McDuffie has, in a metafictional way, killed the "Buck" in graphic narrative. Yet, in pointing out his "time has passed" McDuffie provides self-reflective commentary on his own characters hoping that they too are not villainized or misconstrued as objects of inauthenticity and criticism when Icon hopes "history remembers us as kindly as it remembers him."

Not only does McDuffie use the funeral and Buck Wild as spaces of Signification, critical race humor, and retconning Luke Cage, they also serve to criticize other Black graphic narratives created in the 1970s (Falcon, Brother Voodoo, Black Lightning, and Black Goliath). McDuffie uses the platform of the Icon graphic narrative to question the authenticity of the Luke Cage character, critique, and recognize its temporal importance as it relates to Black graphic narrative superheroes. He ultimately seizes an opportunity to kill a stereotype that often pervades popular depictions of African Americans in this predominately White world of the graphic narrative - the

\footnotetext{
${ }^{52}$ Now known as Doctor Voodoo.

${ }^{53}$ Buck Wild develops a relation with Darniece while impersonating Icon.
} 
Buck. McDuffie utilizes Signification to dissipate racial melancholia of the Luke Cage character by remixing his origin into Buck Wild in order to destroy it and other White-created Black superheroes psychologically stuck in time — a time that has passed.

\section{A Hero Not For Hire, But To Inspire}

On September 30, 2016, Netflix released the television show Marvel's Luke Cage (written and produced by Cheo Hodari Coker). This version of Luke Cage (played by Mike Colter) locates him within current Harlem, New York (2016) in the midst of gentrification, gang violence, and political corruption (see fig. 4). Unlike the previous reiteration of Luke Cage's character, he is a reluctant hero placed in the position of heroism by his mentor and wise guide, Pops (played by Frankie Faison). Journalist Rios quotes Coker as he explains the show's essence: "Luke Cage is what showrunner Cheo Hodari Coker describes as a modern hip-hop western steeped in the mix of grittiness and elegance that defined New York City hip-hop during the 1990s." (Edwin Rios, "Netflix's Luke Cage Is the Superhero America Needs Right Now"). The new version of Luke Cage has all the tenants of Black aesthetics and then some in the representation of the barbershop as a space of intellectual and cultural discourse, music, and strong Black characters. Cage is grounded in hip-hop culture as every episode title shares the title of a Gang Starr (classic Hip-Hop group) song. The popularity of the Netflix series was so in demand that it actually crashed Netflix in the US, Ireland, and UK ("Marvel's Luke Cage is so popular it actually caused Netflix to crash"). Intellectually, in the second episode "Codes of the Street" there is a scene where Luke Cage and several other characters engage in a critical discourse regarding African-American literature within the barbershop. This scene would eventually lead writer Tara Betts to create "The Luke Cage Syllabus" -a reading list dedicated to 
the literary easter eggs dropped within the Netflix series. (Betts, “The Luke Cage Syllabus”). Luke Cage is unapologetically Black in its representation.

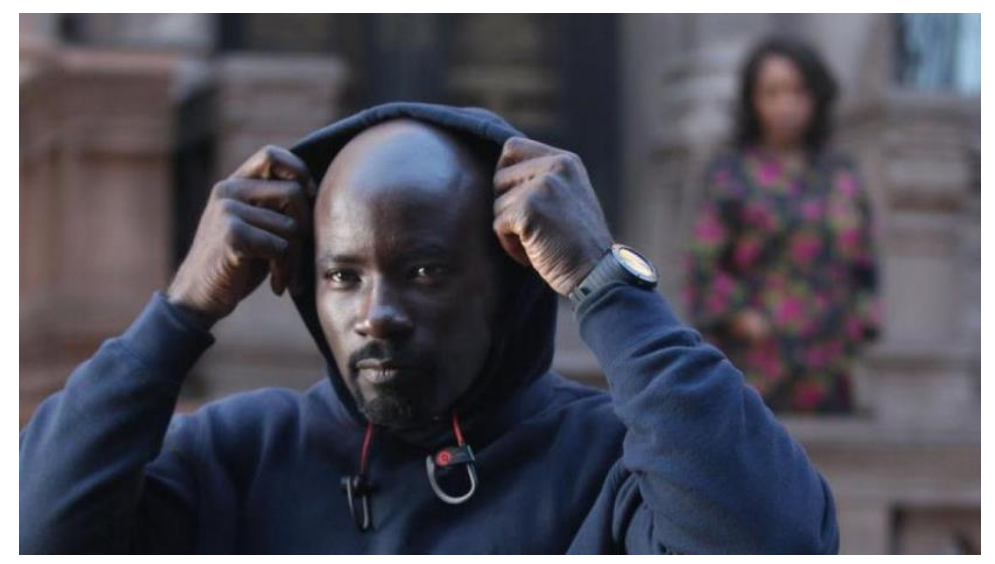

Fig. 4.4. Mike Colter as Luke Cage (Den of Geeks, 2016)

However, what makes this version of Luke Cage both empowering and problematic is Coker's ability to Signify the meaning of the character. Yet, this complexity benefits the remixing of the Cage through three different tenants- the writing of the show, cultural politics presented, and the signification of Cage's costume. As Cage is brought into the new era of Black cultural politics, this character is retconned with socio-political contexts and calls attention to multi-complex issues within the Black community that removes it from the caricatures of its character's origin. Through Cage, Coker revises what the hoodie signifies in relation to the Black male body, but at the cost of conservative and respectability politics.

What makes this show particularly powerful is that the main cast consist of primarily Black actors and writers. In an interview with Edwin Vios for MotherJones.com, director Coker explains his rationale for the cultural makeup of the writing staff while commenting on the absence of Black writers and writers of color in large budget productions:

The reason the numbers are so low is because so few writers of color have gotten opportunities in the past. Part of what it is is exposure. It's not like abject racism as much 
as it is that everybody looks or thinks a certain way - that there's no diversity in opinion. That's why you want a diverse writers' room: You want to think about things that you might not have thought of before. That's all it is, honestly. This story is a black story and yes, having people familiar with the African American experience is helpful, but the fact of the matter is, the writers, because of the shows they worked on and their experiences, were perfect for this show... That's the thing: We realize now we don't shirk from the politics of the show or the story that we are telling... That's always been the power of comic books: You're able to talk about deep, complex, human truths, but when you shroud it with superpowers, you do it in a way where people don't bring their politics into it. Through this show, we're able to talk about a lot of things. Don't get it twisted. We're a comic-book show, and we're a fun, funky-ass show. (Rios, "Netflix's Luke Cage Is the Superhero America Needs Right Now”)

Although Luke Cage was originally written and drawn by White writers and authors, Coker decided to make this show more culturally relevant by using the lens of a writing staff containing six Black writers (four male and two female) and two White writers (males).

In an Huffington Post interview with Joshua Ostroff, actor Mike Colter (who plays the main character Luke Cage), feels that nothing has particular changed with the superhero. Colter states, "I don't think Luke Cage as a superhero is something that has changed dramatically from the '70s to now. He's a black man going through the same thing as other people of colour, it's just that he has superpowers" (quoted in Ostroff, "Marvel's 'New' Superhero is a Black Man in A Hoodie"). Later in the same article director Coker poses this question, after watching his children's response to seeing Black superhero character Falcon appear on screen in Marvel's 2014 film Captain America: Winter Soldier, "What is it like for young [B]lack kids, from an 
imagination standpoint, to see people who look like them doing important things?" (quoted in Ostroff, "Marvel's 'New' Superhero is a Black Man in A Hoodie"). This inquisition is at best, interesting and problematic. Let us consider the positive aspects of Cage's on-screen appearance that adds to the visual importance of seeing Falcon, War Machine, and Black Panther finally make their way to a mainstream audience. Nonetheless, I disagree with Colter's comment that nothing has changed with this character. Cage's conservative politics is a new take on being a hero for all the right reasons, whereas the original version of Luke Cage needed funds to fight aka "no dough, no hero."

For a character influenced by the current social protest movements, Netflix's version of Luke Cage lacks that liberal context to make the protest more effective. Writer Justin Charity, in the article "Luke Cage, Black Conservative," argues "For a character that series creator Cheo Coker has explicitly linked to the \#BlackLivesMatter movement, Cage spouts some surprisingly conservative undertones and mantras. He speaks like a man who has rather bitterly entered middle age... On his own, Cage is a reclusive killjoy who is astoundingly slow to solve or discover anything" (Charity, "Luke Cage, Black Conservative). This comment presents a paradox. If Luke Cage's character is a part of contemporary social issues, then why does this character also contribute to the cultural hegemony of politics? Let me explain, this version of Luke Cage, although admirably portrayed in this Netflix also comes across as the dignified safe Negro - one who rarely speaks and preaches self-dignity. He is Sidney Poitier with super powers.

We can also see the conservative ideology play out in the semiotics of the Pop's swear jar. For those unfamiliar with a swear jar its' intent is to police the language of the person by assigning a fine for every time someone uses profanity in order to keep language "respectful." 
We can note that Cage's character is all about language and manages to only curse one time during the whole show since his language must be a conservative act. Sometimes watching the show is like watching a bulletproof Booker T. Washington performing superhero acts. Although Cage's conservativism does not rely on an Atlanta compromise, he does use the combination of his five fingers to form a fist of persuasion when it comes to saving dignity and being the better person. The conundrum this character presents is in contrast with his own politics. In episode 9, "DWYCK" Cage (a fugitive from the law at this point of the series) actually attacks cops to flee from being arrested or reimprisoned since he is a fugitive under his real name Carl Lucas. However, it is here where he contradicts his own respectability politics in order to avoid arrest. We can read this as a protest of self-preservation (a common trope in superhero narratives). The narrative being that superheroes act outside of a judicial system they cannot be apprehended within that system because it removes their ability to perform their superhero tasks. This idea is repeated through multiple dialogue with Cage and other characters on the show. This ideology eventually influences Detective Misty Knight (played by Simone Missack) to adopt the same distrust, which ultimately leads to the death of a key witness who may or may not have been safe in police custody. These scenes are non-coincidently commentary on the trust of the judicial system by people of color-specifically Black people.

We should also consider that the Netflix version of Luke Cage is also concerned with his own metanarrative Signification. Similar to the graphic narrative origin story, Cage is trying to deny his original name Carl Lucas in order to reinvent a free identity in Luke Cage. Carl Lucas is the criminal framed for a crime he did not commit in the graphic narrative, but in the Netflix series he is a preacher's son and former cop who is framed for a crime he did not commit. Both version of Cage experience the abuse and reluctant medical testing in prison. Both versions 
escape prisons and take on the moniker "Luke Cage." However, their paths diverge from here. The graphic narrative version of Luke Cage pursues financial gain for the exchange of his heroism, while Netflix's Luke Cage rather be in the shadows as he is more aware of his fugitive past and choosing when and where to involve himself when it comes to relationships or heroic deeds. These are issues originally absent from the previous version of Luke Cage.

\section{Hoodie and Hopes}

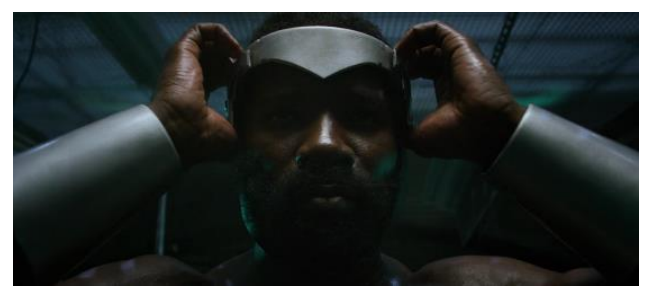

Fig. 4.5. Luke Cage breaks out the experimental chamber. Shows wrist chains and tiara. ${ }^{54}$ Episode 4, "Step into the Arena" presents us with the Netflix version of Luke Cage's origin story, but also a moment of Signification and retcon. After Luke Cage emerges from the experimental chamber we are treated to an Easter egg (hidden connection to other material) of him with wrist bracelets and a helmet similar to the "tiara" Cage once wore in the graphic narrative (see fig. 4.5). Cage breaks out of prison and eventually finds his way to a backyard and snatches a yellow-dress shirt and jeans off a nearby laundry line. He then dresses in the stolen garment and uses his chain to support his jeans (see fig. 4.6). Once dressed, he walks past a car window and catches a glimpse of himself in the reflection of the window. Seeing himself, Cage says "You look like a damn fool" and takes off the helmet (see fig. 4.7) ("Step into the Arena," 2016). When one sees this scene you would think that this is just an isolated commentary to the moment. However, Coker and his writing staff Signify on the original costume and leads to embracing a morbid cultural relic as an alternative costume for Cage.

\footnotetext{
${ }^{54}$ Figures 5, 6, and 7 are taken from the episode "Step into the Arena" (Netflix 2016)
} 


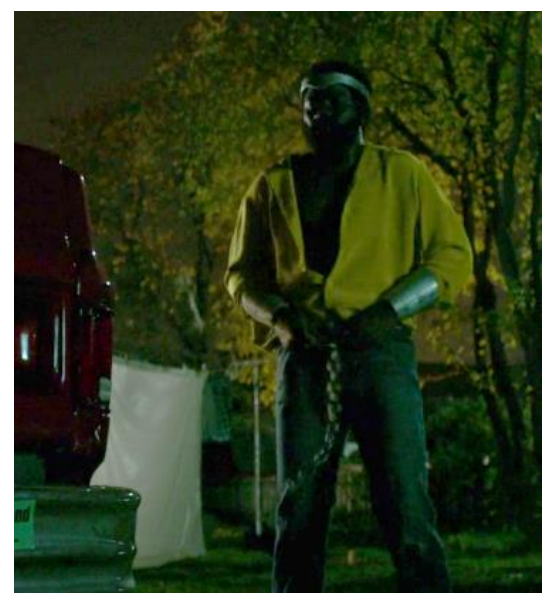

Fig. 4.6. Luke Cage pays homage to his original costume.

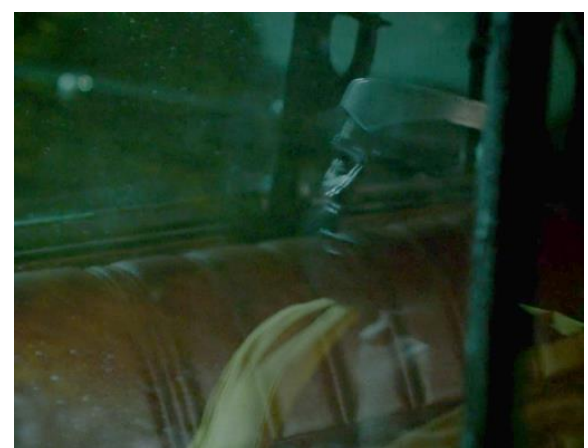

Fig. 4.7. Luke Cage sees his reflection in the car and insults himself.

Cage's rejects this previous outfit through insult and metacommentary so that we can embrace the hoodie as the new superhero costume for a contemporary age. Just as McDuffie does with Buck Wild character, Coker uses this brief meta-critique about Cage's clothes so the hoodie can become Luke Cage's new costume. He rewrites Luke Cage's previous costume while simultaneously resignifying what the hoodie means on the Black-male body. Although I have addressed the issue with Cage's costume earlier in this chapter, this particular Signification serves a conduit of rewriting the costume of Cage as something more culturally relevant - the hoodie. The hoodie is often marred with negative connation when it comes to the Black body. Some argue that the hoodie is the rapper's superhero cape when involved in a cypher; the hoodie is cover for a rainy day. However, for others, the hoodie symbolizes fear and mystery. The inability to read the entire Black-male body hidden under the often cotton-knitted hood. It carries 
the burden of criminality when adorned on the Black body. This burden was felt by the death of Trayvon Martin (see fig. 8) who wore a hoodie on his way home from the store to get some snacks for his younger sibling. It was this hoodie and burden of his Black skin, which caused George Zimmerman to enact a violent act of murder by shooting Trayvon Martin by supposition of suspicion. Zimmerman read Martin's body as a criminal text. Although Zimmerman was acquitted of all charges, the Black community still struggles with the weight of injustice in this particular case. Maybe the new Cage has a point about not trusting the police.

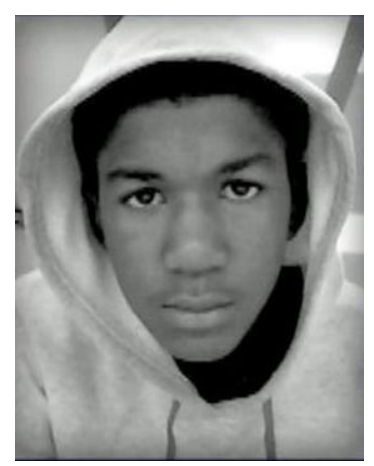

Fig. 4.8. Picture of Trayvon Martin in a hoodie that would become symbolic of racial protest. The hoodie implies reasonable doubt or guilt through debates brought forth by Dallas Mavericks owner Mark Cuban, Fox News correspondent Geraldo Rivera, and even sports network anchors such as Stephen A. Smith in on-air debate with Black intellectual Michael Eric Dyson. There are always questions on how clothing signifies the Black body as a threat or safety. However, all one has to do is look at pictures of lynching and see the criminalized Black body strung high in three-piece suits whose necks were broken by the burden of racial bondage and gravity of prejudice. Yet, who knew the hoodie would become a sight of cultural politics, but more importantly a new superhero costume. When Colter is asked about the purpose of the hoodie, he explicitly states, "It's a nod to Trayvon, no question... Trayvon Martin and people like him. People like Jordan Davis, a kid who was shot because of the perception that he was a danger. When you're a black man in a hoodie all of a sudden you're a criminal" (quoted in 
Ostroff, “Marvel's 'New' Superhero is a Black Man in A Hoodie”). Director Coker also makes a point to show that the hoodie is now symbolic for superheroes. In the article "Luke Cage and the Year Marvel Finally Reckoned with Its Black Audience,” journalist Joanna Robinson articulates Coker's thoughts regarding the hoodie: “Coker points out that Luke's signature hoodie—which is what passes for a superhero's cape and a cowl in this series - is as much an homage to hip-hop as it is to Trayvon Martin" (Robinson, "Luke Cage and the Year Marvel Finally Reckoned with Its Black Audience"). We can derive from this statement that the hoodie has and maintains multiple connotations. More importantly, the hoodie now signifies superheroism by the way of Luke Cage, memorialization of those unjustifiably gunned down by perceived criminality, and street attire personified through hip-hop music. Whereas Cage's original Blaxploitation-based costume is composed of a tiara, yellow blouse, leggings, and wrist cuffs, the hoodie retcons Cage's purpose and represents a more realistic depiction of Black life. No longer has a piecemeal outfit, Luke Cage's hoodie signifies hope and is representative that not only can anyone be a victim/villain, but a hero regardless of what they visually exhibit. Coker uses the site of Cage's hoodie as a reclamation of identity and freedom of dress.

Episode 12, "Soliloquy of Chaos" also emphasizes the importance of the hoodie. Here Cage intervenes in a corner store robbery that leads to an interesting event. The owner, after the robbery, then capitalizes on Cage's heroism by selling hoodies riddled with holes to consumers wear. Afterwards we encounter a montage of various Black males wearing the commodified symbol causing the police distress because they cannot pinpoint who is actually Luke Cage. This scene also shows Black males being celebratory when engaging the police as a show of possible “invincibility" ("Soliloquy of Chaos," 2016). On one hand, this scene is quite empowering since Cage has now become a symbol of hope for the Black male body whose subjectivation is often 
marked as one of hypermasculinity, criminality, and danger. On the other hand, it is important to note that now Cage's hoodie has become a hot "commodity" and this symbolism of support (via the hoodie) is now a commodified garment. It makes one wonder if Coker is making commentary on how religious or political symbols are often marred through their fiscal attachment. Whereas a political symbol is based in freedom of speech or purpose, it can also serve as marketing ploy that makes the revolution profitable. Here one can assert that cultural politics of Cage's costume has now become more profitable before since he can now be more closely tied to the Black perspective. In any case, Netflix's Luke Cage is unapologetic in its symbolism of the hoodie, but turns this hoodie into Cage's costume (see fig. 3.9). A costume that is contemporary and reflective of the holes that signify the bullets that have penetrated Black bodies.

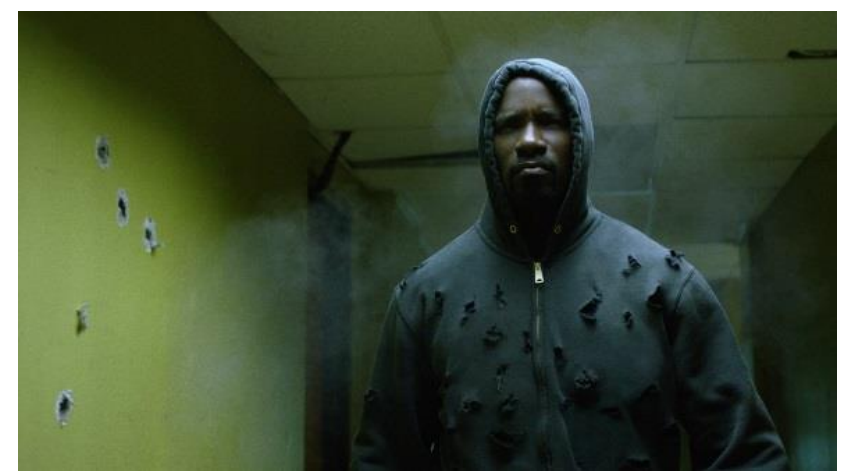

Fig. 4.9. Luke Cage's hoodie as costume/symbol (iMDB, 2016)

\section{The Outro}

In a discourse where fiction is inspired by appropriation of other visual or artistic mediums, McDuffie uses his metafictional character based on Luke Cage to embody his cultural criticism of the Black superhero. McDuffie's signification provides an astute commentary of what would happen if we could rewrite our images in graphic narratives. Coker's retcon portrayal of Luke Cage revises the stereotypical characters that often poorly emulate our culture as a luminal projection to mass culture. These acts of Signification make us question how we 
look at our own images and attack them. Although some of these Black superheroes are generic doppelgängers for their White counterparts, Black graphic narrative superheroes Signify on themselves and engage in racial dialogues among themselves. This Signification also takes place at the level of the author in which race plays a part in the voicing of the character, meaning there is a double talk insinuated by White authors voicing and drawing Black characters representing ideological thoughts of culture in an artistic voyeurism.

Luke Cage is a complex figure; he represents the evolutionary dynamic of growth in contemporary Black characters. Originally cultivated to commodify a market of its readers through the symmetrical depiction of Blaxploitation movies, Cage was trying to accommodate the Black audiences. Put simply, if Black audiences were going to Blaxploitation as a way of living out their fantasy, then why couldn't Luke Cage represent to viewers the same in a graphic narrative format? The most questionable concerns regarding Luke Cage's representation were his felonious origin, Chester Himes-inspired "authentic" Black dialogue, and less than inspired heroic feats in the "hood" to pay the bills. If the purpose of fantasy is to escape reality, why would you want to live cathartically through a hero who is struggling financially and living freelance job to job? Given the context of Luke Cage's creation, he was something when we ultimately had little representation in graphic narratives (sans Black Panther who is an Africanbased graphic narrative superhero, so there is a diasporic connection there). Cage provided a space in which Black children could see themselves - even if it was under the guise as a hustler "hero for hire." One can argue that this idea is similar to enamored fans of rappers whose lyrics reflect avarice, misogamy, and criminality. However, as Icon emphasized in his eulogy for Buck Wild, that time has passed. 
Fortunately for us, Luke Cage has to no longer do something heroically strange for some change, but it does cause us to question was this evolution predicated on McDuffie's bold criticism of Luke Cage in Buck Wild? Why did Coker need to revise this character to make it more "authentic?" If so, McDuffie has intentionally murdered the monolithic Buck narrative for contemporary complex Black superheroes to arise. Dauphin asserts the mentality of contemporary Black graphic narrative writers and authors here: "The new school of black comic makers wants that redemption now. Taking all advantage of their own years as fans and assistants, as well as of a cultural moment when "black-controlled" is a sure sales pitch, the creative types at these companies want to rewrite all those early characters" (Dauphin 35). This revision is evident in Coker's version of Luke Cage now that Black writers are getting "a seat at the table." The Buck Wild character in Milestone Comics' Icon series is a Signifier for the change that "manages to pay tribute and mark the end of an era that has haunted Black comics for decade" (Brown 164). Prior to the introduction of his Blaxploitation themed parody, Milestone Comics wanted to reinvent the Black image in graphic narratives and with this signification of the Luke Cage we see it manifest in a retcon-like fashion in an attempt to rehash the current stereotypes of Black superheroes (164).

For all intents and purposes, Luke Cage as his name signifies, was trapped in his own stereotype; caged by impenetrable skin his Buck trope fixed. Recently, Cage has evolved into a leader of an Avengers group; married to a White female superheroine named Jessica Jones, has a bi-racial daughter, and now fights altruistically in the Marvel universe. Cage has finally morphed to reflect contemporary ideologies. There is still something worthwhile about him. Considering that we are living in an age where young Black males are being assaulted and killed by either the police or other young Black youth, we could use the attributes of a hero like Luke Cage (sans the 
mercenary ideology). In an online website called Comic Book Resources, Joseph Illidge writes this in a blog entry called "Real Life Proves Why Luke Cage Endures":

There are Black men who are wealthy, powerful, formidable and/or dangerous. They can affect change undreamt of by their parents, and their parents' parents. Their children will be able to change the world in ways we can intuit and others we can barely begin to try and predict. But a bullet can rip through their flesh and their future with no effort whatsoever. And so we look at Luke Cage, a man who gets shot on a regular basis, whose body language is such that he is expecting to be shot at, prepared for the impact -because he knows he can take it [Figure 4]. Fantasy is connected to fears superficial and deep, and our heroes represent what we can be, what we hope to be, and sometimes what we can never be. And maybe, in the subconscious of the uni-mind of Marvel Comics, is the understanding that Luke Cage may unfortunately always be a relevant fantasy idea for the Black man (Illidge, "Real Life Proves Why Luke Cage Endures")

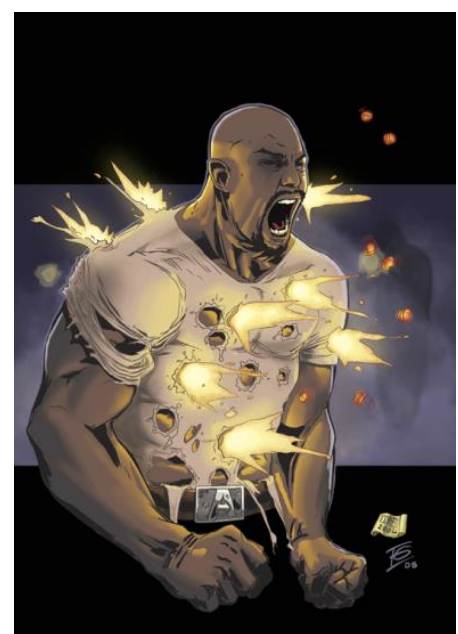

Fig. 4.10. Luke Cage absorbing gunfire (Comic Vine, 2014)

Illidge follows up this prose by listing the dates for the deaths of Trayvon Martin, Jonathan Ferrell, and Michael Brown (Black young men killed through suspicious policing practices) followed by the Netflix series premiere date for Luke Cage. Here, Illidge suggests that desirable 
superhero traits of Cage are still relevant to a generation of youth suffering from violence. Even as I type this, I reflect on the recent death of a twelve-year-old boy by the name of Tamir Rice, killed by police mistaking his fictional gun for a real one - a BB gun sold at Wal-Mart created to appear as an authentic replica of violence. Tamir's gun, because of its similarity to stereotypes of Black male and female images of criminality, has contributed to the Western ideology of being mistaken as the real thing. Maybe Tamir, like his fictional gun, thought this was a form of protection from the ills of the world that made him felt invincible. The color of his skin said otherwise. Maybe Tamir believed he was Luke Cage, but reality reminded him of the stereotype where young Black males are stigmatized for just being black? Hip-hop rap icon Method Man, in his guest appearance as himself on the Netflix series Luke Cage, provided a metacommentary on Luke Cage's significance to the community. He states, "It's something powerful about seeing a Black man bulletproof and unafraid" ("Soliloquy of Chaos") and proceeds to spit a freestyle called "Bulletproof Love" in dedication to Luke Cage on a fictitious rendition of Sway's Sirius XM The Wake Up Show. Although McDuffie and Coker has managed to rewrite a literary narrative so strongly woven into the fabric of this country, imagine if we could retcon our image? Maybe if we (Black men and women) could retcon our image from the Jim Crow era we could rewrite our narrative from being seen as buck wild to respected icons. Icons no longer afraid of bullets and proof that we are more than static images stuck in the psyche of popular culture. 


\title{
CHAPTER V: JUST “US” LEAGUE: RACIALIZED EXCLUSION IN THE RECRUITMENT \\ OF BLACK LIGHTNING INTO THE JUSTICE LEAGUE OF AMERICA
}

\begin{abstract}
Whether racial/ethnic minorities... are perceived negatively, given less status in society, and confined to existing on the margins of our social cultural, political, and economic systems. The result is often exclusion from the mainstream of life in our society, unequal treatment, and social injustice. The inferior status and treatment associated with marginality are constant, continuing, and cumulative experiences of socially devalued groups.

Derald Wing Sue
\end{abstract}

Continuing the argument that Black male superheroes are burdened by Blackness and cultural politics, this chapter examines what transpires when well-meaning purveyors impose their systemic structure of oppression on a person of color in graphic narratives. That person of color, in this case, is Black male superhero Black Lightning. With the release of Black Lightning, created by Tony Isabella with Trevor Von Eeden ${ }^{55}$ in 1977, DC Comics set forth to establish a Black superhero who would redefine expectations of what a Black character should be. Previous Black graphic narrative superhero predecessors, such as Black Panther and Luke Cage (both created by Marvel Comics), lacked in connecting with the Black audience by either dialect choices and/or origins. On one hand, Marvel created Black Panther as a counternarrative to colonial invasion in Africa, but his character was still plagued by totemic, racialized commodification, and "brute" associated stereotypes. On the other hand, Luke Cage's creation was a response to Blaxploitation film heroes, but it quickly became affixed with corny dialogue (phrases like "Sweet Christmas") and suffered from the hero-for-hire attribute that goes against

\footnotetext{
${ }^{55}$ A Black graphic narrative artist. The interesting notion here that he Von Eeden drew the body, but Isabella voiced the character.
} 
altruistic principles established by popular White superheroes since he only fought villains for money. ${ }^{56}$ In essence there was a gap to be filled — enter Black Lightning.

Isabella also created Black Lightning as an ode to his Black friends whom he felt was not fairly represented in comics (Gayles, White Scripts and Black Supermen). Isabella did this by giving Black Lightning's origin a unique spin. Jefferson Pierce (Black Lightning's unmasked identity) is a former Olympian and college graduate who teaches English at Garfield High School (his secondary education alma marta). Isabella appears to replicate what W.E.B. Du Bois refers to as the responsibility of using one's collegiate-attained skills to service the community as is the responsibility of the "Talented Tenth. ${ }^{57 "}$ Although Black Lightning's altruism and service in the community becomes the corner stone for his heroic acts, he presents an identity conundrum. By day Jefferson Pierce is a standard English-speaking English teacher; during his night escapades as Black Lightning, he utilizes an African-American slang; Black English masks Black Lightning's identity, disguising Pierce. Additionally, Pierce is transformed to Black and Black Lightning by mask and afro wig.

When we read Black Lightning, (as written by Isabella) we get an African-American superhero with whom multiple audiences can identify and is not reified by stereotypical dialogue. However, once Isabella stops writing Black Lightning, Dennis O’Neil and Gerry Conway change the tone and dialect of Black Lightning from complex dialogue to simplistic jive-talk. This act removes the context of character development and purpose of his creation. Whether it is Black Lightning or African Americans in the literary world in general, the use of

\footnotetext{
${ }^{56}$ Luke Cage, unlike his superhero colleagues, was stricken with financial issues and had to rent out his superhero powers to survive financially. This could also make for an interesting research in the socioeconomic limitations of Black superheroes that affect their ability to perform without compensation. This is covered in Chapter 4.

${ }^{57}$ Discussed by Du Bois in The Souls of Black Folk (1903).
} 
African American English (AAE) serves to increase cultural authenticity in graphic narratives often at a detriment to character development. It's an act/ion loaded with microaggressions. According to race-specialist psychologist Derald Wing Sue, "Microaggressions" are [E]veryday verbal, nonverbal, and environmental slights, snubs or insults, whether intentional or unintentional, that communicate hostile, derogatory, or negative messages to target persons based solely upon their marginalized group membership ...The most detrimental forms of microaggressions are usually delivered by well-intentioned individuals who are unaware that they have engaged in harmful conductor toward a socially devalued group. (3)

It is this definition of microaggression that empowers my analysis of Black Lightning.

Most noticeably, there are specific types of microaggressions that take place within the selected Black Lightning texts. The first are "microassaults" defined as "conscious biased beliefs or attitudes that are held by individuals and intentionally expressed or acted out overtly or covertly toward a marginalized person or social group" (8). The second are "microinsults" which are "interpersonal interactions (verbal/nonverbal) or environmental cues that communicate rudeness, insensitivity, slights, and insults that demean a person's racial, gender, sexual orientation, or group identity and heritage. Microinsults are subtle snubs often unconsciously disguised as a compliment or positive statement directed toward the target person or group" (9). It is the combination of self-struggle and encountering the microaggressive actions of the Justice League of America (JLA) that contribute to Black Lightning grappling with the burden of Blackness overtly and covertly. Sue points out this tension in how it affects individuals who suffer microaggressions: 
The power of microaggressions lies in their invisibility to perpetrators and oftentimes the recipients. The definition of oppression includes imposing "abusive" messages (microaggressions) that both reflect and perpetuate false beliefs about people of color. Those beliefs cause humiliation and pain, reduce self-determination, confine them to lesser job roles and status in society. And deny them equal access and opportunities in education, employment, and health care. Most of the pain and detrimental impact of racism does not come from that of overt racists but from ordinary, normal, decent people who believe in life, liberty, and the pursuit of justice for all. (6-7)

However, what happens when these microaggressions are also instituted in the cultural politics of the graphic narrative? More importantly, what if the superhero elite are guilty of perpetuating these microaggressions? Who benefits from such messages and what work can we do to demystify these issues? These questions prove that not only is it tough being a superhero, but real marginalization because of your written racialized narrative comes at a cost.

Although Black Lightning was a creation of Isabella, he was fired and replaced by multiple writers to helm the Black Lightning character and its guest appearances. One of those appearances takes place in Justice League America \#173 and \#174 (DC Comics 1979-80). Instead of the empowering narrative Isabella wanted, we find that writer Gerry Conway (Daredevil, The Incredible Hulk, etc.) places Black Lightning in an interesting predicament against some of the most notable superheroes in the DC Comics universe. Conway situates the character Black Lightning as one who is literally split between fighting crime and proving his self-worth as a Black male superhero in front of the White gaze of JLA. However, instead of just fighting crime, Black Lightning ends up fighting for his superhero agency in metanarrative stereotyping and racial exclusion by some of America's iconic heroes through microaggressive 
encounters. These microaggressive acts not only occur through the depiction of Black Lightning's interaction with the JLA, but also by his narrative, situated-narrative location, and dialogue.

We need consider that the microaggression (whether authorial intent or not) comes at the expense of the fictional Black body. And, regardless of its fictionalized presence, Black Lightning's body is the object in which we can actually see how microaggression works in these texts. The conundrum is the masking of authorial intent. Although seeing microaggression is often considered as attributional ambiguous (hard to distinguish through ambivalent processing), characters can also hide the subconscious and conscious experience of the writers. It is also not a matter of what these microaggression do, but why they exist in the borders of the graphic narrative. The danger here is that although these microaggressions happen within the texts they reflect the real world application of microaggressions and how they function in quotidian normality. Again, this conversation refers to Eisner's and McCloud's argument ${ }^{58}$ that the writer is relinquished of the responsibility of the character. Yet, how can they (fictional characters) be isolated from its creator's ideology since they are not sentient beings of themselves and are informed by the politics of the writer?

${ }^{58}$ See Chapter 1 


\section{Here We Are Now, Entertain Us...}

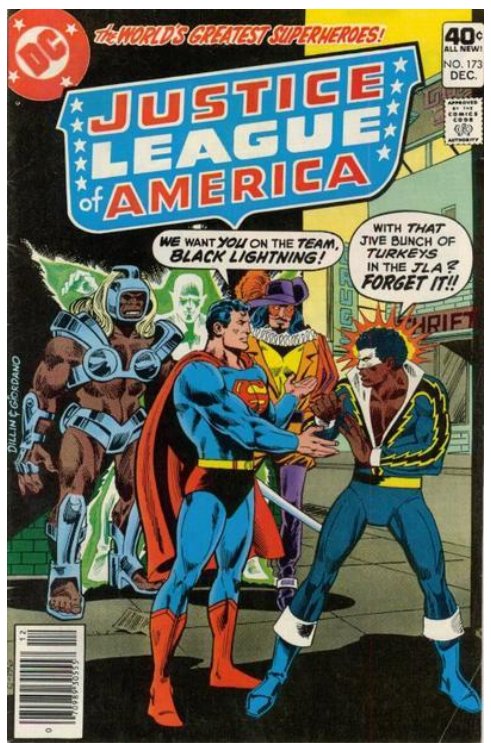

Fig. 5.1. Cover art for Black Lightning's guest appearance in Justice League of America \#173.

Justice League America (JLA) \#173, “Testing of a Hero!” (DC Comics, 1979) (see fig.

5.1), provides an introspective analysis of interracial relationships and expectations within a graphic narrative. The beginning of this graphic narrative shows the JLA (Flash, Zatanna, Superman, Green Arrow and Green Lantern in this instance) surveying Black Lightning stopping a crime from a rooftop; they are using this scenario as an indicator for whether or not to recruit Black Lightning (see fig. 5.2). This recruitment is unbeknownst to Black Lightning. Superman is the first to refer to Black Lightning as a subject that "mystifies" and "worries me" (1). Zatanna inquires why and Flash responds by saying “isn’t it obvious?” (1). Green Arrow vouches for Black Lightning's skills and is enamored with him because he is "Smart, Brave, and Black" (4), but is met with resistance by Flash who does not want to recruit a "token Black" (4) and accuses Green Arrow of doing so because of his "liberal agenda" (5) (see fig.3). From the initial pages of this graphic narrative, Conway presents us with the conflict of racialized rhetoric in JLA. 


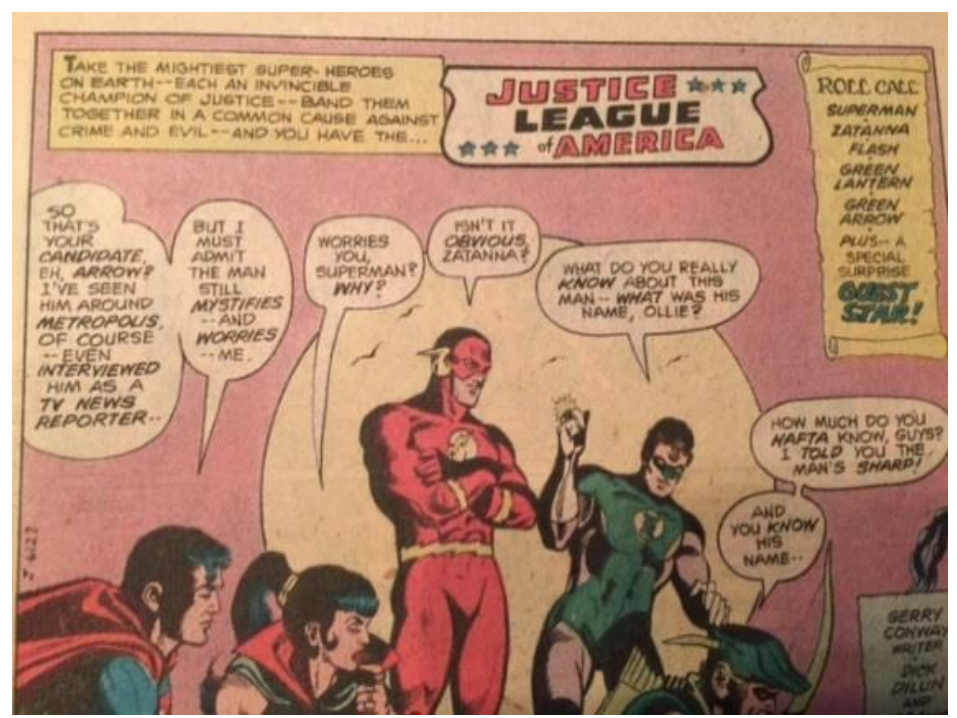

Fig. 5.2 The JLA surveying Black Lightning stopping crime in JLA \#173.

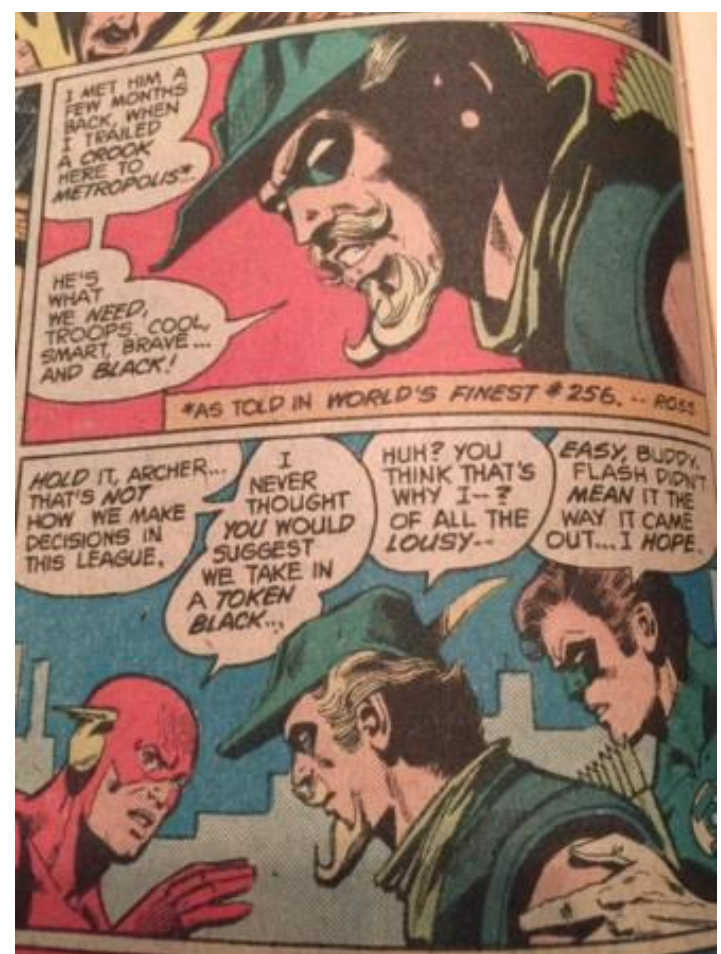

Fig. 5.3. The Flash and Green Lantern have a conflict over Black Lightning in JLA \#173

There are several things happening here in this dialogue. First, Conway writes Superman and Flash as characters who operate in a coded language of racial exclusion. One might not notice this due to the surface conversation, but Superman is engaging in a microaggression, specifically a microassault. He poses that Black Lightning "mystifies" and "worries me," yet 
there is no subtext to verify his concern outside of Flash alluding to the "obvious." The obvious in this instance is Black Lightning being Black. The second is the conversation between Flash and Green Arrow. Taken for the context we can read this portion as one that denotes inclusive tokenism or exclusion based on race. The inclusive tokenism is Green Arrow's eagerness to recruit a Black superhero into an exclusive unspoken normative superhero league. Green Arrow's excitement to recruit Black Lightning because "[H]e's smart, brave, and Black" (4) is highly suggestive of the Whiteness pervading through the JLA; this White normative substance of ideal superhero representation. It can also be read as Green Arrow being guilty of his own microassault through an adjective categorization of Black Lightning being intersectionally acceptable as “Smart, Brave and Black.” Maybe Flash's accusation happens because of Green Arrow's racialized highlighting. This characterization leads to Green Arrow's defensive response since those who operate in microaggressive activities can be conscious of their self-image. Sue posits, "Because most people experience themselves as good, moral, and decent human beings, conscious awareness of their hidden biases, prejudices, and discriminatory behaviors threatens their self-image" (5). Conway situates Green Arrow, in this act, as progressive, but in the selfimage of being liberal lies a microassault. Through this accusation, Flash's continual attacks on Green Arrow's self-image is in direct contrast to the liberal mindset Green Arrow is accused of having that compels him to retaliate in disbelief. Nevertheless, this conflict regarding Green Arrow's progressivism comes at the expense of Black Lightning's presence/body.

Yet, counter to Green Arrow's inclusive tokenistic attitude we have Flash's hesitancy or resistance to Black Lightning inclusion based on race. One can read Flash's statement as one of not using race as a factor in the recruitment of Black Lightning; that Black Lightning, on his own superhero merit, should be subject for recruitment based on his abilities alone. Unfortunately, the 
alternate perspective may also hold true as this resistance to Black Lightning reads as the microaggressive notion of "choosing the best candidate for the position regardless of race, culture, etc." Conway writes Flash in a way that reifies racial exclusion through his rhetorical use of Green Lantern's political ideology of being “liberal” and wanting a "Token Black.” As superheroes who are often battling in international, time-warped, and galactic affairs, Flash makes an effort to "keep things the way that they are." Here Flash uses a microinsult on Green Arrow because of the perceived political progressive ideology. It appears the main conflict within these few pages is not a threat to public safety, but a disagreement that is grounded in discrimination. It is a reductive notion of diversity occurring at the racialized level and not intergalactically. Perhaps Conway's point here is that even those who are supposed to uphold the high morality of superhero culture are also victim to the same oppressive content or context which they fight. Although the assumptions of racism operates as an act that is directly confrontational, the unspoken covert racial practices hold as much danger as the other. This practice is something that we do not consider when addressing popular superhero characters. Who knew that superheroes could also be super-prejudice?

Interestingly enough, when one does finally encounter Black Lightning in this particular issue (on page two), he mirrors the same speech pattern of a Luke Cage (Marvel Comics' Black American superhero) with period-based Black slang as he single-handedly takes down the criminal under the supposed innocuous gaze of the JLA and utters the phrase "Heard bout me!" [in response to the criminals not knowing who he is] (2). It's important to note that this linguistic mark is a guise used by Black Lightning to fight crime - it is the performance of slang attached to the performance of a Black superhero ${ }^{59}$. During this surveillance, JLA decides to let Superman be the judge of Black Lightning's abilities as the sole factor to initiate him into the Justice

\footnotetext{
${ }^{59}$ This subject will be addressed later in the chapter.
} 
League. Superman decides to test how Black Lightning fairs against "an unfamiliar enemy with unfamiliar power[s]" (5). This test is an insinuation of Black Lightning's liminal experience with crime-fighting since most Black superheroes are relegated to fighting crime in the "hood"; in this case, Black Lightning is fighting crime in the "Suicide Slums" and against low-level thugs ${ }^{60}$.

One could read superhero localization as fulfilling a role too small for White superheroes that are too busy fighting internationally and galactically to worry about the local low-income areas. Yet, I also find it interesting that Superman becomes the gatekeeper for Black Lightning's initiation. What is also intriguing is Superman's perception of Black Lightning as unfamiliar.

Glen Weldon in his essay "Superheroes And The F-Word: Grappling With The Ugly Truth Under The Capes," argues, "In the process, the visual iconography of superheroes which, comics being comics, is $50 \%$ of the formula, remember - melded with that of patriotic imagery. This [iconography] continued for decades after the war, as once-progressive heroes like Superman came to symbolize bedrock Eisenhower-era American values — the American Way — in addition to notions of Truth and Justice" (Weldon, "Superheroes and the F-Word"). Superman, created by Jerry Siegel and Joe Shuster in 1933, was to be the ultimate fantasy escape for young (White and Jewish) males. His purpose is to uphold truth, justice and the American way. Consider this PSA distributed by The Institute for American Democracy and National Comics Publishing (DC Comics' original name) in 1949 (see fig. 5.4):

${ }^{60}$ A name loaded with symbolism. 


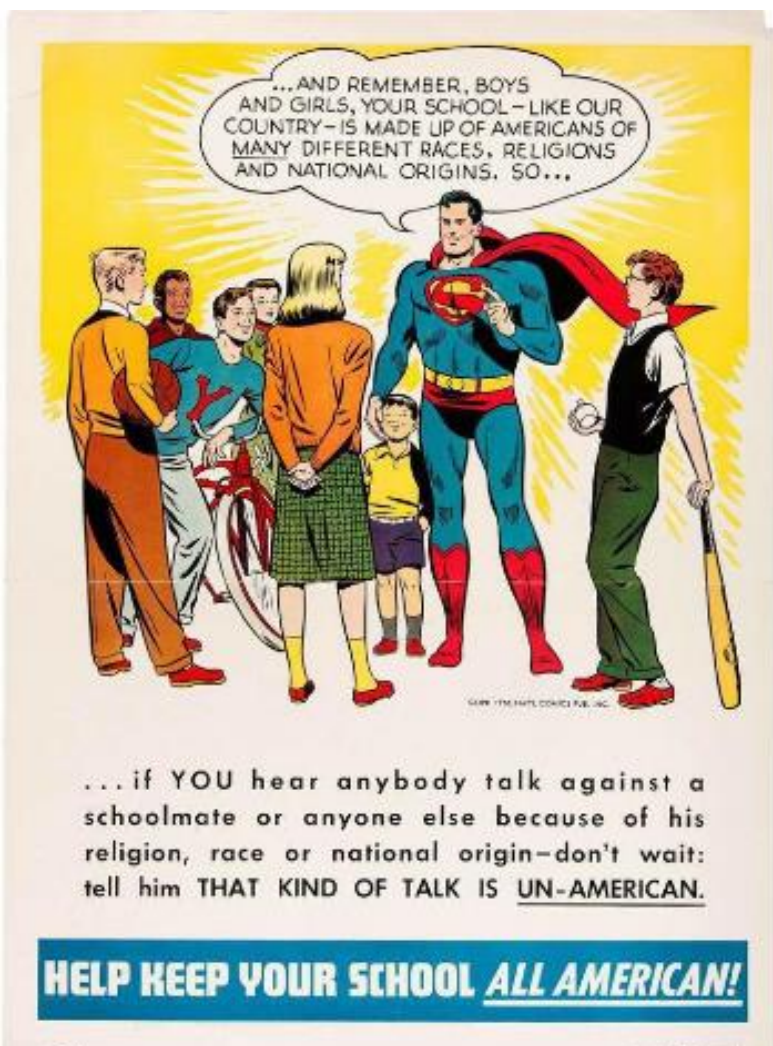

Fig. 5.4. Superman PSA on discrimination from 1949.

Here we see that patriotic dialect of Superman who is presumably standing for all regardless of their cultural, religious, and national affiliation. However, this is not the same "patriot" we encounter in the Black Lightning appearance in JLA. In actuality, Conway (in this instance) narrates Superman as a cultural gatekeeper whose main role as leader of the JLA is actually hypocritical to this very PSA. Superman does in fact discriminate against Black Lightning through traditional typecasting of the foreign, oriental or primitivistic gaze. Superman's position is also interesting since the dualistic nature of his attributes is being alien with "normative" complexion. This skin tone does render him associated with the popular ${ }^{61}$ rather than disassociated by his skin color. Superman's Whiteness is his protection from othering. Truly a conundrum when considering that the son of an alien planet is the leader of an American team.

\footnotetext{
${ }^{61}$ Readers and characters in the DC Universe.
} 
This idea also obscures the argument of who is truly belonging when an alien or outsider can determine selective national inclusion. One can make the argument that Superman is just being selective, but this selectivity is also contingent upon who is gets into JLA and at the costs of contrived rituals to pacify White hesitancy. What also makes this selectivity argument complicated is that the process of selection here has included additional steps in who is allowed in JLA that has not been previously established. This involuntary hazing, if you will, contributes to the microaggressive behavior of the hidden initiate selection process.

Later in the issue, Black Lightning, after making initial commentary about slang talk hurting his jaw, is ambushed by four random villains who are actually JLA members in disguise as part of this "test." He bests the first two random villains, but is subdued by the third who appears after the previous two. Black Lightning is then accosted by a fourth villain that he does defeat, but not without being pushed to the brink of anger. Black Lightning warns the fourth villain that he is lucky because he almost killed him because of the intensity of the fight. At this point that Green Arrow reveals himself as the fourth enemy ${ }^{62}$. Suddenly, Superman appears and tells Black Lightning that he has passed the test to join the JLA. Black Lightning, clearly frustrated from this unbeknownst initiation process, rejects the invite and tells the JLA that they "better get [themselves] another boy" (19) to which Superman tells the JLA (as Black Lightning walks off) that "some people just do not work well in groups" (19). Superman, along with his JLA companions, seems to be constructing a Black male superhero that is mystical, worries the dominant male leader, and has issues with control and anger even though the JLA are the perpetrators of violence who, at their own whim, are testing the Black superhero. Even in a meta self-actualization moment, Conway makes Black Lightning reject the perceived notion of being a "token Black." But in the end, White superiority in the JLA reifies itself in a microassault by

${ }^{62}$ This has a hidden enemy reading to it as well. 
suggesting that Black Lightning is not meant to work with the group because he cannot work well with others. This rejection also works to erase the injustice of an unwelcomed initiation process (see fig. 5.5).

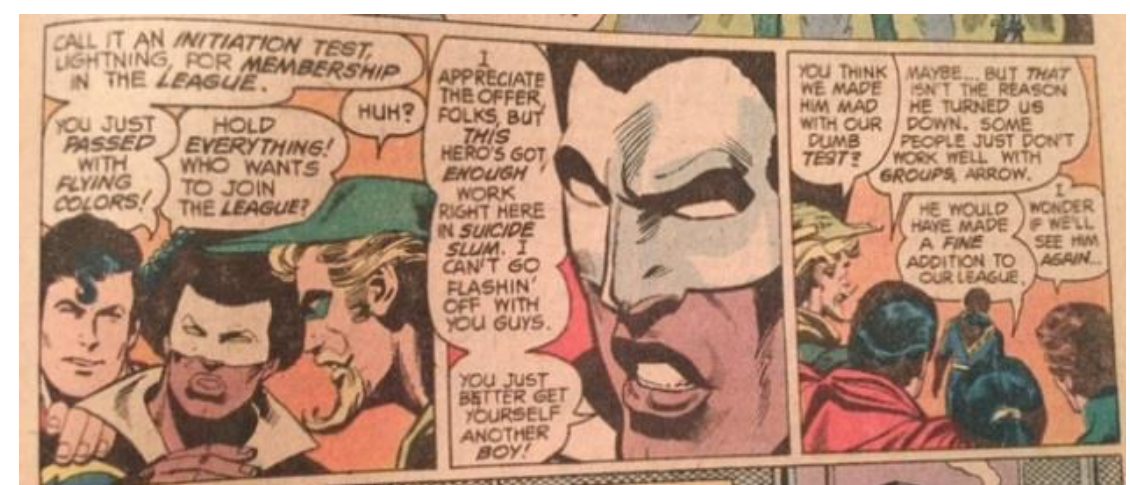

Fig. 5.5. Black Lightning rejects the JLA invitation the first time $\mathrm{n}$ in $J L A \# 173$.

In the second part of the Black Lightning JLA-centered graphic narrative, Justice League America \#174 "A Plague of Monsters," we are presented with a more inclusive look at the villain called "Regulator" from the last installment (JLA \#173). The Regulator is as an AfricanAmerican scientist who is scorned by his corporate employers and seeks to take revenge on S.TA.R Labs by using his animal-communication device to attack the lab and then the entire city. It is not until the city is in danger that the Justice League decides to intercede on the matter (1-3). It is no coincidence that in the issue where Black Lightning appears as a superhero so does a Black villain. Although one could read this as an attempt to bring diversity into this graphic narrative series, it directly fits the motif/trope of Black superheroes relegated to fighting Black villains in the "hood." The microaggression here is not only in the characters treatment, but formulaic tropes by Conway. Instead of fighting a White, international or intergalactic enemy, Black Lightning fights a Black villain (Black guy fights Black guy). This scenario reinforces Black-on-Black violence that still alleviates the responsibility of White superheroes from having 
to engage in this conflict. A troublesome trope continues the same didactic message of inclusion without barriers of exclusion while utilizing the same exclusive practices.

The narrative continues to redeem the JLA by having Green Arrow call attention to Superman, Green Lantern, and Flash's racial connotations during the test to join JLA in the previous issue. Green Arrow, Zatanna, and Elastic Man venture to apologize and again attempt to recruit Black Lightning. Possibly Conway makes this reconciliation important to salvage the image of the JLA. During this process, the previously mentioned heroes arrive at a police station to speak to the detective who says that he does not know where to find Black Lightning and adds "The problem with the guy is he's a vigilante" (5). Vigilantism is a common trope in association to masked superheroes who one-up the police in pursuit of criminals, but it's also interesting that this detective has this conversation with superheroes who are not vigilante by their mainstream affiliation. These members of JLA are superheroes, and since Black Lightning is liminal in his crime-fighting (neither police or JLA affiliate but Black) he is thus a vigilante. Yet, the issue is all superheroes are vigilantes who operate outside the restriction of international, federal, and state laws, but Black Lightning is considered more vigilante than the normative; he's given a sort of hyper-vigilantism by his physical presence in the text.

One of the most important parts of this text is a five-panel introspective of Black Lightning as Jefferson Pierce struggling with figuring out if he should give up being a teacher (his day-time job) or Black Lightning since he cannot be both. Black Lightning concludes that he should be both (5-6). This scene is fascinating because it captures the complex nature of the superhero. It is Conway's attempt to humanize and complicate the Black Lightning character. Nonetheless, in addition to his own burden he must deal with the burden of Blackness. This burden remains marked by Black Lightning's linguistic and physical masking. 


\section{More Than Meets the Eye}

When it comes to this notion of secret identity for superheroes of color, Professor Marc Singer in "'Black Skins' and White Masks: Comic Books and the Secret of Race” argues,

This representation of the super-hero as a mask which splits and scars the psyche bears a deep resonance with queer theory and critical race theory-or, perhaps, with the realities of life for minorities. Because superhero comics have evolved their own conventions for representing the dilemmas of a divided self, they have the potential to become perfect vehicles for exploring minority-group identity; similarly, from the perspective of the comics, minority groups may be ideal subjects for these same reasons. Superhero comics can literally personify the other-wise abstract ontological divides of minority identity, assigning each self its own visual identifier, its own body, and then charting the effects as these bodies house and are housed by the same mind. Those few comics writers who already use the superhero split identity to portray this aspect of minority identity generally present race and sexuality with richness and complexity, free of the tokenism and erasure. (116)

As Singer describes, the Black Lightning character is a visual depiction of the double-conscious experience. Jefferson Pierce is a middle-class Olympic athlete who dons a mask affixed with an afro wig that also changes his diction and/or vocabulary. I posit that there is another level here. Isabella's (the original writer) gazes affects the impact of the double consciousness in Black Lightning. We need to consider that in a traditional Black culture, Black vernacular/diction is not the masked element/intent. In fact, it is the opposite, often subversive. The linguistic masking (better known as code switching) that embodies the complexity of Black identity is reduced to a trope or an empty signifier filled with stereotypes and preconceived notions. Isabella actually 
flips this linguistic concept since the mask is the site where Black authenticity and dialogue occurs. The mask is Black authenticity, but the man, Jefferson Pierce is not authentically Black without it.

Several issues arise when investigating this authentic Blackness as funneled through the gaze of Black Lightning's appearance and dialogue, especially when it comes to his location and language as continuously presented by Isabella and Conway (in the JLA specifically).

Considering the parameters of Black Lightning's crime fighting is situated in the Suicide Slums, the reading of Black Lightning is also plagued by the tropes of inner-city perception. If Isabella was trying to write Black Lightning as anti-Luke Cage narrative, it would help if he moved Black Lightning out of the constructs of the urban environment and into local, state, national, international, and intergalactic spaces. Yet, this is where the Black superhero is placed in their narrative. Although it appears east to assert that Black Lightning is a hero for the people, the only difference spatially between Black Lightning and Luke Cage is their morality, but the location never changes. This location is also criticized by the JLA as why Black Lightning may not be suitable for initiation because of his figurative and literal placement. If we take up the idea that characters, like human beings, are social constructs in their narratives, then Isabella writes Black Lightning as a superhero who chooses to return to his roots to serve his community, while Luke Cage has no choice. Even with this altruistic notion of choice, Black Lightning is marginalized by a superhero stigma due to his place of service being regarded as "hood," so to speak in Conway's writing.

When it comes to the linguistic aspects, Black Lightning's slang talking is only triggered by his encounter with crime. This issue promotes the idea that Black Lightning's identity and linguistic speech is synonymous to crime fighting. It feels like a commentary trying to prove that 
in order to speak the language one also has to be criminal. That language in its act is criminalizing. The language of criminality is Black slang. This linguistic guise literally raises the two issues. First, there is the racial commodification of AAE in the use of Black graphic narrative superheroes as a conduit for performing "authentic" Black language by White graphic narrative authors. However, in an attempt to create alternative perception of AAE and life in the graphic narrative industry, Black Lightning's creation reflects a Black superhero that is both educated and street-smart. His language is reflective of code switching based on whether he is Jefferson Pierce or fighting crime masked as Black Lightning. The second issue, albeit an honest endeavor, still demarcates a language binary. In order to engage with criminals or the superhero persona, Black Lightning uses AAE. This usage fosters a stigma associating AAE with street life and/or villainous characters even though it used to disguise Jefferson Pierce's voice.

How a character is drawn and colored can assist in determining cultural and ethnic identity, language and visual representation that works in conjunction with a reader's schema of specific cultural identities in order to form an idea of "authenticity." The mixture of illustrated identity and dialogue can reinforce cultural stereotypes. AAE, in graphic narratives, can add to authenticity, reify stereotypes, and/or support reinforcement of standard English. We must consider the role that visual language (how characters are drawn) contributes to creating "socalled" authenticity. The visual aspect plays an important role in aligning culture with character. This visual depiction can also be complicated because a character can be Black in the comics, but she or he may not be limited to just being African American, but other diasporic cultures as well. One way to comprehend this difference is by the dialectic choice of the writer. According linguist Neil Cohn, we can develop a cultural understanding of a graphic narrative character since "comics can be written in both a visual language (of images) and a written language (of 
text)" (Cohn 2). Furthermore, with that complication“[c]omics do not fall within the normal scope of inquiry for contemporary linguistics and psychology—not because they are in inappropriate topic, but because language is a human behavior while comics are not, Comics are social objects created by incorporating the results of two human behaviors: writing and drawing" (Cohn 1). However, Cohn alludes to concerns that graphic narratives combine visual images with written language to help create a single message and that the grammar of writing is and continues to be tied to the verbal language (Cohn 2,6). What we can assert from these statements is that what is heard phonetically does not translate to written, but that a connection is always made by the language and image of a character by a writer. This process is essential to understanding how AAE is heard and transcribed in the graphic narratives by taking what may be heard and writing it to character - especially if it is White writers playing with AAE. In essence, the combination of language and artistic representation of ethnic identity performs White notions of authenticity.

In these two particular JLA issues, language connects characters to their cultural ethnicity. Professor Frank Bramlett in "Linguistic Codes and Character Identity in Afro Samurai" argues, "Characters who are authentic use authentic language. This means that the character will produce speech that conforms to a range of linguistic features deemed acceptable by an audience capable of judging; a character's linguistic production will index a (reasonably) authentic identity" (197). Noted linguist Lisa Green proposes a similar argument in that "[1]anguage plays a major role in creating images of [B]lackness...Speech patterns, along with other attributes, are intended to invoke certain images in the minds of the viewers" (201). As a simple fact, for characters to emulate an ethnicity they will also have to reflect this in speech. The reader cannot establish a cultural identity for a character without some linguistic marker or assistance. For instance, is there a way to establish an authentic Asian character without 
dialogue? Although Cohn contends graphic narratives are a "visual language," we can tell by certain artistic features, which denotes ethnicity and the language. This is the point Bramlett emphasizes - you cannot have a "perceived" authentic visual depiction without language to make it seem genuine, real. This is the crux of the matter-when White writers begin to appropriate cultural-linguistic traits to authenticate characters in conjunction with the drawn image we have a trope that participates in the microassault of identity.

Regarding cultural linguistic appropriation, anthropologist and linguist John Baugh says that White writers must be careful in a historic context to AAE:

Whites most typically imitate [B]lack speech when they mock minority accents, which are often part of racist jokes and therefore restricted to limited social contexts. Also, street speakers ${ }^{63}$ become particularly sensitive when [W]hites try to adopt [B]lack speech patterns; this is usually viewed as patronizing because the [W]hites are perceived as talking down to the [B]lacks. Therefore, what is natural to the standard English speaker, because it was acquired with the ease of any first language, translates into a much more complicated situation for street speakers, who face the more difficult problem of trying to acquire a second dialect (6-7)

Being conscientious of racialized language can assist White writers in making the mistake of replicating a language that carries with it a negative stigma to prevent reinforcing stereotypes.

James Haskins and Hugh F. Butts in Psychology of Black Language also assert that this appropriation can lead to an unnatural process for White writers: "But generally in the case of white nonstandard-English speakers this deviation is not consistent; simple correction can often bring the speaker to essentially standard English" (41). In this statement Haskins and Butts are implying that since is AAE is a linguistic cultural performance tied to common practitioners.

${ }^{63}$ Street speech is part of the AAE lineage, but rephrased to remove some negative stigma. 
Those who try to use AAE who are not common practitioners ultimately correct themselves based on previous conditioned linguistic patterns. In short, if you speak standard English and try to use a nonstandard form without normalcy you will automatically correct yourself because you will not articulate it correctly and will come off as disjointed language aka "corny." This argument is why Black Lightning's costumed dialogue is problematic. Although Black Lightning uses AAE during crime fighting, he reverts to standard English as Jefferson Pierce. Maybe this transposition is normal for the White writer in some aspects since White writers/creators struggle with AAE representation. Language is coded. Not so easily decoded. It's in the decoded and reception process that Black Lightning's dialogue becomes fraught.

There are literary and linguistic scholars who state we should not assume nor judge the merits of authorial intent. Linguist J.L. Dillard proposes that we not use literature as an avenue of judging authenticity since it would be fraught to base fiction on reality: "It would be better, I think, to use such literary works as a means to general overview—not to make confident decisions about either lexical items or grammatical structures solely on the evidence provided by any writer of fiction" (152-153). Dillard emphatically believes that "a Black English vernacular lexical form seems to be suggested on the bases of fictional materials, I see no reason not to assume that it is authentic" (153) and "[w]hen the same lexical items appear repeatedly in the works of writers of fiction and nonfiction, of Black and white fieldworkers in folklore, it would seem that those items are genuine" (154). The problem is that such thinking absolves the author of language appropriation for means that do not manifest in levels of respectability. And in a historical context, the concept of how AAE has been used in literature can be difficult to relinquish. In respects to this matter, Green postulates "[t]he representation of AAE in literature raises questions about the authenticity of the speech patterns associated with African American 
characters, and it also raises questions about the types of features that used to mark the speech of African Americans. In addition, representations in literature can give us more insight into what features are taken to be associated with [B]lack speech" (198). Green makes it clear why an analysis of cultural identity and language is important. We see this discrepancy play out in the final battle between Black Lightning and Regulator, occurring after Regulator's mind-controlled mutant rats have rampaged the city. Black Lightning is the only superhero who isn't affected by Regulator's mind-controlling helmet. As they battle, Regulator accuses Black Lightning of being a pig and not caring that he's Black (5) to which Black Lightning responds:

Yeah, I'm [B]lack and I know the brothers and sisters've got their problems, but maybe you didn't notice it you turkey----some'a the people you say you wanna help are first ones getting killed! Your lousy monsters're are hittin' the ghetto right? Who lives in ghettos you dumb jackass? $(15)^{64}$

Regulator has his revelation cut short by his death. Regulator disappears as quickly as he appears. His use, like Black Lightning, is limited only by Black Lightning's appearance. Besides the shallow attempt at Black dialogue, we are confronted with two issues of Black authenticity: the first being Regulator's charge that Black Lightning is not Black because of his interference in Regulator's scheme (as if he is aiding the establishment) and his dialectic. This linguistic exchange is also problematic due to the voice of Conway trying to discuss race relations, by also emulating Black speech which comes off as stale and insensitive; a microinsult at best by Conway. The text also turns Black Lightning as one who protects the hood and the establishment; a protector of the status quo, yet protector of the poor. We should also suspect that Conway is also making a meta-commentary on Black-on-Black crime. Afterwards, the last three

$\overline{64 \text { (Note to self) Double check dialogue }}$ 
panels of the graphic narrative have Black Lightning politely declining to join the Justice League, again emphasizing he's best by himself (see fig. 5.6).

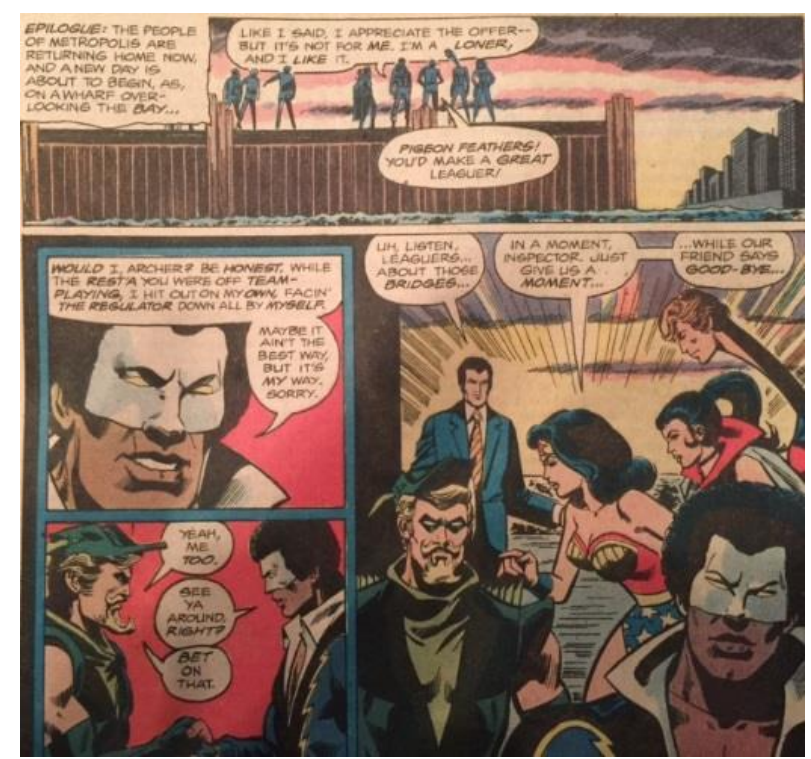

Fig. 5.6. Black Lightning rejects the JLA invitation again in JLA \#174

\section{(Not) All in the Same Gang}

In conclusion, we need to consider how this appearance by Black Lightning in the JLA series reflects a larger issue of cultural exclusion. Regarding this matter, critical race theorist Richard Delgado states:

Racism injures the career prospects, social mobility, and interracial contacts of minority group members. This, in turn, impedes assimilation into the economic, social, and political mainstream of society and ensures that the victims of racism are seen and see themselves as outsiders. Indeed, racism can be seen as a force used by the majority to presence an economically advantageous position for themselves. But when individuals cannot or choose not to contribute their talents to a social system because they are demoralized or angry or when they are actively prevented by racist institutions from fully contributing their talents, society as a whole loses (Delgado 181-82) 
Black Lightning, burdened by race through the White gaze, superheroism, and inclusion becomes a fraught character or even a realistic one depending on your perspective. While confronting his own self-doubt and racial hazing, Jefferson Pierce aka Black Lightning becomes a key figure in showing the stress of being Black, male, and superhero while also caricaturized a burden that is not shared by his JLA colleagues. The cultural politics of this interaction between Black Lightning and JLA is reflective of the Black artists or writers who often get scrutinized by their colleagues or potential employees for their perceived lack of qualification as being read on the Black body. The Black body is read as being out of place or is often prone to such terminology as being "not the right fit." In this instance, Conway writes Black Lightning as one who chooses not to "fit" in with the Justice League. I mean, who wants to be a part of a team of superheroes who practice overt and covert racism?

Although Conway wanted there to be a "testing" of a superhero it comes at the expense of the Black body. Again, as indicated by his skin color, Black Lightning becomes the experimental figure fit for universal superheroism criticism while a victim of his own hood (Suicide Slums). Conway deliberately writes Black Lightning as one who would rather work in solace than to become a part of the JLA. Almost tragically, this ambivalent rejection comes with a subversive line by Superman who frames Black Lightning as "unfit." Can Conway also be commenting on the isolationism often perceived by those who looking out at the Black Liberation or Pan Africanist movement as one of separatism typically devoid of cultural unity? We must assess whether or not this is also commentary on the Black limitation in popular White texts. Are the White writers interested in Black figures in the narrative, but like Superman and Flash, hesitant because they are in unfamiliar territory? We cannot exclude that this may also be the reflection of some writers own hesitancy with diversity and they are using this narrative as a 
cathartic process. One could interpret it this way, but the cultural segregation here is not from Black Lightning's doing. The concern is JLA using a process of recruitment for a superhero of color that they do not usually conduct. This process is one where the superhero of color has to endure tests and coded language and eventually reject the system that he never wanted to be involved with anyway. His choice can also be read as reflective of systemic oppression. This racialized system so engrained in biasness and separation that Black Lightning and JLA knew that neither were playing a part in the perpetuation of microaggressive issues. A system that corrupts the supposedly incorruptible morals of one most people might believe best models the genre-Superman.

In the end, we see White writers, such as Conway and Isabella, continue to use Black characters to address race, but also (whether consciously or subconsciously) reinforce the status quo of microaggressive narratives that feed into the paternalistic attitude of wanting and needing to represent the Black body absent of the Black voice. An act articulated through the mimicry of culture that is often indicative of the worse of that particular culture. Black Lightning does rightfully reject his invitation from the JLA, but it also pushes him back to the margins of the DC Comics universe as a loner moved to an ancillary role in later Batman and the Outsider narratives until he receives his own graphic narrative series again in the 1990s. Maybe this is the price to pay when you choose to not play by the rules, even when those rules are created, changed, and morphed to accommodate those who already benefit from them. Maybe if Black Lightning played the "game" and assimilated to the JLA he would be more universally accepted? I can think of no better commentary to end on when it comes to the refusal of assimilation and what happens to those who say no. They get Black-balled from narrative continuity as an "outsider" whose own fault has shaped their exclusion and alleviated the responsibility of those 
who are the aggressors. Ultimately, solidifying their own pre-conceived notions of the inferior's inability to play nice that justifies their exclusion. That's a catch-22 for any rebellious Black male superhero. 


\section{CHAPTER VI: I, TOO, AM AMERICA (CONCLUSION)}

Stuart Hall, in further meditations on popular culture, spits:

$[\mathrm{P}]$ opular culture, commodified and stereotyped as it often is, is not at all, as we sometimes think of it, the arena where we find who we really are, the truth of our experience. It is an arena that is profoundly mythic. It is a theater of popular desires, a theater of popular fantasies. It is where we discover and play with the identifications of ourselves, where we are imagined, where we are represented, not only to the audiences out there who do not get the message, but to ourselves for the first time. (Hall 32) According to Hall, popular culture is often the site where we are introduced to our external representation of ourselves. This "self" is often a stranger reflected to us by the multimedia mirror of our (American) culture. A self derived from a morbid fantasy manufactured by those without the interest of impact of certain images on cultures they are poised to represent. Therefore, if the first time we encounter the self it is loaded with thoughts that induce insecurity or are ignorant, then this imposed self becomes a corrupt signifier of self-consciousness. More specifically, a self-conscious commodified gaze of culture tattooed in tropes and bad politics. We are often afraid of this reflection as it is one unfamiliar to our subjective experience. When engaging with graphic narratives about the Black body or other non-normative subjects, we are often left with an authentic dissonance that screams "not me" and revisionism must occur to battle the often constant reflective stranger in the cultural mirror of our lives.

It is this identity contestation, revolutionary thinking Frantz Fanon refers to in his call for a collective catharsis of graphic narratives where we no longer see ourselves hyper-fantasized through another's gaze. A vision not reinforced by negative motifs regurgitated from a system that also perpetuates Black identity as a submissive secondary character or just plain wack. If 
popular culture is a component of the larger system of power and resistance, it is not devoid of the same political hindrance that sustains static representations. For instance, in the realm of popular culture, record companies tell "urban" artists what to be and how to sell records. It is often the complaint of many artists such as Common in his verse from " 6 th Sense." He raps, "I'm the truth, being across the table from corporate lies/immortalized by the realness I bring to it" (Common, " 6 th Sense"). Common embraces identity dissidence to retain an authentic self/voice in his music while operating within a music business corporate structure built on false representation for people of color (identity, culture, politics, business, etc.). This imposter placement remains the by-product of fixed cultural gazes. Gazes, in themselves that are also sites of power. If the gaze becomes the avenue for Black cultural politics to be expressed, then it is intentionally relegated to a position where representation fails to relinquish a position of power instituted by dominant culture. In fact, the same dissidence Common expresses matches what I feel when I sit across from a Black graphic narrative supposedly indicative of my perspective and find myself missing in this gaudy (mis)representation.

We must be cognizant that studies and research projects, such as mine, are not just about identity displacement, cultural exceptionalism or authorial intent, but rather the ability to rewrite one's own identity to empower the marginalized self. This same empowerment led the protest of Black male sanitation workers in the Memphis Sanitation Strike of 1968, post-Civil Rights Act, marching with "I AM A MAN" poster draped from their necks (see fig.6.1). This exhibition is a visual and literal reminder that, outside of the tropes, stereotypes, and negative images frequently presented by mainstream media or dominant cultural groups, in the end, I am a man - I am a living person to be humanized and treated as such. Currently, the \#BlackLivesMatter movement is symbolic of that same protest energy from the 1960s that speaks on two levels. On one level, 
Black lives matter in the continuum of human life on local, national, and international levels. The other level is a self-proclamation to redirect a spirit of hate and self-destruction that permeates the Black community from decades of senseless intraracial violence. It's a violence often glorified by Black popular culture in music and movies.

Correlating these tangible examples to the graphic narrative realm can appear hyperbolic. Yet, is this aesthetic protestation not what Black creators of graphic narratives are doing? They are remixing previous images and turning them into complex creations to show the multifaceted depictions of Black graphic narratives once perverted/twisted/drawn/warped by White authors within the con/text of the world they were hoping to create for Black characters. The reclamation of agency speaks back against internal and external voices pimped coerced to gain my attention but it does not resonate with my spirit. That is, in this visually rhetorical place of cultural politics, "I, too, sing America" (Hughes) both inside and outside the panels of graphic narratives.

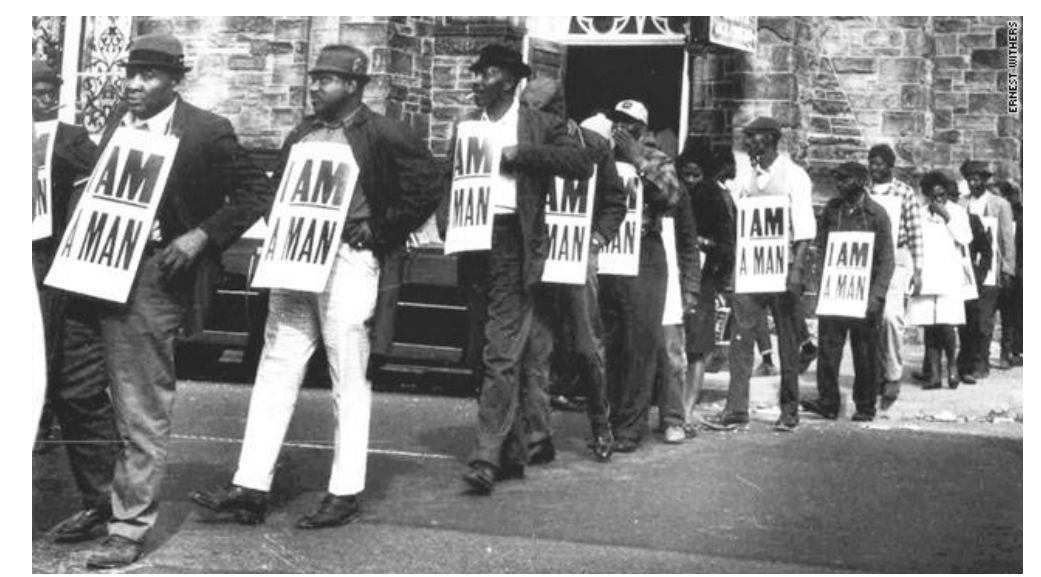

Fig. 6.1. Black protesters march in the Memphis Sanitation Strike of 1968

Although this project addresses earlier reiterations of popular Black superheroes, these characters have evolved. However, the evolution process is not exempt from criticism and the role that these superheroes played within the cultural politics of race and identity at key moments in American history. As systems evolve and new theories of meaning-making derive, we must 
continue to investigate artifacts of the past. We can argue that it's no longer important to look at historical representations when the current versions of Black Lightning, Black Panther, and Luke Cage supplant old images with more contemporary complex characters. Luke Cage's revisionism has already been addressed in a previous chapter, and Black Panther's new movie, set to be released in 2018 and featuring a predominately Black cast and director, has led to such Twitter hashtags as \#BlackPantherIsSoLit (Rodriguez, “Marvel's 'Black Panther' Is Going to Be So Lit”). 2017 Black Lightning even has a show currently in development with the CW network that focuses on him being a father and mentor to his crime fighting daughters (Goldberg, "Greg Berlanti's DC...”). So, after forty years of existence, these characters may finally be getting their just due. These revisions of Black superheroes also prove that revisiting previous representations of these characters allows us to appreciate their evolution. In this research process, I found myself asking one question? Why do we find ways to reemphasize and re-examine the importance of Romantic and Enlightenment Lit or so-called classic/al lit, but cannot return forty years in the past to address cultural hi-jacking and commodification of Black identity in popular culture spaces? Even after/across four decades, we still have White writers leading projects on multicultural graphic narrative while Black artists and writers are still trying to get a seat at the table. And, just when these Black artists and writers are finally able to join the conversation, they are often silenced by the indignation of their "colleagues" questioning the cultural authenticity of their characters. These are characters that do not fit into a specific white-gaze category of Blackness. It is still a seat at the table, but unfortunately this table is located in the kitchen of popular culture identity creation. 
Exemplifying this contention is Black graphic narrative writer David Walker. Walker uses Marvel titles such as Power Man ${ }^{65}$ and Iron Fist, and Nighthawk, and DC Comics' Cyborg series to tackle issues of race, urban violence, and identity in their run. Sadly, the Nighthawk series was cancelled due to its inability to sell the world on a Black superhero equivalent to Batman (Walker). The main criticism Nighthawk received was its near realistic depiction of Nighthawk battling political, judicial, and surreal Black-on Black violence permeating a fictionalized Chicago. In the opinion-section article for the Washington Post, "What Marvel canceling Nighthawk means for superheroes of color," writer David Betancourt says:

Maybe when it comes to heroes of color at top publishers, readers want more fantasy than reality. Comic books can be a great escape. Super-powers. Secret identities. Masks. A fictional African paradise, led by a panther king that has never been invaded and a black man using an indestructible shield to defend his country can be visually digested a lot easier than a bird-man taking on real world inspired injustice. (Betancourt, "What Marvel canceling Nighthawk means for superheroes of color")

Betancourt also articulates Marvel's diversity initiatives as coming with complicated issues of race (Sam Wilson aka Falcon becoming Captain America to an America that does not want him). The racial remixing efforts of popular Marvel superheroes, such as making Miles Morales a Latino and Black version of Spider-Man, Kamala Khan taking over for a White Carol Danvers as Ms. Marvel, Sam Wilson replacing a White Steve Rogers as Captain America, and Riri Williams becoming the new Iron (Wo)Man, to boost diversity and enact social justice still has a long way to go. All of this, in conjunction with the implosion of the political content in Ta-Nehesi Coates' version of Black Panther, try but still need help themselves. Although these characters are evolved representations of Blackness in the graphic narrative pantheon of superheroes, when

\footnotetext{
${ }^{65}$ Power Man is another name for Luke Cage.
} 
written by Black writers, they too can be burdened by race. Heroes of color can't be too real because it does distort the fantasy escape one desires when reading a graphic narrative (Betancourt). It's also possible to argue this realness imprisons static notions of Blackness, limiting the ability of character complexity since they cannot be Black and not deal with race. Race continues to feel like the biggest obstacle one must overcome along with being a superhero. Graphic narratives' Black characters need an affirmative action narrative to make sure they are properly represented or they represent a Du Boisan double-consciousness (meaning Black and superhero) that White superheroes find themselves absolved from engaging.

Black graphic narratives seemingly struggle not only with Blackness, but also with authenticity. Can s/he truly be a Black superhero if never encountering the "hood," racism, politics, and power outside the realm of supervillain agendas? It feels like a cognitive catch-22you can't be too Black or you risk isolating the mainstream audience. If you are not Black enough in content, then the authenticity of characters becomes an issue for a Black audience. Yet, this trap may not be problematic for a White male who is not threatened by hypermasculinedrawn superheroes so long as empowering a Black-male superhero does not disempower or compromise the White-male superhero. The politics of superheroism is embedded in a battle of identity and power within the racial context of a superhero.

Perhaps one way of continuing the investigation of Black identity struggle in graphic narrative is broadening the scope of analysis through a new lens. To comprehend of identity reformation we need to develop complex avenues to comprehend how these complex systems of oppressions and cultural reflections occur. One possible strategy is through what Nadine GeorgeGraves in Black Performance Theory calls "diasporic spidering." She defines diasporic spidering as "the multidirectional process by which people of African descent define their lives. The 
lifelong ontological gathering of information by going out into the world and coming back to the self' (33). Even though postcolonial theory has been used in third-world lenses, there are ways in which systems have been adapted for diasporic hybridity and to accommodate cultural migrations this theoretical concept allows for incorporation of outside theory. For instance, Black Panther is an American cultural production rooted in Africa and framed by the colonial contexts of modernity. However, these narratives also carry fictionalized concepts of Africanism. And so even if postcolonial theory is not being used in the third-world context, the idea of Blackness (authentic or not) does not disappear when taken out of context in this type of analysis. Thus the use of diasporic spidering allows for the relevance of continuity_-ways in which our webs of understanding meaning-making through these lenses (transnationally) link together are imperative to establish how systems of postcolonialism replicate and morph themselves into new forms within graphic narratives. This diasporic spidering also informs our gaze in determining if we moved past these new forms linked to old ways. Diasporic spidering also allows us to “intersectionalize" how identity, power, and resistance affect other cultural groups. Even while focusing on the Black masculinity aspects of graphic narratives, we should also consider how Black women's representation in such narratives might also benefit from this examination through transnational cultural politics.

Through identity and cultural politics, popular culture lends itself as a space of reclamation. The potential to control one's own image and narrative makes this resistance important. Cultural theorist Herman Gray states, "Historically black people in the United States have used the expressive arts and popular culture aggressively to imagine and narrate a collective past, the political aim of which was to protect [B]lack people and that (imagined) past from the cultural control of [W]hites" (121). What Gray refers to is the aesthetic clap back of Black 
cultural representation by the White culture used through Black artists revising their own image through the control of the content produced. This revision happens through contemporary Black artists such as those in Black Kirby (John Jennings and Stacey Robinson's collective group), whose remixing of Jack Kirby's graphic narrative work controls the master narrative of the Black body - the collective visually rewriting and drawing its own lifesaving figure. Black Kirby does this revisionism intentionally "to introduce an unsuspecting audience to works that challenge their own ideas of class, race, gender, and economics through an amalgam of art techniques, based on the popular consumer art of comics to challenge, analyze, and de-stabilize a monolithic idea of what 'blackness' is” (Jennings and Robinson 9). Black Kirby proudly uses themes found primarily in Afrofuturism. Afrofuturism can be defined as a genre that "considers issues of time, technology, culture and race, focusing on Black speculations about the future, foregrounding Black agency and creativity, explored through literature, film, art and music" (Jackson and Moody-Freeman 3). Through an Afrofuturistic lens, Black Kirby (and Damian Duffy known as “Tan Lee") creates a destabilization through its graphic narrative titled Kid Code: Channel Zero (see fig. 6.2).

Kid Code is another intellectually charged work that challenges cultural representations of popular culture through heavy symbolism and references. It's an aesthetic mixtape dedicated to the intersection of hip-hop, Greek mythology, theology, astrophysics, Afrofuturism and funk. Afrofuturism is one space that opens up the possibilities for not only Black men, but Black women as powerful beings and superheroes. One can see this manifest in Octavia Butler's character Anyanwu in Wild Seed (1980). Anyanwu can be considered a polymorph, and a healer with super strength. In essence, Anyanwu is not bounded by perceptions or liminal expectation of the Black woman's body. Butler write's Anyanwu as one who adapts to and empowered by 
her own surroundings as well as powers her environment through love, violence, and healing. Having taught a course on Afrofuturism twice, I've seen students across various cultures impacted by this genre. Black students are excited to engage with material that privileges their identity and puts them in empowering position of a (super)s/hero. White students have also approached me regarding the lack of Black representation in science fiction. Many have stated they did not know it was an issue, but are now aware that — even in the future-Black bodies are written out of the sci-fi genre's continuity. This action is rewritten and rectified by Butler and Black Kirby through Afrofuturism.

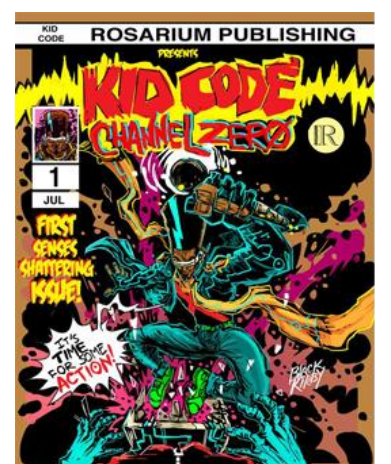

Fig. 6.2. Black Kirby and Tan Lee's Kid Code: Channel Zero (2014)

Reconstruction of Black identity also occurs in Kwanza Osajyefo's graphic narrative, Black (2016). Black's premise is, what if Black people were the only ones able to manifest superpower (see fig. 6.3)? Black graphic narratives, such as Black, counter the notion that superheroism flows from the White body into other spaces by relocating super powers through the often marked Black body as a space/place of empowerment. Osajyefo work can be considered exceptionalism in the case of isolating powers to that of the Black body, but why not? Efforts to rewrite the Black body in graphic narrative (or other places of popular culture) are often met with claims of reverse racism. It's interesting that this claim of reverse racism, privileging, or exceptionalism occurs when it comes to the reclamation of one's own identity- 
specifically people of color. These criticisms appear to level the field in respectability politics, but one whose field is this leveling occurring?

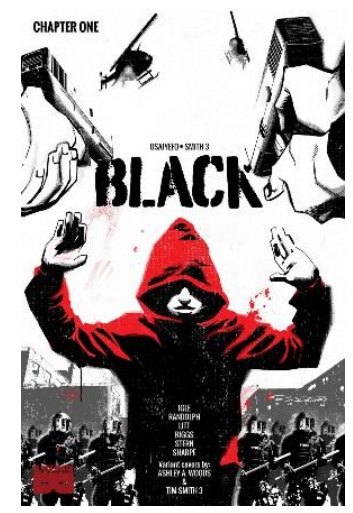

Fig. 6.3. Cover art for Black \#1 by Kwanza Osajyefo (2016)

\section{Where Do We Go}

Since there are many topics to address in the cultural politics of graphic narratives, we need to see more "spidering" investigation of graphic narratives as sites of power and resistance in cultural politics. There needs to be more exploration into the idea of "superhuman" abilities as well as what this concept of ability means from an intersectional lens. For instance, what does this ability consider if addressing those who are disabled from the normative lens? In terms of "disabled," I mean in two contexts. First, disabled in their (those "dis"abled) ability to articulate their own existence. There needs to be more investigation into Black women, Latino/Hispanic, Asian and other cultural representations in graphic narratives that have been made invisible. There is already scholarship addressing LGBTQ identity in graphic narrative, none much better than The New Mutants (2016) by Ramzi Fawaz, but not enough. The second context worth examining is based on physical ability. Can the (dis)abled body perform hyperactive feats? How are Charles Xavier (paraplegic, but a powerful mutant) and Daredevil (blind from a freak accident as a child) seen or not seen in this instance? Yet, these descriptions 
of powerful White superheroes overcoming physical adversity still represent all other cultures in a subversive and subliminal multi-disabled frame of Whiteness.

Let's consider that Charles Xavier is endowed with the ideology of Martin Luther King, $\mathrm{Jr}$ and his complex frenemy Magneto is representative of Malcolm X. There are two arguments here with the Civil Rights/ Black Power movements' dispute funneling through the White bodies. First, Whiteness is ideologically freed by Black politics. Pushing this idea, the Civil Rights Movement is often credited with opening the door to women's, Latino/Chicano, and LGBTQ rights. So when Civil Rights/Black Power ideology is subsumed and articulated through the guise of the human/ mutant (race, sexual orientation, etc.) analogies it becomes less threating in its reception. The danger, of course, in pursuing such a translation is the reduction of power from the original movement. Nevertheless, there is a benefit by relating the movement to and through the bodies of difference (mutants). The X-men have the closest connection to representing Eugenics and science as a platform for discrimination (normative versus anomaly biology). X-men has also been stated by graphic narrative writer Phil Jimenez as being representative of the LGBTQ community (Kantor, "A Hero Can Be Anyone”). Even the critique of Whiteness and graphic narrative political discourse becomes fraught by Magneto (formerly fictionalized Jewish-Nazi internment camp survivor) since his presence now calls for an intersectional analysis of historical Jewish representations in graphic narratives that is separate from what takes place in the Civil Rights movement. Also complicating the argument here is that Whiteness becomes the representation for the movement that has a cultural-political purpose. Instead of Stan Lee and the Marvel faction (and other studios) creating characters that visually reflect this complicated cultural narrative, we are presented with Whiteness as the intercession for cultural amends; the revolution still winds up filtered through White writers, authors, and 
their characters. Filtration then lessens the impact of said cultural political resistance. This contention is one that Black writers and artists often voice as to why they feel the need to speak their own language and control the narrative through their own development of Black superheroes. These Black writers and artists gladly accept a mission to make sure that they and/or their content are not whitewashed.

We need to consider my study as piece of a larger body of academic work, which challenges the subtle notions of race and cultural politics in popular culture, particularly in graphic narratives. An analysis, such as this, realizes the exigency of striving for a high level of honesty when it comes to the complex configuration of Black identity and cultural themes represented in a multitude of visual and narrative rhetoric within popular culture. Don't get it twisted. This exploration is about race and much more. Consider this pop cultural analogy: Bruce Lee, in the beginning of Enter the Dragon (1973), chastised his student for not focusing. Lee tells his student, "It's like a finger pointing away to the moon. Don't concentrate on the finger or you will miss all that heavenly glory" (Lee, Enter the Dragon). As an artist myself, I, in this research, set out to point to the complications of cultural politics through the lens of race. Focusing on just the racial aspects will make you miss the complex cultural work that is happening behind the wizard's curtain of ideological state/multinational apparatuses.

Although we tend to dismiss the idea of graphic narratives being a field of academic engagement, recent years have brought a multitude of research in the genre since the days of Will Eisner's Graphic Storytelling and Visual Narrative and Scott McCloud's Understanding Comics, which are widely regarded as seminal texts. Thankfully, the field of examining Black identity in graphic narratives is developing. Graphic narratives are a valuable foray into exploring other meaningful topics. 
In the renegotiation of Black male superhero identity, we find influences arise in other popular culture spaces. Two worthy of mentioning are sports and hip-hop. Athletics has become a place where athletes from sports are heralded as Black superheroes, no other league more so than the National Basketball Association (NBA). As a child of the 1980s, I idolized professional basketball. Growing up I did not know about Black superheroes in a graphic narrative sense. My fascination with the supernatural powers of an individual revolved around one person at first: Michael Jordan. There was something poetic and above human about how "MJ" sliced through hapless defenders, hung in the air and finished in spectacular fashion with a contorted lay-up or dunk over an opponent. Jordan was no superman, but he could defy gravity and seemed unstoppable. The current generation of NBA fans often speaks of LeBron James in the same vein, but I do not want to engage in the discourse over who is greater here. The point is that superheroism in the Black community has been displaced to other avenues of popular culture.

We can consider the empowerment of hip-hop culture (specifically rap music) as the street where Black male superheroism has been re-directed and grown quite vocal. Within the culture of lyrical empowerment, self-fulling Black financial prophecy, and the ever invincibility of the writer we find that heroism for Black men wishing to be like Jay-Z, Nas, Drake, Lil Wayne, Common, Andre 3000,etc. Even the duality of the rap name alias has a flavor similar to superhero aliases. It's as if these rappers are empowered by their rap name. We can also point to the elevation of the music by Kendrick Lamar. Lamar is known for two hip-hop anthems of encouragement, "Alright" and "D.N.A." Both songs contain uplifting lyrics not often seen in the large spectrum of current rap music. However, hip-hop is also problematic because of its misogynistic lyrics and content. As empowering as rap music can make one feel, it disempowers 
the essence of the Black community - the Black woman. One can make the claim that even within the empowerment of hip-hop lies the same critique of hegemony and oppression politics.

Although there seems to be exhaustive research about hip-hop culture, we need to re/imagine hip-hop (specifically rap as its voice) as a space of not only cultural rebellion, but also differential racialization. For instance, how can we expect mainstream record labels like Arista, Warner Brothers, and others to fully promote an art form built on rebellion without serving the commodification needs of themselves as paternalistic companies? Can there really be a revolution sponsored by the mainstream with the commercialized deradicalization of content that is made through it? We can consider this problem the commercialization of consciousness or the profit of protest \#StayWoke \#ButDrinkPepsiToo. We must do a better job scrutinizing capitalism in this (music) industry, the ways rap artists use record companies to disseminate subversive content in a contemporary version of subversive slavery communication methods, while on the plantation of mainstream distribution companies.

Hip-hop culture is a space of constant negotiation. Often hindered by relics of its past, hip-hop can come across as a pseudo-liberal culture. What I mean is that hip-hop can be a conservative culture with proclamations similar to the coded language of Republican rhetoric, especially when hip-hop heads make statements such as "we need to bring back hip-hop" or hiphop "just ain’t the same" (\#MakeHipHopGreatAgain). In fact, there is also a demarcation of who and who is not hip-hop by cultural gatekeepers. It is by this gatekeeping that we often experience the silencing of voices that differ from those who do not reflect hyper-heteronormative behavior. Again, there's an irony here. As rap from hip-hip becomes a conduit for revolution, it also serves to reinforce the same systemic hegemony that it proclaims to battle. Maybe the damage of racialized and sexualized coding has permeated more places than we thought... 
Before I drop the mic on this intellectual verse, we must consider the importance of image. Canon's famous slogan "image is everything" can be no further from the truth when it comes to the negotiation of one's own image. Can you imagine waking up, looking in the mirror, and seeing yourself, your face, but hearing another person's voice? The world needs to stop this cultural ventriloquism and allow people to speak for themselves without the arrogant idea that what you see on television or hear in music is an authentic reflection. The danger from consuming this image and regurgitating it out into the continuum of cultural representation retain static images in the matrix of identity. As a result of this consistent problematic representation of Black identity in graphic narrative, many Black artists and authors have moved away from pursuing mainstream masters to establish their own spaces and independent publication. But, appropriation remains. The issue is, that once individual effort proves to be successful, a larger entity, almost as a matter of company policy, steps in to entrol the image commodify the image.

We must continue to investigate these spaces because cultural identity created by normative standards always leverages the negotiation process and reinvents these images as what I call neotropes. As one image is contested and revised another manifest that is hereditarily an old image with new threads. I contend that the Black image has always been commodified to the point that almost every action or behavior perpetuated by the Black body is stigmatized as a stereotype. A false view of Blackness that is considered a matter of convenience for some White creators because of their power in the multi-complex representation of culture. The Black superhero written in the White gaze must continue to resist and contradict. \#StayWoke \#ButDontDrinkPepsiFirst 


\section{REFERENCES}

Abad-Santos, Alex. "Meet Sana Amanat, the Shonda Rhimes of Marvel Comics." Vox, Vox Media, 19 Nov. 2015, www.vox.com/2015/11/19/9757682/sana-amanat-marvel. Accessed 16 Jan. 2016.

Abrahams, Roger. "Some Varieties of Heroes in America." Journal of the Folklore Institute, vol. 3, no.3, 1966. pp. 341-362.

Achebe, Chinua. “In Image of Africa: Racism in Conrad's Heart of Darkness.” Hopes and Impediments: Selected Essays. Anchor, 1990.

“Anti-Bullying Campaign: Superman.” https://twitter.com/YMBBastepaway/status/797568355465097216/photo/1 Accessed 15 Mar. 2017

Baugh, John. Black Street Speech: Its History, Structure, and Survival. Texas UP, 1983.

Beard, Jim. “Jack Kirby Week: The Black Panther.” Marvel, Marvel Entertainment, 25 Aug. 2016, news.marvel.com/comics/26638/jack_kirby_week_the_black_panther/. Accessed 8 Apr. 2017.

Bell, Derrick, Jr. "Brown v. Board of Education and the Interest-Convergence Dilemma.” Harvard Law Review vol. 93, no. 3, 1980. pp. 518-533.

Betancourt, David. “Opinion: What Marvel Canceling Nighthawk Means for Superheroes of Color." The Washington Post, WP Company, 8 Sept. 2016, www.washingtonpost.com/news/comic-riffs/wp/2016/09/08/what-marvel-cancelingnighthawk-means-for-superheroes-of-color/?utm_term=.c452f3fa9f5a. Accessed 15 Apr. 2017. 
Block, Alan. "Hey, I'm No Superman: The Teacher as Hero.” Journal of Curriculum Theorizing, vol. 31 , no. 1 , 2014, pp. 30-45.

Bracey, Earnest N. Prophetic Insight: the Higher Education and Pedagogy of African Americans. University Press of America, 1999.

Bramlett, Frank. "Linguistic Codes and Character Identity in Afro Samurai." Linguistics and the Study of Comics, edited by Frank Bramlett, Palgrave Macmillan, 2012. pp. 183209.

Brown, Jeffrey A. Black Superheroes, Milestone Comics, and Their Fans. Jackson, University Press of Mississippi, 2005.

Casetti, Francesco. "Adaptions and Mis-Adaptions: Film Literature, and Social Discourses." A Companion to Literature and Film, edited by Robert Stam and Alessandra Raengo, Blackwell, 2004, pp. 81-91.

Charity, Justin. "Luke Cage, Black Conservative.” The Ringer, The Ringer, 30 Sept. 2016, theringer.com/luke-cage-black-conservative-f5be622daf67. Accessed 14 Oct. 2016.

Chaney, Michael A. "Drawing on History in Recent African American Graphic Novels."MELUS: Multi-Ethnic Literature of the United States, vol. 32, no. 3, Jan. 2007, pp. 175-200. JSTOR [JSTOR], doi:10.1093/melus/32.3.175. Accessed 7 Oct. 2014.

Closson, Rosemary B., et al. "Toward a Race Pedagogy for Black Faculty.” Adult Learning, vol. 25, no. 3, 2014, pp. 82-88., doi:10.1177/1045159514534192.

Coates, Ta-Nehisi. Between the World and Me. New York, Spiegel \& Grau, 2015.

Cohn, Neil. The Visual Language of Comics: Introduction to the Structure and Cognition of Sequential Images. Bloomsbury Publishing, 2013. 
Comicguy2. "Luke Cage.” Comic Vine - Luke Cage, GameSpot, 23 Feb. 2014, comicvine.gamespot.com/images/1300-3660907. Accessed 2 Dec. 2014.

Common. "6th Sense." Like Water for Chocolate. MCA, 2000

Conway, Gerry, et al. “A Plague of Monsters." Justice League of America. vol. 21, Issue 174. DC Comics, January, 1980.

---. “Testing of a Hero." Justice League of America. Vol. 20, Issue 173, DC Comics, December, 1979.

Coon, Katharine. “'A Rip in the Tent:' Teaching (African) American Literature.” Teaching African American Literature: Theory and Practice, edited by Maryemma Graham et al., Routledge, 2008, pp. 31-51.

Dauphin, Gary. “To be Young, Super powered \& Black.” Village Voice, 17 May 1994, pp. 3138.

Davidson, Douglas. "The Furious Passage of the Black Graduate Student.” Berkeley Journal of Sociology, vol. 15, 1970, pp. 192-211. JSTOR [JSTOR], Black Graduate Students. Accessed 10 July 2014.

Davis, Blair. "Bare Chests, Silver Tiaras, and Removable Afros: The Visual Design of Black Comic Book Superheroes.” The Blacker the Ink: Constructions of Black Identity in Comics and Sequential Art, editors Frances K. Gateward and John Jennings, Rutgers University Press, 2015, pp. 193-212.

Delgado, Richard. "Words That Wound: A Tort Action for Racial Insults, Epithets, and NameCalling." Critical Race Theory: The Cutting Edge, edited by Ricard Delgado and Jean Stefanic, Temple Univ. Press, 2013, pp. 179-186. 
Delgado, Richard, and Jean Stefanic. Critical Race Theory: an Introduction. Second ed., New York University Press, 2012.

Delpit, Lisa D. “The Silenced Dialogue: Power and Pedagogy in Educating Other People's Children." Education for a Multicultural Society, edited by Kolajo Paul Afolabi, Harvard Educational Review, 2011. pp. 123-43.

Dillard, J. L. Lexicon of Black English. Seabury Press, 1977.

Duffy, Damian, and John Jennings. Black Comix: African American Independent Comics, Art and Culture. Mark Batty, 2010.

"Dwayne McDuffie on Chester Himes, Luke Cage and "SWEET CHRISTMAS!" YouTube. Ed. Jonathan Gayle. YouTube, 01 Mar. 2011. Web. 15 Sep. 2014.

Eisner, Will. Graphic Storytelling and Visual Narrative: Principles and Practices from the Legendary Cartoonist. New York, W.W. Norton, 2008.

---. "The Spirit Ain't Fair to Ebony.” The Spirit. N.p.: Register and Tribune Syndicate, 1945. Print.

Fanon, Frantz. "On National Culture.” The Wretched of the Earth. Grove, 2004. pp. 206 - 49

---. "The Black Man and Psychopathology." Black Skin, White Masks, Grove, New York, 2008, pp. 120-185.

Flowers, Alonzo M., III. "Self-Reflection as a Critical Tool in the Life of an Early Career African American Male Scholar." Black Faculty in the Academy: Narratives for Negotiating Identity and Achieving Career Success, edited by Fred A. Bonner et al., Routledge, 2015. pp. 105-14.

Foster, William H. Looking for a Face Like Mine: The History of African Americans in Comics. Fine Tooth, 2005. 
Francis, Consuela. “American Truths: Black and the American Superhero.” The Blacker the Ink: Constructions of Black Identity in Comics and Sequential Art, , editors Frances K. Gateward and John Jennings, Rutgers University Press, New Brunswick, NJ, 2015, pp. $137-52$.

Gates, Henry L., Jr. The Signifying Monkey: A Theory of Afro-American Literary Criticism. Oxford UP, 1988.

Gateward, Frances K., and John Jennings, editors. "The Sweeter the Christmas.” The Blacker the Ink: Constructions of Black Identity in Comics and Sequential Art, Rutgers University Press, New Brunswick, NJ, 2015, pp. 1-15.

Gayles, Jonathan, director. White Scripts and Black Supermen: Black Masculinities in Comic Books. California Newsreel, 2012.

George-Graves, Nadine. "Diasporic Spidering: Constructing Contemporary Black Identities." Black Performance Theory, edited by Thomas DeFrantz and Anita Gonzalez. Duke UP, 2014. pp. 33-44.

Gil Scott-Heron \& Brian Jackson. “Ain't No Such Thing As Superman.” The First Minute of a New Day, Arista, 1975.

Gilyard, Keith. "Literacy, Identity, Imagination, Flight." True to the Language Game: African American Discourse, Cultural Politics, and Pedagogy. Routledge, 2011. pp. 137-46.

Goldberg, Lesley. “Greg Berlanti's DC Comics Drama 'Black Lightning' Scores Pilot Order - at The CW." The Hollywood Reporter, 3 Feb. 2017, www.hollywoodreporter.com/livefeed/greg-berlantis-dc-comics-drama-black-lightning-scores-pilot-order-at-cw-971745. Accessed 19 Apr. 2017. 
Graham, Maryemma. "When Teaching Matters." Introduction. Teaching African American Literature: Theory and Practice, edited by Maryemma Graham et al., Routledge, 2008, pp. 1-11.

Green, Lisa. J. African American English: A Linguistic Introduction. Cambridge University Press, 2002.

Hall, Stuart. "Culture, Resistance, and Struggle." Cultural Studies 1983: a Theoretical History, edited by Jennifer Daryl Slack and Lawrence Grossberg, Duke University Press, Durham, NC, 2016, pp. 180-207.

---. "Notes on Deconstructing 'the Popular'." Cultural Theory and Popular Culture: A Reader, edited by John Storey, 2nd ed., University of Georgia, 2013, pp. 442-453.

---. "What Is This 'Black' in Black Popular Culture?" Black Popular Culture, edited by Michele Wallace and Gina Dent, Bay Press, Seattle, 1992, pp. 21-33.

Hall, Stuart, et al., editors. Representation: Cultural Representations and Signifying Practices. Los Angeles, CA, Sage Publications Ltd, 2013.

Hannigan, Ed, et al. “The Killing of Windeagle!” Marvel Premiere featuring Black Panther, vol. 1, no. 51, Marvel Comics, 1979.

---. "Journey through the Past." Marvel Premiere featuring Black Panther, vol. 1, no. 52, Marvel Comics, 1980.

--- "The Ending in Anger!" Marvel Premiere featuring Black Panther, vol. 1, no. 53, Marvel Comics, 1980.

Harvey, David. "The Body as an Accumulation Strategy.” Spaces of Hope, Univ. of California Press, 2008, pp. 97-116. 
Haskins, James H., \& Butts, Hugh F. The Psychology of Black Language. Hippocrene Books, 1993.

Henderson, Stephen E. "Inside the Funk Shop: A Word on Black Words.” African American Literary Theory: A Reader, edited by Winston Napier, New York UP, 2000, pp 97-101. Holman, Omar. “'Black': A Graphic Novel That Asks, 'What If Only Black People Got Superpowers?".” Black Nerd Problems, 16 Feb. 2016, blacknerdproblems.com/black-agraphic-novel-that-asks-what-if-only-black-people-got-superpowers/. Accessed 19 Apr. 2017.

hooks, bell. Teaching Critical Thinking: Practical Wisdom. Routledge, 2010.

---. Teaching to Transgress Education as the Practice of Freedom. Routledge, 1994.

---. "Eating the Other.” Black Looks: Race and Representation. South End, 1992. pp. 21-39.

Hopson, Rodney K. "Towards the Language and Scholarship of Freedom and Resistance: Coming to Terms with Being A Young, Black Male Academic in America.” Brothers of the Academy: Up and Coming Black Scholars Earning Our Way in Higher Education, edited by Lee Jones, Stylus, 2000. pp. 71-82.

Hudlin, Reginald, et al. Black Panther: Who Is the Black Panther? Marvel Entertainment, 2006. Hughes, Langston. “I, Too.” Poetry Foundation, Poetry Foundation, www.poetryfoundation.org/poems-and-poets/poems/detail/47558. Accessed 19 Apr. 2017.

Illidge, Joseph Phillip. “Real Life Proves Why Luke Cage Endures.” CBR, 15 Aug. 2014, www.cbr.com/real-life-proves-why-luke-cage-endures/. Accessed 18 Sept. 2014. Jennings, John et al. Kid Code: Channel Zero. Vol. 1, ser. 1, Rosarium Publishing, 2014. 
“Jungle Action \#19 Cover Art." [Online image], http://www.comicvine.com/jungle-action-19blood-and-sacrifices/4000-16006/_Accessed 15 Oct. 2014.

“Jungle Action \#21 Cover Art.” [Online image], http://www.comicvine.com/jungle-action-21-across-burning-darkly-blackening/4000-16344/ Accessed 15 Oct. 2014.

"Jungle Action \#22 Cover Art." [Online image], http://www.comicvine.com/jungle-action-22death-riders-on-the-horizon/4000-16510/_Accessed 15 Oct. 2014.

“Jungle Action \#24 Cover Art.” [Online image], http://www.comicvine.com/jungle-action-24wind-eagle-in-flight/4000-16876/ Accessed 15 Oct. 2014.

Kantor, Micahel, director. “A Hero Can Be Anyone.” Superheroes: A Never-Ending Battle. PBS, 2013. Kanopy, illstu.kanopystreaming.com/video/superheroes-never-ending-battle-herocan-be-anyone. Accessed 23 Apr. 2017.

Keating, AnnLouise. "Interrogating "Whiteness," (De)Constructing "Race"” Teaching African American Literature: Theory and Practice, edited by Maryemma Graham et al., Routledge, 2008, pp.186-209.

Kingkade, Tyler. “A 1950s Superman Poster Says What We All Need To Hear About American Values Right Now." The Huffington Post, TheHuffingtonPost.com, 23 Nov. 2015, www.huffingtonpost.com/entry/superman-poster-americanvalues_us_5650a695e4b0879a5b0b42a7. Accessed 20 Apr. 2017.

Lloyd, Brian. "Marvel's Luke Cage Is so Popular, It Actually Caused Netflix to Crash." Entertainment.ie, 2 Oct. 2016, entertainment.ie/tv/news/Marvels-Luke-Cage-is-sopopular-it-actually-caused-Netflix-to-crash/385950.htm. Accessed 14 Oct. 2016. “Luke Cage.” 2016, www.imdb.com/title/tt3322314/mediaviewer/rm2370964736. Accessed 13 Mar. 2017 
"Luke Cage." Den of Geek, 2 Dec. 2016, cdnstatic.denofgeek.com/sites/denofgeek/files/styles/main_wide/public/luke-cage-season-2marvel-netflix.jpg?itok=UU3mz8hK. Accessed 25 Mar. 2017.

"Marvel Premiere." Wikipedia, Wikimedia Foundation, 4 Apr. 2017, en.wikipedia.org/wiki/Marvel_Premiere. Accessed 6 Apr. 2017.

Maslon, Laurence, and Michael Kantor. Superheroes!: Capes, Cowls, and the Creation of Comic Book Culture. Crown Archtype, 2013.

Mastin, Luke. "Lysistrata - Aristophanes - Ancient Greece - Classical Literature.” Lysistrata Aristophanes, Ancient Literature, 2009, www.ancientliterature.com/greece_aristophanes_lysistrata.html. Accessed 25 Mar. 2017.

McDuffie, Dwayne et, al. "It’s Always Christmas." Icon, vol. 1, no. 13, DC Comics, 1994.

---. “The Buck Passes” Icon, vol. 1, no. 30, DC Comics, 1995.

McLaughlin, Eliott C. "Uncovering the Hidden Archives of the Civil Rights Movement." CNN, Cable News Network, 18 Feb. 2011, www.cnn.com/2011/LIVING/02/18/archiving.civil.rights/. Accessed 19 Apr. 2017.

McCloud, Scott. Understanding Comics: the Invisible Art. New York, NY, Harper Perennial, 1994.

Morrison, Toni. Playing in the Dark: Whiteness and the Literary Imagination. First Vintage, 1993.

Nama, Adilifu. Super Black: American Pop Culture and Black Superheroes. Univ. of Texas Press, 2011.

Narcisse, Evan. “The Politics of Marvel's Black Panther.” Kotaku, Kotaku.com, 6 May 2016, kotaku.com/the-politics-of-the-black-panther-1766701304. Accessed 8 Mar. 2017. 
O’Neil, Dennis, et al. "No Evil Should Escape My Sight!” Green Lantern, vol. 2, no. 76, DC Comics, 1970.

Osajyefo, Kwanza, et al. Black. Vol. 1, ser. 1, Black Mask Studios, 2016.

Ostroff, Joshua. "Marvel's 'New' Superhero Is A Bulletproof Black Man In A Hoodie.” The Huffington Post, The Huffington Post, 30 Sept. 2016, www.huffingtonpost.ca/2016/09/29/marvel-luke-cage_n_12202516.html. Accessed 14 Oct. 2016

---. "Stan Lee On Superhero Diversity: 'A Lot Of People Are A Little Bit Bigoted'.” The Huffington Post, The Huffington Post, 1 Sept. 2016, www.huffingtonpost.ca/2016/09/01/stan-lee-marvel-superherodiversity_n_11198460.html. Accessed 8 Mar. 2017.

Pappademas, Alex. "Collecting Black Comix: African-American Superheroes and the Luke Cage Problem." GQ, 01 Jul. 2010, www.gq.com/story/collecting-black-comix-africanamerican-superheroes-and-the-luke-cage-problem. Accessed 28 Aug. 2014.

Perelman, Chaïm, and Lucie Olbrechts-Tyteca. The New Rhetoric: A Treatise on Argumentation. University Press of Notre Dame, 1969.

Plencner, Joshua. "Gentrifying Luke Cage: The Racial Failure of Nostalgia." AAIHS, 15 Jan. 2017, www.aaihs.org/gentrifying-luke-cage-the-racial-failure-of-nostalgia/. Accessed 18 Jan. 2017.

Phillips, Nickie D., and Staci Strobl. “Aren’t There Any Brown People in this World?" Comic Book Crime: Truth, Justice, and the American Way. New York UP, 2013, pp. 169-196.

Priest, Christopher J. "Introduction." Stan Lee Presents-- Black Panther: The Client. Marvel Comics, 2001. pp. 1-2. 
Rankine, Claudia. Citizen: an American Lyric. Penguin Books, 2015.

Rifas, Leonard. "Race and Comix." Multicultural Comics: from Zap to Blue Beetle, edited by Frederick Luis Aldama, University Of Texas Press, Austin, 2011, pp. 27-38.

Rios, Edwin D. "Netflix's Luke Cage Is the Superhero America Needs Right Now.” Mother Jones, 29 Sept. 2016, www.motherjones.com/media/2016/09/luke-cage-marvel-netflixblack-superhero-cheo-hodari-coker. Accessed 14 Oct. 2016.

Robinson, Joanna. "Luke Cage and the Year Marvel Finally Reckoned with Its Black Audience.”, Vanity Fair, HWD, 30 Sept. 2016, www.vanityfair.com/hollywood/2016/09/luke-cage-mike-colter-black-panther-netflixmarvel-black-voices. Accessed 14 Oct. 2016.

Rodriguez, Mathew. "Marvel's ‘Black Panther’ Is Going to Be So Lit.” Mic, Mic Network Inc., 14 May 2016, mic.com/articles/143468/marvel-s-black-panther-is-going-to-be-so-litsays-twitter\#.zGbyxyjyF. Accessed 19 Apr. 2017.

Royal, Derek P. "Introduction: Coloring America: Multi-Ethnic Engagements with Graphic Narrative." MELUS: Multi-Ethnic Literature of the United States, vol. 32, no. 3, Jan. 2007, pp. 7-22., doi:10.1093/melus/32.3.7.

Said, Edward W. "Introduction.” Orientalism, Vintage Books, New York, 2004, pp. 1-28.

Seitz, Matt Zoller. “The Offensive Movie Cliche That Won't Die.” Salon, 14 Sept. 2010, www.salon.com/2010/09/14/magical_negro_trope/. Accessed 2 Sept. 2014.

Singer, Marc. “'Black Skins' and White Masks: Comic Books and the Secret of Race.” African American Review, vol. 36, no. 1, 2002, pp. 107-119. JSTOR [JSTOR], doi:10.2307/2903369. Accessed 7 Sept. 2014. 
“Soliloquy of Chaos.” Marvel's Luke Cage, season 1, episode 12, Marvel, 30 Sept. 2016. Netflix, https://www.netflix.com/watch/80002541?trackId=14170286\&tctx=5\%2C 0\%2C545a2e6c-42fe-4e7e-a0ea-1f0003b4bd9e-90981351

"Step in the Arena." Marvel's Luke Cage, season 1, episode 4, Marvel, 30 Sept. 2016. Netflix, https://www.netflix.com/watch/80002541?trackId=14170286\&tctx $=5 \% 2 \mathrm{C}$ 0\%2C545a2e6c-42fe-4e7e-a0ea-1f0003b4bd9e-90981351

Stephens, Michelle Ann. Skin Acts: Race, Psychoanalysis, and the Black Male Performer. Durham, Duke University Press, 2014.

Sue, Derald Wing. "Microaggressions, Marginality, and Oppression: An Introduction."” Introduction. Microaggressions and Marginality: Manifestation, Dynamics and Impact. John Wiley \& Sons, 2010. pp. 1-17.

Tatum, Beverly Daniel. "Talking About Race, Learning About Racism: The Application of Racial Identity Development Theory in the Classroom.” Education for a Multicultural Society, edited by Kolajo Paul Afolabi, Harvard Educational Review, 2011. pp. 267-93. Thomas, Roy et al. Essential Luke Cage, Power Man. Vol. 1: Hero for Hire. Marvel Comics, 2005.

Thompson, Gail L., and Angela C. Louque. Exposing the "Culture of Arrogance" in the Academy, Stylus, 2005.

“Trayvon Martin Hooded.” 2016, https://en.wikipedia.org/wiki/File:TrayvonMartinHooded.jpg. Accessed 13 Mar. 2017

“Tyroc.” 2010, https://comicvine.gamespot.com/images/1300-1124525 Accessed 13 Mar. 2017 Van Dyk, Michael. "What's Going On? Black Identity in the Marvel Age." International Journal of Comic Art, vol. 8, no.1, 2006, pp. 466-90. 
Walker, David F (@DavidWalker1201).“Marvel is making a reasonable decision given the sales. We made a great book, but sales didn't warrant a longer run. https://twitter.com/riot71/status/769733110103617536 ... “August 28, 2016. 12:13AM. Tweet.

Wanzo, Rebecca. "It's a Hero? Black Comics and Satirizing Subjection.” The Blacker the Ink: Constructions of Black Identity in Comics and Sequential Art, edited by Frances K. Gateward and John Jennings, Rutgers UP, 2015. pp. 314-332.

Weldon, Glen. "Superheroes and the F-Word: Grappling With the Ugly Truth under the Capes.” NPR, NPR, 16 Nov. 2016, www.npr.org/sections/monkeysee/2016/11/16/502161587/superheroes-and-the-f-wordgrappling-with-the-ugly-truth-under-the-capes. Accessed 29 Nov. 2016.

Whaley, Deborah Elizabeth. Black Women in Sequence Re-Inking Comics, Graphic Novels, and Anime. Seattle, University of Washington Press, 2016.

Wright, Bradford W. Comic Book Nation: The Transformation of Youth Culture in America. University Press of Johns Hopkins, 2001. 